\title{
Clinically diagnosed borderzone infarction : fact or fiction?
}

Citation for published version (APA):

Hupperts, R. M. M. (1994). Clinically diagnosed borderzone infarction : fact or fiction? [Doctoral Thesis, Maastricht University]. Rijksuniversiteit Limburg. https://doi.org/10.26481/dis.19940624rh

Document status and date:

Published: 01/01/1994

DOI:

10.26481/dis.19940624rh

Document Version:

Publisher's PDF, also known as Version of record

\section{Please check the document version of this publication:}

- A submitted manuscript is the version of the article upon submission and before peer-review. There can be important differences between the submitted version and the official published version of record.

People interested in the research are advised to contact the author for the final version of the publication, or visit the DOI to the publisher's website.

- The final author version and the galley proof are versions of the publication after peer review.

- The final published version features the final layout of the paper including the volume, issue and page numbers.

Link to publication

\footnotetext{
General rights rights.

- You may freely distribute the URL identifying the publication in the public portal. please follow below link for the End User Agreement:

www.umlib.nl/taverne-license

Take down policy

If you believe that this document breaches copyright please contact us at:

repository@maastrichtuniversity.nl

providing details and we will investigate your claim.
}

Copyright and moral rights for the publications made accessible in the public portal are retained by the authors and/or other copyright owners and it is a condition of accessing publications that users recognise and abide by the legal requirements associated with these

- Users may download and print one copy of any publication from the public portal for the purpose of private study or research.

- You may not further distribute the material or use it for any profit-making activity or commercial gain

If the publication is distributed under the terms of Article $25 \mathrm{fa}$ of the Dutch Copyright Act, indicated by the "Taverne" license above, 
Geboren 5 november 1954 te Maastricht

1975 Examen Atheneum B, Henric van Veldeke College, Maastricht

1975-1981 Studie geneeskunde. Rijksuniversiteit Limburg. Maastricht

1982-1989 Opleiding tot neuroloog. Academisch Ziekenhuis Maastricht

1984 stage Interne Geneeskunde 1987 stage Klinische Neurofysiologie 1989-heden Neuroloog. Academisch Ziekenhuis Maastricht. 
CLINICALLY DIAGNOSED BORDERZONE INFARCTION

FACT OR FICTION? 
Ontwerp en drukwerkbegeleiding: Peter Geelen, Maastricht Figuren: Jef Maris

Druk: Grafische Groep Groenevelt B.V., Landgraaf

Bindwerk: Martin van den Berg, Simpelveld

Omslag: Borderzones: Facts and Fictions. Ontwerp: Ria Jussen, Merkelbeek.

\section{CIP DATA KONINKLIJKE BIBLIOTHEEK, DEIN HAAG}

Hupperts, Raymond M.M.

Clinically diagnosed borderıone infarction. Fact or fiction? / Raymond M.M. Hupperts / Maastricht Proefschrift Maastricht. - met lit. opg. - Met samenvatting in het Nederlands.

ISBN $90-9007216-0$

Trefw.: borderzone infarction/clinical/CT scan 


\title{
Clinically diagnosed borderzone infarction Fact or fiction?
}

\author{
PROEFSCHRIFT
}

ter verkrijging van de graad van doctor

aan de Rijksuniversiteit Limburg te Maastricht, op gezag van de Rector Magnificus, Prof.dr. H. Philipsen, volgens het besluit van het College van Dekanen,

in het openbaar te verdedigen

op vrijdag 24 juni 1994 om 16.00 uur

door

RAYMOND MARIA MATHIEU HUPPERTS

geboren te Maastricht in 1954 
Promotor:

Co-promotor:

Beoordelingscommissie:
Prof.dr. J. Troost

Dr. J. Lodder
Prof.dr. J. Drukker (voorzitter)

Prof.dr. B. Hillen (Rijksuniversiteit Utrecht)

Prof.dr. J. De Reuck (Rijksuniversiteit Gent (B))

Prof.dr. P. de Leeuw

Prof.dr. J. Wilmink

Financial support by The Netherlands Heart Foundation for the publication of this thesis is gratefully acknowledged.

This study was also financially supported by: Asta Medica, Boehringer Ingelheim, CIBA, Duphar Nederland, Ely Lilly Nederland, Glaxo, Karwijk Farma, Nycomed, Sanofi, UCB Pharma en Yamanouchi Pharma. 
Zolang men gezond is, doet men er goed aan zich te harden door het lichaam, zowel in zijn geheel als in elk van zijn delen de nodige inspanning en vermoeienis op te leggen en zich aan te wennen om aan ongunstige invloeden van allerlei aard weerstand te bieden.

De spieren worden door intensief gebruik versterkt: de zenuwen daarentegen verzwakt. Vandaar dat men zijn spieren door elke geschikte vorm van inspanning dient te oefenen, de zenuwen daarentegen tegen elke inspanning dient te beschermen.

Bron: Arthur Schopenhauer, 1851

Bespiegelingen over levenswijsheid. 
Ter herinnering aan mijn grootoom Dominicus Hupperts Aan mijn ouders

Voor Lianne 


\section{VOORWOORD}

Dit proefschrift is tot stand gekomen door de plezierige en effectieve samenwerking van velen. Eenieder daarvoor persoonlijk te bedanken is welhaast niet mogelijk.

Een aantal mensen ben ik echter bijzonder veel dank verschuldigd:

Allereerst co-promotor Jan Lodder. Beste Jan, als initiator van dit onderzoek heb jij mij niet alleen aangezet tot het zelf doen van enig wetenschappelijk onderzoek, maar bovenal heb jij mij geleerd plezier te vinden in het doen van onderzoek. Daarnaast is jouw praktische bijdrage aan dit onderzoek wat betreft de opzer, data-opslag en analyse, en de uiteindelijke totstandkoming van het manuscript zo belangrijk geweest dat het wellicht overbodig is te stellen dat ook dit proefschrift er zeker niet zou zijn gekomen zonder jouw hulp. Naast de fijne samenwerking ten tijde van dit onderzoek, heeft je oprechte steun tijdens 'bange dagen' van de vakgroep onze relatie tot een heel speciale vriendschap gemaakt.

Lizette Heuts-van Raak, die aan de basis stond van dit onderzoek. Beste Lizette, jij hebt in de periode vanaf 1987 tot medio 1992, en dus al lang voordat ik met dit onderzoek begon, de meerderheid van de data verzameld. De nauwkeurigheid en volharding waarmee jii dit deed, hebben in zeer belangrijke mate de uiteindelijke kwaliteit van deze studie bepaald. Hiervoor ben ik je eigenlijk veel meer dan dank alleen verschuldigd.

Promotor Jaap Troost, voor de uitstekende werksfeer en onderzoeksfaciliteiten die jij binnen de kortste keren vanaf je komst naar Maastricht binnen onze afdeling wist te creëren. Jaap, door jouw toedoen draait de neurologie nu weer als een goed geoliede machine.

De leden van de beoordelingscommissie, Prof.dr. J. Drukker, Prof.dr. B. Hillen, Prof.dr. J. De Reuck, Prof.dr. P. de Leeuw, en Prof.dr. J. Wilmink, voor de precisie waarmee ze het manuscript hebben doorgewerkt en voor de nuttige opmerkingen waarvan ze mij hebben voorzien. Speciaal van hen wil ik nog noemen Prof.dr. J. Drukker, Prof.dr. B. Hillen en Prof.Dr. J. De Reuck voor hun inhoudelijke bijdragen in de loop van dit onderzoek, die mede het uiteindelijke gezicht van dit onderzoek hebben bepaald, en Prof.dr. J. Wilmink voor zijn bijdrage in de beoordeling van de CT-scans.

Fons Kessels voor het steeds opnieuw aanpassen van de statistische analyses na het toevoegen van wéér nieuwe gegevens; maar meer nog voor de inhoudelijke bijdrage aan de diverse hoofdstukken.

Paul van der Lugt, voor de prettige opleiding tot neuroloog die ik dank zij hem mocht genieten.

Thera van Lieshout, die een heel speciale plaats verdient. Niet alleen omdat je steeds weer de schier oneindige reeks van 'nieuwe versies' van het manuscript typte, maar vooral heb jij steeds inhoudelijk goed meegekeken en waardevolle opmerkingen gemaakt. Bovenal genoot ik van de bijzonder prettige samenwerking met jou.

Jef Maris, voor zijn deskundige en zeer artistieke weergave van de figuren.

Ann Hilton voor de correcties van het Engels en de snelle service.

De medewerkers van het röntgenarchief, met name Fred Thimister, en de medewerkers van het medisch archief, voor hun soepele houding en hun medewerking aan dit onderzoek. 
Peter Geelen, voor zijn deskundigheid, enthousiasme, creativiteit en de vele uren die hij uit vriendschap aan de grafische vorming van dit proefschrift besteedde.

Heel speciaal ook Marc de Krom, Albert Twijnstra en Hans Vles voor hun solidariteit in moeilijker tijden!

De paranimfen Eric van Amstel en Denis Florack voor hun steun maar vooral voor hun warme vriendschap.

Mijn ouders voor datgene wat ze voor mij betekenen.

Mijn allerliefste Lianne, de kracht van dit alles. 
CONTENTS

\section{Voorwoord}

CHAPTER 1 General introduction

CHAPTER 2 Review of the literature

Part 1: The variability of the cerebral vascular supply areas of the major cerebral arteries

Part 2: Borderzone brain infarcts in pathological-anatomical studies

Part 3: CT scan and other imaging characteristics of borderzone infarcts

Part 4: Summary of possible pathophysiological mechanisms in borderzone infarcts

Conclusions

Questions for this study

CHAPTER 3 Haemodynamic mechanism in small deep borderzone infarcts?

CHAPTER 4 CT-defined borderzone brain infarcts; relationship with clinical features among stroke subgroups

CHAPTER 5 Infarcts in areas of variable vascular supply: borderzone infarcts?

CHAPTER 6 Infarcts in the anterior choroidal artery territory; anatomical distribution, clinical syndromes, presumed pathogenesis, early outcome and relationship with the 'deep borderzone'

CHAPTER 7 Borderzone brain infarcts following cardiac surgery and their relationship to cerebral haemodynamic compromise

CHAPTER 8 General discussion 


\section{LIST OF ABBREVIATIONS}

ACA anterior cerebral artery

AChA anterior choroidal artery

(a)OR (adjusted) odds ratio

CABG coronary artery bypass graft

CBF cerebral blood flow

$\mathrm{CI} \quad$ confidence interval

COPD chronic obstructive pulmonary disease

(c)OR (crude) odds ratio

CT computed tomography

DCHS/AH dysarthria clumsy hand syndrome/ataxic hemiparesis

DM diabetes mellitus

ECG electrocardiogram

EEG electroencephalogram

HMPAO hexamethyl-propylene amine oxime

$\mathrm{Ht}$ haematocrit

ICA internal carotid artery

IHD ischaemic heart disease

IWI internal watershed infarct

MCA middle cerebral artery

MRI magnetic resonance imaging

PCA posterior cerebral artery

PChA posterior choroidal artery

PET positron emission tomography

PMS pure motor syndrome

PSS pure sensory syndrome

rCBF regional cerebral blood flow

ROI region of interest

SBI small borderzone infarct

SDI small deep infarct

SMS sensorimotor syndrome

SPECT single photon emission computed tomography

TI territorial infarct

TIA transient ischaemic attack 


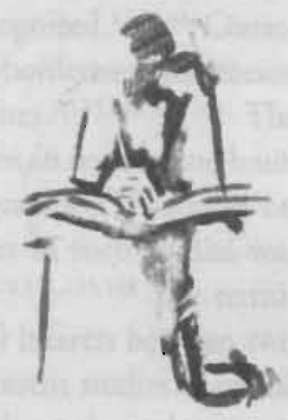

General Introduction

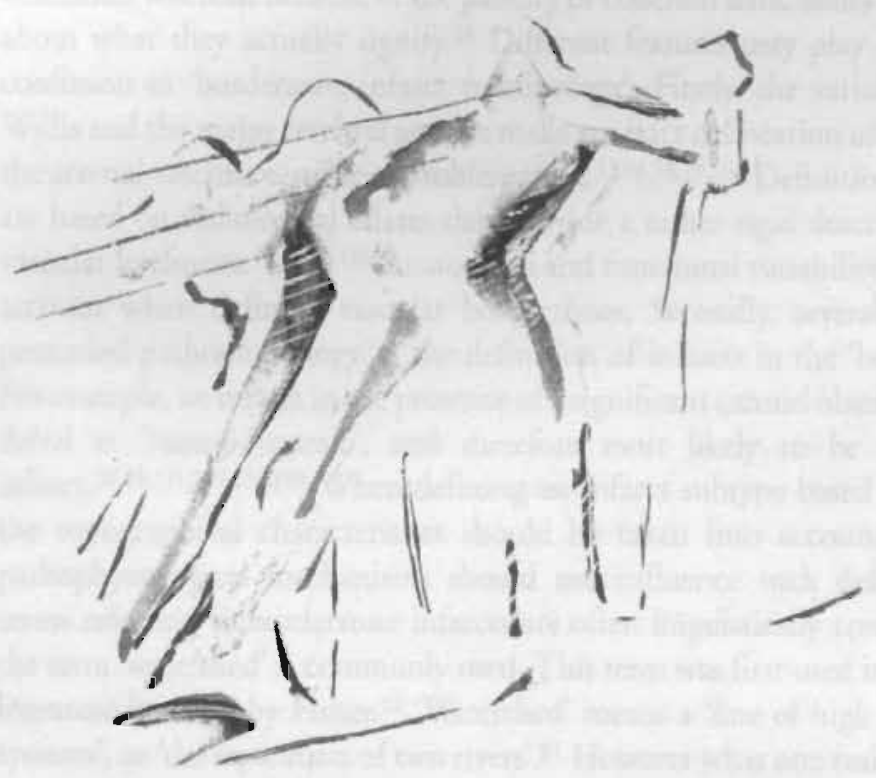


vascularisation pattern in the paraventricular white matter that constitutes a structure that is 'typical' for a (subcortical) 'vascular borderzone'. $15,44,45$ Here again, factors other than topographical ones are introduced into the infarct definition. It would be more appropriate to refer to subcortically located infarcts as 'deep' or 'subcortical borderzone infarcts' only to indicate the location of the infarct subtype. Finally, the shape of the infarcts, for example striated, wedge-shaped, triangular, small ovoid, was considered by several authors to be 'typical borderzone', and therefore included into the definition of 'borderzone infarcts'.21,22,82,156,158 Recently, Donnan et al. (1993) ${ }^{49}$ even introduced the terms 'confluent internal borderzone infarct' and 'partial internal - borderzone - infarct (non-confluent)', and Bladin and Chambers (1993) ${ }^{17}$ introduced the terms 'confluent internal watershed infarct' (CIWI) and 'partial internal watershed infarct' (PIWI), suggesting that differences in infarct size and shape may indicate different borderzone infarct subtypes. There is no evidence from pathological or clinical studies that there is any infarct shape that is 'typical borderzone'; therefore, the infarct size and shape should not be included in the definition of 'borderzone infarcts'.

In summary: the definition of 'borderzone infarcts' should relate only to the location of the infarcts, and should not include presumed pathophysiological or functional characteristics that are as yet unvalidated. Unfortunately, the inter-individual variation of the vascular supply areas makes an exact localisation of such infarcts in CT/MRI studies difficult, if nor impossible. Therefore, borderzones should be looked upon as 'areas' rather than rigid lines drawn on CT templates constructed from insufficient data. More data are required to define 'borderzone infarcts' topographically, before clinical characteristics can be identified.

The aim of this study is to characterize topographically defined borderzone infarcts in two different ways. Firstly, infarcts divided by a demarcation line at the border of two major cerebral arteries (territorial borderzone infarcts), and small deep infarcts at the border of the medullary branches and deep penetrators of the major cerebral arteries (deep borderzone infarcts), based on the most currently used topographical CT radiology atlases. ${ }^{41.66,88}$ Secondly, infarcts located mainly in an area of variable vascular supply of two adjacent major cerebral arteries, as described by Van der Zwan et al. 166,168 Vascular risk factors, CT scan characteristics, natural history, and presumed pathophysiological mechanisms were studied in such 'borderzone infarcts' and compared with other infarct subtypes. Special attention was focused on features of potential cerebral haemodynamic compromise such as prior stroke hypotension and carotid obstructive disease, with regard to the frequency in what has classically been considered as borderzone infarcts. 


\section{CHAPTER 2}

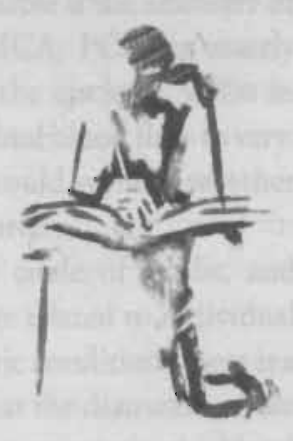

\section{REVIEW OF THE LITERATURE}

Part 1: The variability of the cerebral vascular supply areas of the major cerebral arteries

Part 2: Borderzone brain jnfarcts in pathologicalanatomical studies

Part 3. CT scan and other imaging characteristics of borderzone infarcts

/ Part 4: Summary of possible pathophysiological mechanisms in borderzone infarcts Conclusions Questions for study 


\section{PART 1 THE VARIABILITY OF THE CEREBRAL VASCULAR SUPPLY AREAS OF THE MAJOR CEREBRAL ARTERIES}

Defining what 'vascular borderzone territory' signifies is only possible if the anatomy of the distal supply areas of the major cerebral arteries (ACA, MCA, PCA) is exactly known. With regard to the differences in blood flow through the circle of Willis in different pathophysiological conditions one could expect the cerebral blood flow to vary, particularly in the most distal supply areas. Consequently, one could wonder whether these (distal) vascular areas are consistently supplied by the same artery.

Hillen $(1986)^{78,79}$ developed a mathematical model of the circle of Willis, and concluded that the anatomical variations in the circle of Willis are related to individual variations of blood flow through the circle. He showed that in static conditions there is a significant relationship berween blood flow and vessel size, and that the diamerers of the proximal part of the major cerebral arreries vary significantly. Consequently, the blood flow through each major cerebral artery is also variable. These findings led Van der Zwan et al. to suggest that the basic peripheral resistance of the six major cerebral arteries and consequently the extent of the territories they supply is as variable as their proximal diameters' 166,169 . These authors further suggested that such variability in supply areas could lead to problems in neuroradiological interpretations of 'watershed ischaemia', when using the current, rather static topographically neuroradiological templates. ${ }^{41,66,88,100}$ In accordance with the findings of Van der Zwan and Hillen ${ }^{166,169}$, Van Overbeeke (1991) ${ }^{116}$ showed, in his thesis on 'the development of the variations of the human basal cerebral arteries', that already in foetal and neonatal life haemodynamic factors cause variations in the anatomical development of the circle of Willis. This means that haemodynamic requirements in certain brain areas determine the final structure of the circle of Willis.

Van der Zwan et al. (1991) ${ }^{166,167}$ reviewed the anatomical literature of injection studies of the vascular supply areas of the major cortical and intracerebral arteries. They concluded that there were many differences between most of the studies done on supply areas of such arteries. They suggested that one of the factors necessary to give a 'real' picture of the vascular supply areas of the major cerebral arteries in vascular autopsy studies is the simultaneous injection of these arteries. Only the studies of Beevor ${ }^{13}$ and Shellshear ${ }^{141}$ fulfilled these criteria. Beevor $(1907)^{13.14}$ investigated the distribution areas of the major cerebral arteries of 87 brains, by injecting the arteries simultaneously under equal pressure with gelatine containing soluble colours. Using different colours for different arteries a precise description of the course and the relationship to other arteries could be established for the vessels under study. Beevor investigated the ACA, MCA, PCA, the AChA, and the posterior communicating artery in this way. He mostly used the combination of one-sided simultaneous injection of the anterior, middle and posterior cerebral artery, whilst ligating the posterior communicating artery and/or the anterior choroidal artery at their origin. Beevor provided a detailed description of the vascular supply areas of the investigated arteries in the different brains. He concluded that the corrical supply areas of the ACA, MCA and PCA varied significantly: Figures 2.1-2.8. He also showed left-right differences when comparing the left and right hemisphere of the same brain. Beevor found anastomoses between the major cortical 
arterial systems, but no leptomeningeal anastomoses. There were more anastomoses at the 'borders' of the arteries than between contiguous branches of the same artery. Furthermore, he concluded that the arteries which penetrate and supply the cortex are endarteries. He stated that the presence of anastomoses may explain the variation in the findings in sequential injection studies done by others. Beevor investigated the deep vascular supply areas of the $\mathrm{ACA}, \mathrm{MCA}, \mathrm{PCA}, \mathrm{ACh} A$ and posterior communicating artery in the same way as he studied the cortical areas, and found also a considerable variability in vascular supply in these areas. The work of Beevor shows that there is obviously a large variability in cortical and deep vascular supply areas of the major cerebral arteries, most strikingly in the cortex. Investigating one case by the same method as used by Beevor, Shellshear (1927) $)^{141}$ had similar results.

Encouraged by the discrepant findings in most pathological studies, Van der Zwan et al. performed a morphological and quantitative study on the variability of the supply areas of the major cerebral arteries. ${ }^{166,168,169}$ They studied the cortical and intracerebral distribution areas of the six major cerebral arteries of unfixed human brains after simultaneous injection of differently coloured injection material into the separate arteries. ${ }^{165}$ In 50 hemispheres, 25 different patterns of the area of supply of the ACA, 17 of the MCA and 22 of the PCA were found. From these findings they constructed composite figures illustrating the minimal and maximal areas of corrical vascular supply (Figures 2.92.13). ${ }^{168}$ The authors concluded that the cortical territories of the ACA, MCA and PCA vary considerably. Van der Zwan et al. further studied the intracerebral vascular distribution of the major vascular territories in 23 brains that had previously been used for the examination of the cortical distribution areas. They found that the intracerebral (deep) territories of the anterior, middle and posterior cerebral artery contribute in varying degrees to the blood supply of the hemispheric white matter, the internal capsule, the caudate nucleus, the putamen, the lateral globus pallidus and the thalamus. The areas of minimal and maximal distribution at the level of the internal capsule are shown in the Figures 2.14-2.16. ${ }^{168}$ They further found a relationship of vascular territorial volumes with the diameters and the peripheral resistance of the contributing arteries originating from the circle of Willis. Van der Zwan et al. (1993) ${ }^{169}$ hypothesized: 'that the morphological variability of the cerebral vascular system is related to the peripheral resistance of the major cerebral arteries and, consequently, to flow patterns, both of which are haemodynamic factors'. The studies of Beevor ${ }^{14}$, Shellshear ${ }^{141}$ and especially those of Van der Zwan et al. ${ }^{168}$ strongly suggest that there is a large variability in the cortical and intracerebral vascular supply areas of the ACA, MCA and PCA. Consequently, it seems unrealistic to consider borderzones between the major cerebral arteries as being static, and current vascular templates used to characterize brain infarcts may be inadequate. Not only may the vascular supply areas vary between individuals, but also even within one person as a result of variability in the demand of blood supply, depending on several factors, and influenced by the abundance and functional properties of collaterals. 
2.1
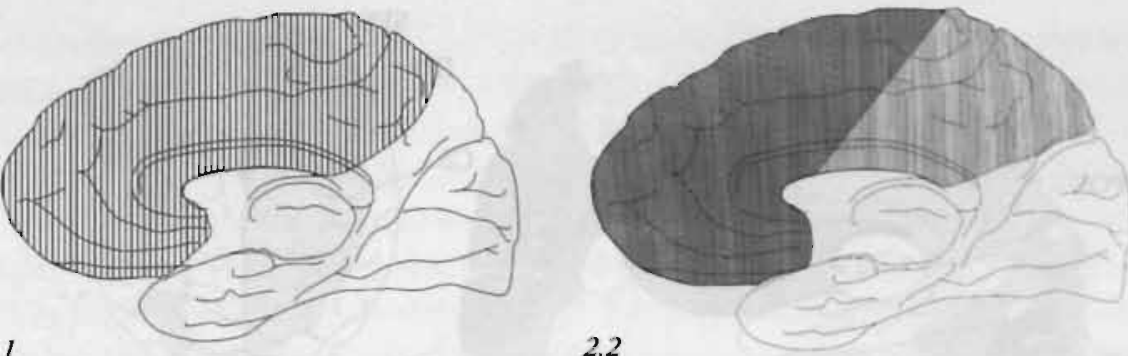

2.3

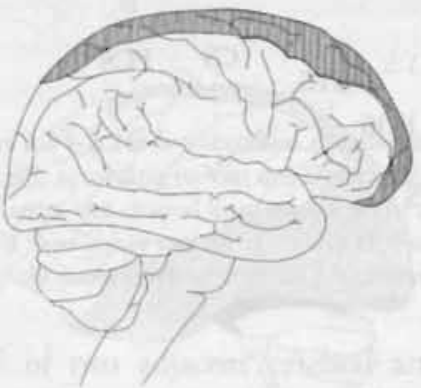

2.4

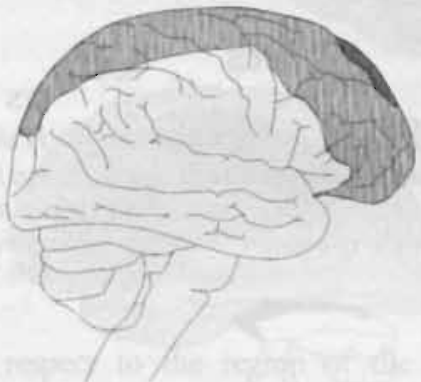

2.5
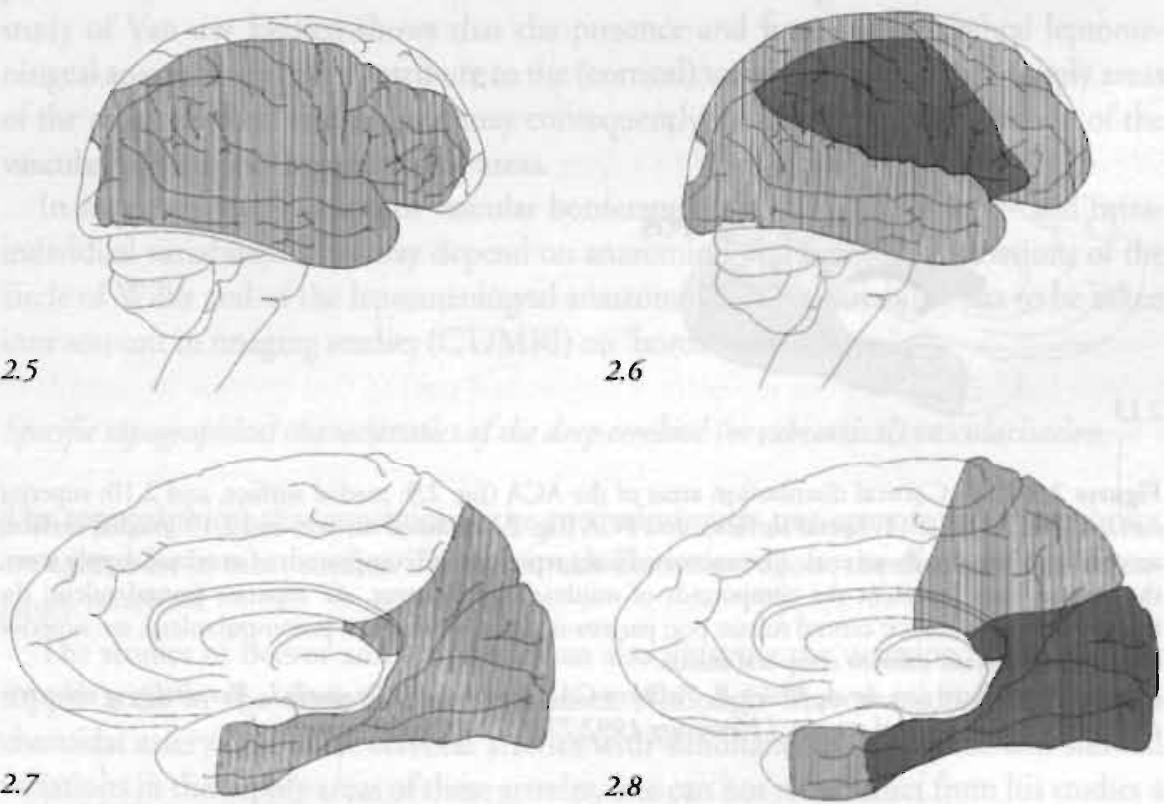

Figures 2.1-2.8: Areas of minimal and maximal cortical vascular supply of the ACA, MCA, and PCA according to Beevor.

Fig. 2.1: ACA, median surface. Most frequent supply area (light shaded). Fig. 2.2: ACA, median surface. Minimal (dark shaded) and maximal (light shaded) supply area. Fig. 2.3: ACA, outer surface. Most frequent supply area (light shaded). Fig. 2.4: ACA, ourer surface. Minimal (dark shaded) and maximal (light shaded) supply area. Fig. 2.5: MCA, outer surface. Most frequent supply area (light shaded). Fig. 2.6: MCA, outer surface. Minimal (dark shaded) and maximal (light shaded) supply area. Fig. 2.7: PCA, median surface. Most frequent supply area (light shaded). Fig. 2.8: PCA: median surface. Minimal (dark shaded) and maximal (light shaded) supply area.

Adapted from Beevor CE. On the distribution of the different arteries supplying the human brain. Philos Trans R Soc London (Biol) 1909;200:1-55. 

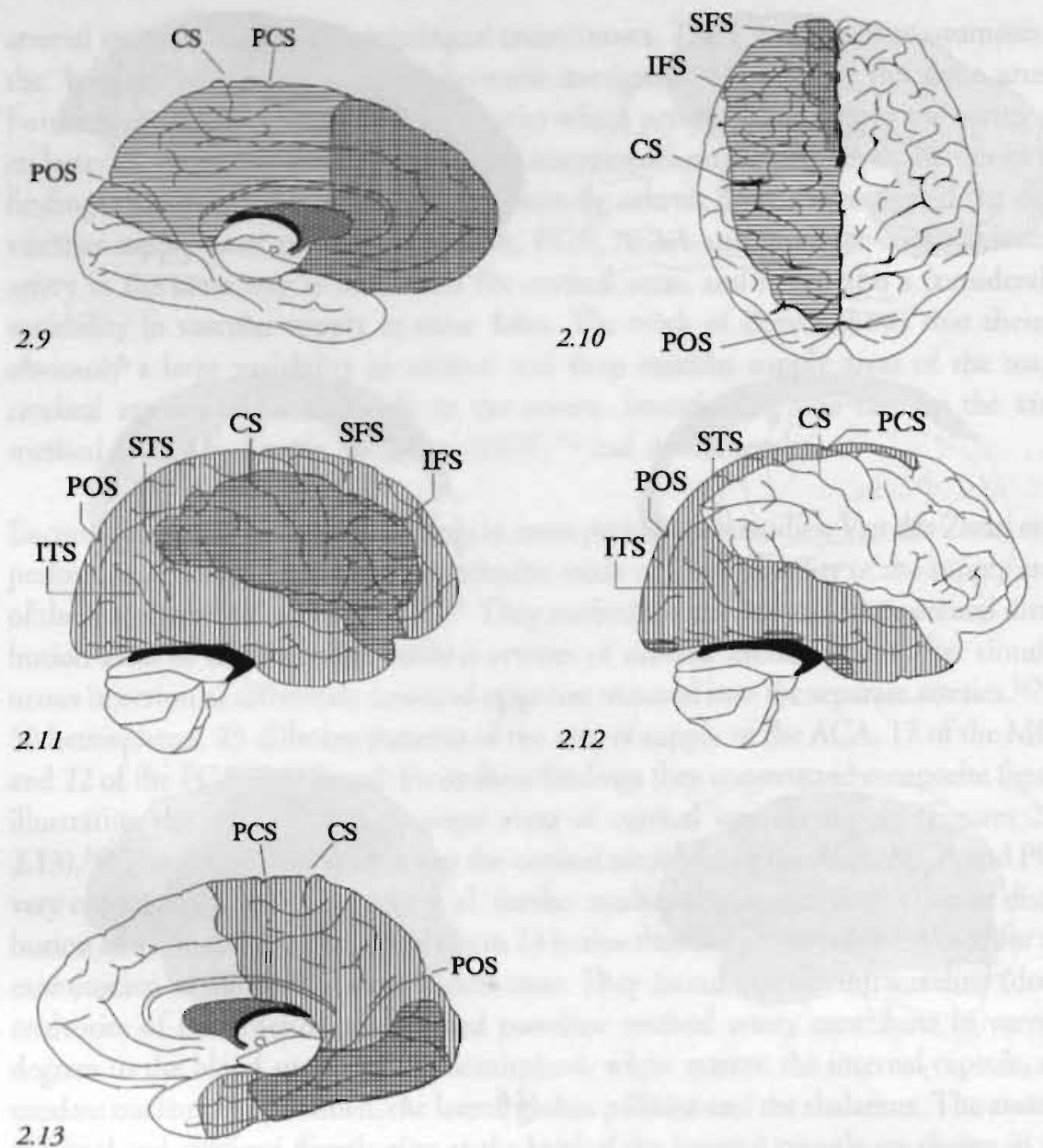

Figures 2.9-2.13: Cortical distribution areas of the ACA (fig. 2.9: medial surface, and 2.10: superior surface), MCA (fig. 2.11: lateral surface), and PCA (fig. 2.12: lateral surface, and 2.13: medial surface) according to Van der $Z$ wan et al. The uncrossed lines represent the compounds of maximal supply areas, the crossed lines represent the compounds of minimal supply areas. sfs: superior frontal sulcus; ifs: inferior frontal sulcus; cs: central sulcus; pos: parieto-occipital sulcus; pcs: precentral sulcus; sts: superior temporal sulcus; its: inferior temporal sulcus.

Adapred from Zwan van der A, Hillen B. Tulleken CAF, Dujouny M, Dragovic L. Variability of the territories of the major cerebral arteries. J Neurosurg 1992;77:927-940 (with permission).

The significance of anastomoses between different brain arteries was also studied by Van der Eecken (1959)..$^{51}$ In an autopsy study he examined 40 brains after injecting a fluid mass in one or several cerebral or cerebellar arteries. He found large meningeal arterial anastomoses between cerebral and between cerebellar arteries, and concluded that these anastomoses are particularly functional in states of ischaemia in preventing tissue necrosis. Van der Eecken suggested that the variation in number, size and site of the anastomoses may be of importance in limiting the extent of brain damage due to ischaemia. Although he could not assess the function of anastomoses under physiological circumstances he suggested that the anastomoses could modify the 'demarcation 


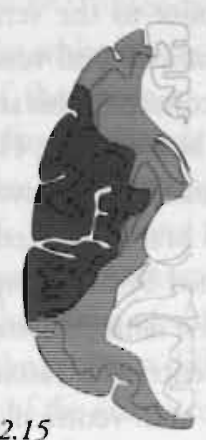

2.16

Figures 2.14-2.16: Intracerebral distribution areas of the ACA (fig. 2.14), MCA (fig. 2.15) and PCA (fig. 2.16), according to Van der Zwan et al. The uncrossed lines represent the compounds of maximal supply areas, the crossed lines represent the compounds of minimal supply areas.

Adapted from Zwan van der A, Hillen B, Tulleken CAF, Dujouny $M$, Dragovic L. Variability of the territories of the major cerebral arteries. J Neurosurg 1992;77:927-940 (with permission).

zones' of two adjacent cerebral arteries. With respect to the region of the deep penetrating arteries at the base of the brain he found no important anastomoses. The study of Van der Eecken shows that the presence and function of cerebral leptomeningeal anastomoses may contribute to the (cortical) variability of the brain supply areas of the major cerebral arteries, and may consequently influence the exact location of the vascular borderzones between these areas.

In summary, the location of vascular borderzones may show large inter- and intraindividual variability. This may depend on anatomical and functional variations of the circle of Willis and of the leptomeningeal anastomoses. This variability has to be taken into account in imaging studies (CT/MRI) on 'borderzone infarcts'.

\section{Specific topographical characteristics of the deep cerebral (or subcortical) vascularisation}

The topographical characteristics of the cortical vascular tree apart from its variability, are agreed on in most studies. There is much discussion about the deep cerebral vasculature. $15,26,44,108$

The studies of Beevor and Van der Zwan also illustrate the variation of the vascular supply areas in the deep cerebral structures. Although Beevor studied the anterior choroidal artery and other cerebral arteries with simultaneous injections, and showed variations in the supply areas of these arteries, one can not reconstruct from his studies a demarcation zone between the perforating medullary branches of the major cerebral arteries and the small deep penetrators. Although Van der Zwan et al. also described the variability in supply of several deep white matter areas, they did no simultaneous injection studies of the anterior choroidal artery ( $\mathrm{AChA}$ ) combined with one or more of the major cerebral arteries. Therefore, a deep vascular borderzone could not be reconstructed from their study, and consequently the variability in vascular supply in such zone could not be studied. The existence and the specific physiological significance of a deep vascular demarcation area was discussed by Van den Bergh (1969) ${ }^{15}$. He postulated a model of 'ventriculofugal' arteries, originating from the anterior choroidal and lenticu- 
lostriate arteries, and directing opposite to the ventricular wall (centrifugal). In the opposite direction (centripetal), leptomeningeal vessels directed into the brain parenchyma. De Reuck (1971) ${ }^{44}$ used this concept in his studies on the periventricular vascularisation including the deep vascular borderzones. He studied the course and ending of arterioles and their anatomical relationship, and gave special attention to differences in periventricular arterial flow, using 26 brains injected with a colloidal barium sulphate solution. The information was obtained by radiographs of different brain sections and from a translucidation technique on the same preparations. From his studies, De Reuck suggested three possible types of periventricular vascularisation. In the first type (type I) ventriculopetal medullary branches and ventriculopetal perforating branches pass through the cortex, and terminate in the walls of the lateral ventricles. These arteries do not have terminal anastomoses with other arteries, but end in the ventricular wall as endarteries. Some of these arteries supply the tissue adjacent to the ventricle, creating an endzone. In the second type (rype II) De Reuck described ventriculofugal arteries originating from the choroidal or lenticulostriate arteries. These ventriculofugal arteries penetrate into the brain substance from the choroid plexus, and at a distance of 3-10 $\mathrm{mm}$ from the ventricular wall they meet the ventriculopetal medullary or perforating branches. The connecting areas of these vessels were called 'borderzone'. In a third type (type III) a 'periventricular borderzone' consisted of medullary or perforating branches reaching the ventricular wall and then turning away in a ventriculofugal direction, thus creating a 'borderzone' some $3-10 \mathrm{~mm}$ from the ventricular wall with shorter medullary ventriculopetal directed branches. The author concluded that: type I endzone vascularisation is infrequent and only prominent in the anterior part of the corpus callosum and in the brainstem; type II is the most frequently found borderzone type and dominates around the posterior horn of the lateral ventricle, being replaced by type III when directing to the anterior horn of the lateral ventricle. De Reuck stated that the periventricular borderzones' are like the cortical borderzone areas in that they are susceptible to a decrease in cerebral blood flow. In another study De Reuck (1976) ${ }^{46}$ studied 75 brains with multiple small deep infarcts predilected in the periventricular borderzone, and suggested the existence of deeply situated vascular 'borderzones' being predilection sites for (small) deep infarcts occurring as a result of flow disturbances.

Anastomoses in the cortical 'borderzones' may be important in states of ischaemia, as was previously discussed. Little is known about the existence of 'anastomoses' in the deeply located 'borderzones'. Classically, the small deep penetrators are invariably considered to be functional endarteries. ${ }^{105.106}$ However, Marinkovic $(1986)^{98}$ found a high frequency $(79 \%)$ of anastomotic channels among the thalamoperforating branches of the posterior cerebral artery (PCA), the basilar artery and the cerebellar arteries, in an autopsy study on the vasculature of the thalamoperforating arteries in 33 brains. He suggested that such anastomoses could be important components of collateral circulation in the case of occlusive cerebrovascular disease.

The above-mentioned studies provide a model for understanding the special vasculature in (relation to) the deep borderzones: ventriculofugal and ventriculopetal small vessels connect in a 'borderzone'. The 'borderzones' may be compromised in states of blood flow alterations such as an acute drop in blood pressure, - chronic - cerebral hypoperfusion, or local arteriolar occlusions. However, the work of De Reuck has been 
criticized in the recent literature. ${ }^{101,108,111}$ Moody et al. $(1990)^{108}$ studied the microvascular anatomy of the periventricular white matter. They stated that the medullary veins converge in radial fashion out of the centrum semiovale towards the ventricles', in patterns identical to the vessels that De Reuck and others considered as centrifugal arteries, and they believed that these ventriculofugal vessels were both arteries and veins instead of arteries only. Moody's conclusions were strengthened by Nelson et al. (1991) ${ }^{111}$ who studied the vascular development of the fetal telencephalon in the last two months of gestation and in the brains of children from $0-15$ years. In an autopsy study of 43 brains, they used a technique that differentiated between arteries and veins. They found no evidence in favour of the existence of ventriculofugal arteries that would create deep white matter arterial borderzones, nor did they find any ventriculofugal arteries at all. In summary, De Reuck and Van den Bergh suggested the existence of a deep vascular borderzone similar to the cortical vascularisation. Although their findings are contradicted by others, there may be at least some evidence for specific pathophysiological mechanisms in such 'borderzone'. However, these pathophysiological mechanisms were all hypothetical in the case of infarction. 


\section{PART 2 BORDERZONE BRAIN INFARCTS IN PATHOLOGICAL- ANATOMICAL STUDIES}

Before the introduction of sophisticated imaging techniques such as CT, MRI, PET and SPECT, current knowledge on borderzone (watershed) infarcts was obtained from autopsy studies. This paragraph considers the possible pathological and pathophysiological mechanisms of so-called 'borderzone infarcts', as inferred from the results of autopsy studies.

Lindenberg and Spatz (1940) ${ }^{94}$ described 22 cases of 'cerebral thromboangiitis obliterans' of the brain arteries. Up till then this form of endarteritis was known only as a peripheral arteritis (Von Winiwarter-Buerger disease). The authors characterized this 'cerebral thromboangiitis obliterans' as an endarteritis, thrombosis of arterioli, thrombus building in the internal carotid artery and discontinuous granular atrophy of the cerebral cortex. Two types of thromboangiitis obliterans were distinguished. Type I thromboangiitis obliterans was not restricted to the borderzone territories, but was present in all arterial brain territories. Type II was characterized by symmerrical granular atrophy of the cerebral cortex in the borderzones of the vascular territories of the three major cerebral arteries, and was found in 14 of the 22 investigated patients. The abnormalities had often not led to brain infarcts. Few clinical-neurological signs were described which led to a poor clinico-pathological correlation. Hypertension and general atherosclerosis were infrequently found in 'thromboangiitis obliterans', and specific causes were not described. The so-called thromboangiitis obliterans type II may be regarded as a specific pathological entity in the borderzone territories of the major cerebral arteries, but infrequently leading to infarcts in these territories. Therefore, the relationship between 'thromboangiitis obliterans' and the clinical features is unclear.

Götze and Krücke (1942) ${ }^{69}$ described a male patient with dementia and amyloidosis of the peripheral nerves, the heart and the venous system. Microscopically, granular atrophy of the cerebral cortex was found mainly in the borderzones between the large cortical arteries, but there were no abnormalities of the (larger) cerebral arterial vessels. The authors concluded that the cortical abnormalities in the borderzones were not caused by the earlier described 'thrombo-endarteritis obliterans' of the brain arteries, but by circulatory disturbances due to amyloidosis of the heart. This case can be considered to be the first report of a supposed specific vulnerability of the vascular (cortical) borderzones related to circulatory insufficiency (hypotension?).

Akelaitis (1942) ${ }^{4}$ described a male patient with hypertension who became mentally retarded after a vague illness at the age of seven, and who died at 32 years. The case was presented in order to emphasize the unique distribution of the cerebral atrophy, which was topographically limited to the junctions of vascular supply of the three major cerebral arteries. Microscopy revealed narrowing and occlusion of the cortical arterioles in the 'vascular junctional' territories of the anterior, middle and posterior cerebral artery, that had resulted in glial scarring. This process was called 'granular atrophy'. In this case extensive general atherosclerosis was found. Lindenberg and Spatz found 'granular atrophy' as a result of a 'thromboangiitis obliterans'. Although Akelaitis doubted if his patient with atherosclerosis had a 'thromboangiitis obliterans', his 
findings are very similar to those of Lindenberg and Spatz concerning the 'typical' pathological findings of 'granular atrophy' in the borderzones of the major cerebral arteries.

Meyer (1953) ${ }^{103}$ described post mortem findings in 153 neonates who had died from postnatal cerebral circulation disturbances. He focused special interest on the cerebral 'arterielle Grenzgebiete'. In 30 out of 153 cases the findings resembled those of 'thromboangiitis obliterans', described by Lindenberg and Spatz: lesions in the vascular (mostly parieto-occipital) borderzones, which contained patchy infarcts and multiple arterial thrombosis. With respect to possible causes the author stated that the 'arterielle Grenzgebiete' were particularly vulnerable to cerebral circulatory disturbances. He thought that the absence of pre-capillary anastomoses at the junctions of the major cerebral arteries contributed to haemodynamic insufficiency in these territories. The findings of Meyer support the hypothesis of a specific - haemodynamic - mechanism in borderzone infarcts. The microscopic descriptions in this study resemble those of Lindenberg and Spatz in that signs of 'endarteritis' often restricted to the arterial borderzones, were found. However, the granular atrophy as described by Lindenberg and Spatz as a typical hallmark for 'thromboangiitis obliterans' was not found by Meyer. The studies of Lindenberg and Spazz, Götze, Akelaitis and Meyer describe cases with a typical pattern of arterial 'endarteritis', which was often combined with cortical granular atrophy restricted to what the authors considered as arterial borderzones. Specific aetiological factors were not found, although Meyer, and Götze and Krücke, suggested that haemodynamic factors play a causative role.

In a pathophysiological review on stroke, Zülch $(1961)^{162,163}$ described several subtypes of brain infarcts. Firstly, 'Grenzlinie Infarkte', or 'Grenzfläche Infarkte', which were infarcts located on the 'borderzone' between two or more major cortical or subcortical arteries. To explain the presumed pathophysiology in such infarcts Zülch used the physiological concept that the flow is lowest in the most distally located areas. Therefore, the author suggested that a territory where two arteries connect in their most distal parts ('Grenzfläche' area) had low flow, leading to a low perfusion pressure. Consequently, Zülch concluded that those 'Grenzfläche' areas are particularly vulnerable to haemodynamic alterations, such as hypotension. Such haemodynamic alterations were mentioned (hypothetically) as the most important cause of infarction in the 'Grenzfläche' territories. Secondly, Zülch described 'Endfläche Infarkte', which were infarcts in a terminal arterial zone, the so-called 'letzte Wiese'. With respect to the pathophysiology of such infarcts Zülch suggested the same mechanisms in 'Endfläche' as in 'Grenzfläche' territories. Dysfunction of the circle of Willis and its collaterals was mentioned by Zülch as an important cause of haemodynamic alterations, but not especially with respect to either infarct type. In our opinion, it may be important to distinguish 'Endfläche' or 'letzte Wiese' zone infarcts from 'Grenzfläche' infarcts. 'Endfläche' infarcts are infarcts in the most distal part of only one artery and could therefore be considered to be distal 'territorial' infarcts, which may have other causes than 'Grenzfläche' infarcts. Such 'Grenzfläche' infarcts may be what most authors consider nowadays as 'borderzone' infarcts, which are infarcts located in adjacent endzones of at least two different cerebral arterial territories. The hypothesis of Zülch of a 'haemodynamic stroke cause' in 'Grenzfläche' or 'Endfläche' zones has frequently been 
referred to in the current literature. This is surprising because, although some logic in Zülch's hypothesis cannot be denied, lack of sufficient data leaves room for considerable doubt regarding the supposed pathophysiological mechanisms of infarcts located in the 'vascular borderzones'.

Romanul and Abramowicz (1964) ${ }^{133}$ studied 13 brains with infarcts in the arterial border zones' between the territories of the major cortical arteries. They aimed to describe the mechanism commonly responsible for the pathological changes in infarctions in the arterial 'borderzones'. In five patients they found ipsilateral occlusion of the internal carotid artery. In three patients with patent carotid arteries the neurological deficit occurred after episodes of severe and prolonged hypotension, whereas in the remaining five patients the neurological deficit developed gradually over a longer period. Microscopy revealed occlusive and proliferative changes in only small arteries in the infarcted brain areas. These microscopic changes were not specific for any particular disease. The authors concluded that the changes in the infarcted borderzone territories were produced by a specific 'disturbance in the cerebral haemodynamics', as a consequence of the decreased blood flow through the major cerebral arteries. They further suggested that such disturbances in cerebral blood flow resulted from an occlusion of the (internal) carotid arteries, or from decreased cardiac output in systemic hypotension without carotid artery occlusion. These pathophysiological considerations concur with the ideas of Zülch. The study of Romanul and Abramowicz suggests that the occurrence of borderzone brain infarcts may be caused by several conditions that lead to a state of lowered cerebral blood supply such as hypotension, or hypotension aggravated by other factors like carotid artery stenosis or cardiac disease. However, it is unclear from what population of stroke patients the studied cases came from. Moreover, the supposed 'state of lowered cerebral blood supply' was substantiated in only three cases.

Fisher and McQuillen (1981) ${ }^{59}$ described a case with severe left internal carotid artery stenosis and occlusion of the right internal carotid artery. The patient presented with acute bilateral weakness of the extremities and the tongue. He died four days later due to recurring ventricular arrhythmias. Microscopy revealed infiltrates around the blood vessels in the haemorrhagic infarcted areas, which were located at the junction of the middle and anterior cerebral artery on both sides. No occlusions of the vessel lumen in the infarcted area were found. In this patient a borderzone brain infarct was the result of a cerebral perfusion disturbance caused by cardiac arrhythmias combined with severe carotid artery obstructive lesions. This case is another casuistic presentation of a probable haemodynamically caused 'borderzone' infarct, but is not conclusive as to wherher the combination of features is an exception or the rule.

Adams et al. (1966) ${ }^{3}$ presented clinical and neuropathological findings in eleven patients who died following systemic hypotension of varying speed of onset, intensity and duration. Four patients sustained a syncope, three had cardiac arrest, whereas the remaining four suffered a period of low blood pressure. In two cases the lesions were confined to the 'watershed' or 'arterial boundary zones', and could be attributed to a precipitated reduction in cerebral blood flow due to syncope during cardiac failure, although blood pressure recordings were not done until some hours later. In four cases small 'watershed' lesions, combined with some degree of diffuse neuronal loss in the cerebral and cerebellar cortex were found. In two of these cases, a period of hypotension 
had been registered. In the remaining five cases moderate but sustained hypotension had been registered prior to the neurological event. Diffuse and severe neuronal loss were the only microscopic findings. The authors concluded that all patients sustained variable reductions in cerebral blood flow resulting from some periods of hypotension, which had led to a spectrum of pathological changes, ranging from lesions confined to the 'watersheds' to a complete diffuse destruction of neurons. Because six of the eleven patients with signs of systemic hypotension had infarcts 'in the watershed territories', these findings illustrate the fact that infarcts located in the 'watershed' territories may be caused by a sudden drop in blood pressure. However, it is obvious from this study that systemic hypotension may also cause infarcts in other cerebral territories.

In 994 consecutive autopsies Jörgensen and Torvik (1969) ${ }^{84}$ found 320 cases with ischaemic cerebrovascular disease; 354 supratentorial infarcts with a diameter of more than $0.5 \mathrm{~cm}$ were found. The authors aimed to study the frequency, topography, pathogenesis and clinical course of the 320 cases. Four types of supratentorial infarcts were distinguished: firstly, 'watershed' area of cerebral cortex and white matter $(n=37)$; secondly, in the cerebral cortex and white matter with or without 'central ganglionic area' $(n=210)$; thirdly, cerebral white matter only $(n=36)$; fourthly, 'central ganglionic only' $(n=71)$. 'Watershed' infarcts were defined as 'infarcts in the borderzone between the territories of two major arteries'. Thirty of these infarcts were located between the territories supplied by the anterior and middle cerebral arteries, whereas the remaining 7 infarcts were located in the 'watershed area' between the anterior and posterior or middle and posterior cerebral arteries. An infarct was said to be thromboembolic if the patient had atrial fibrillation, or if endocardial thrombi in the cavities of the heart in the absence of cerebral atherosclerosis were present, or in the case of multiple infarcts located outside the brain. At least two of these criteria had to be present in the infarcts to be classified as 'embolic'. Eight (22\%) 'watershed' infarcts fulfilled these criteria. In the cortical white matter infarct group, and in the ganglionic infarct group these percentages were 34 and 22 respectively. Infarcts without any evidence of embolic pathogenesis were grouped as 'non-embolic'. In this group 23 (62\%) of the 'watershed' infarcts were classified, whereas the percentages in the other infarct groups ranged from 51 till 78. Infarcts were considered as 'unclassified lesions' ( $16 \%$ of the watershed infarcts) when there was any doubt about the cause of the infarct. Patients with carotid artery obstruction were not classified as embolic but as non-embolic or unclassified. In eight (22\%) cases with 'watershed' infarcts carotid occlusions were found. The study did not clearly state the number of patients with non-occluded carotid obstruction and 'watershed' infarcts, nor did it provide such information for the other infarct groups. In five patients with carotid artery occlusion who sustained a period of severe hypotension only one had a 'watershed' infarct. In this large study on brain autopsies 37 of 354 described supratentorial infarcts were 'watershed' (10\%). Although signs of carotid obstruction, hypotension or a cardioembolic stroke cause were found in 'watershed' infarcts, the frequency of these features did not differ significantly between the four investigated groups. Therefore, no specific cause of 'watershed' infarct was identified.

In 18 autopsied patients Torvik and Skullerud (1982) ${ }^{149}$ studied 'cortical watershed infarcts'. They distinguished three watershed infarct subtypes which they related to specific causes. In the first group, four patients with 'watershed' infarcts caused by 
unusual micro-emboli were described. In two of these patients numerous small arteries in the infarct area were filled with loose atheromatous masses consisting of necrotic material with needle-like spaces stemming from cholesterol crystals. In the orher two cases, known to have a malignancy and widespread metastases to many organs, brain autopsy showed infarcts of varying age in the 'watershed' areas with multiple 'tumour emboli' in the involved small arteries. The second group consisted of ten patients who died after a well defined period of hypotension due to various causes. Six cases had bilateral, and four unilateral 'watershed' infarcts between the territories of the anterior and middle cerebral arteries. On histological examination only one patient showed occlusion of the vessels in the infarct area. No further details on microscopic examination were provided. The third group consisted of four patients with 'watershed' infarcts and thromboembolic occlusion of the leptomeningeal vessels. Several infarct causes in these four patients were suggested: thromboembolism due to carotid artery obstruction, or thromboembolism in a patient with multiple bilateral 'watershed' infarcts with patent carotid arteries but occlusion of the vessels in the infarct area, and finally haematogenous infarction due to excessive platelet consumption. The authors concluded that: firstly, 'watershed' infarcts may be caused by multiple occlusions of small arteries due to showers of micro-emboli of different origins (cholesterol, tumour); secondly, 'watershed' infarcts may be caused by hypotension without any signs of occlusion of the leptomeningeal arteries; and thirdly, 'watershed' infarcts can result from multiple thromboembolic occlusions of the leptomeningeal vessels due to haematogenous disorders, or thromboembolism due to carotid artery obstruction.

From another study, Torvik (1984) $)^{150}$ further suggested that in patients with carotid artery occlusion and 'watershed' infarcts the (often) occluded overlying vessels are the consequence of micro-thromboemboli originating from the carotid artery, just before it becomes completely occluded, rather than from 'stagnation thrombi' due to locally reduced blood flow. The studies of Torvik and Skullerud suggest several possible pathophysiological mechanisms causing 'watershed' infarcts: periods of hypotension and showers of micro-emboli from varying causes were most frequently found, whereas a carotid obstruction was regarded as causing watershed infarcts due to micro-emboli rather than due to 'stagnation thrombi'. Some of the 'watershed' infarcts with occluded leptomeningeal arteries, resemble the states of 'cerebral thromboangiitis' as described by Lindenberg and Sparz. Although refuted by others ${ }^{53}$, this would imply at least one 'known' stroke cause (micro-emboli from various origins) in frequently described 'watershed' infarcts (thromboangiitis obliterans). Unfortunately, the autopsy study by Torvik $^{149}$ lacks information about the carotid arteries in all but two patients, which makes any conclusion about the contribution of the carotid artery in the pathophysiology of 'watershed' infarcts speculative.

Pollanen and Deck (1989) ${ }^{120}$ described three autopsy cases with multiple small infarcts in the 'watershed' areas between the major cortical arteries. All patients showed numerous thrombotic occlusions of varying age in the leptomeningeal or subarachnoidal arteries overlying the infarcted areas. All had a potential thromboembolic source (two cardiac and one carotid). None of the patients had a documented period of hypotension, which was therefore considered unlikely to explain why the massive thromboemboli were preferentially located in the 'borderzone' territories. The authors 
hypothesized that at least in some cases of 'watershed' infarcts the arterial branching pattern, characterized by bifurcations of unequal size, and the diameter of the thromboemboli played a significant role in the distribution of emboli to vascular borderzones. Therefore, they suggested that emboli of 'a limited range of diameters' would preferentially be distributed in the 'borderzone' territories. Torvik and Skullerud ${ }^{149}$ in a previously mentioned study suggested that emboli tend to lodge in the leptomeningeal vessels at the surface of the brain rather than in branches diverging at right angles to the basal ganglia, and that micro-emboli in the 'watershed' areas are a specific example of this general rule. In an experimental study Pollanen found that, at bifurcations of unequal size, the larger branch directs peripherally, which means in the direction of the 'watershed' area ${ }^{121}$. He hypothesized that emboli of a specific size were selectively directed to the 'watershed' zones due to the tendency of emboli to bypass the small arterial branches which emerge proximal to the major borderzones. He perfused brain cadavers with particles of different size and found that particles of a limited size were indeed preferentially distribured to the 'watershed' zones. From the (clinical and) experimental studies of Pollanen it can be concluded that a vascular borderzone may exist due to a specific configuration of the vascular tree. The multiple occlusions of 'distal' leptomeningeal vessels, described by Torvik and Skullerud in many 'watershed' infarcts, could have been caused by multiple small emboli. However, on topographical and morphological grounds there is no proof that such 'watershed' infarcts involve two major arterial supply areas; multiple emboli may simply lodge in the distal area of one major artery only, instead of in two or even three.

\section{Experimentalstudies}

To investigate the pathogenesis of ischaemic neuronal damage along the 'arterial boundaries', Brierley et al. $(1980)^{32}$ studied the effect of brain hypoxia in 20 lightly anaesthetized baboons with bilateral carotid occlusion. Artificial hypoxia followed by occlusion of the carotid arteries on both sides resulted in an electrically silent EEG in all baboons. After a certain period of electrical silence, hypoxia and carotid occlusion were terminated. In 15 brains neuronal damage was found to be restricted to the arterial borderzones of the cerebral cortex. Parts of the basal ganglia were also involved in seven brains. During the experiments no periods of systemic hypotension were registered. The authors concluded that, in the presence of profound hypoxia, oligemia due to bilateral carotid occlusion can reduce tissue oxygenation locally to a level that is critical enough to produce ischaemic damage, especially in the cortical 'boundary' zones. However, the artificial state of experimental carotid occlusion combined with controlled hypoxia may not reflect possible cerebral perfusion alterations caused by precerebral arterial obstruction or other possible haemodynamic alterations in human clinical states. 


\section{PART 3 CT SCAN AND OTHER IMAGING CHARACTERISTICS OF BORDERZONE INFARCTS}

With the introduction of CT scanning brain infarcts could not only be visualised during life, but also categorized based on size, shape, location, and whether or not they were haemorrhagic, etc. Later, with the advent of the MRI, these possibilities were further developed. Different infarct subtypes were defined such as small deep infarcts, territorial infarcts, 'low-flow' infarcts and 'borderzone' infarcts. Different infarct features were combined to describe a certain infarct subtype. In 'borderzone' infarcts, shape and location but also pathophysiological features such as hypotension, presumed degree of cerebral perfusion, or a carotid stenosis were involved in the definition. ${ }^{21,22,156,158}$ Most authors suggest that a borderzone infarct should be located at the 'junction zone' between the vascular territories of different (major) cerebral or cerebellar arteries, or between the medullary branches and deep penetrators of the major cerebral arteries. $21,22,31,82,153,156,158$ Some authors suppose that the infarct shape should have a typical configuration, although they sometimes mismatch the configuration of an endzone infarct with a 'real borderzone' infarct. ${ }^{158}$ The slitlike, or right-angled infarct configuration extending along a supposed arterial borderzone is a typical borderzone infarct hallmark according to some authors. ${ }^{22,131,158}$ However, because most clinical (CT scan) studies lack pathological confirmation, it is doubtful whether the mentioned infarct criteria are valid. Although most authors agree about the topographical aspects of a 'borderzone' infarct, the exact localisation of the 'borderzone' may vary widely as discussed earlier in this thesis. Most authors used brain templates to locate the borderzone territories, like those of Damasio ${ }^{41}$, Ghika ${ }^{66}$, Kretschmann ${ }^{88}$ or Matsui and Hirano ${ }^{100}$, based on the most up-to-date anatomical standard atlases. Damasio constructed brain templates of the cerebrovascular supply areas based on the work of Matsui and Hirano. She mentioned that the borderzones between the major cerebral arteries were not marked but that 'they can be easily identified on the basis of neighbouring territories of the three principle vessels'. Ghika et al. ${ }^{66}$ provided the distribution of basal perforating arteries in the carotid system, also based on the work of Damasio. ${ }^{41}$ The use of any vascular template to study the location of infarcts on CT with respect to vascular territories fails to account for the significant variation in vascular supply areas between and within individuals. Therefore, defining and characterizing borderzone infarcts with the use of such templates may not be realistic. Although the demarcations between different vascular supply areas are difficult to identify in individual cases, the templates could however be used as a best grip, whereas vascular demarcations should at least be considered to represent something as 'an average', around which the virtual borderzone areas may be located. As such, it might still be worthwhile to use vascular templates, but this means that relatively large numbers of infarct patients should be studied.

In conclusion: the borderzone locations in CT-scan studies may only roughly approximate the 'real' vascular borderzones, because the vascular territories of the major cerebral arteries vary strongly, and therefore also size, shape and locarion of borderzone infarcts may be more variable than was previously thought to be.

Wodarz $(1980)^{158}$ investigated 55 patients with carotid artery stenosis and/or 
occlusion by means of angiography and CT scan in order to outline the topographical presentation of the 'watershed infarctions'. No clinical data were provided. The author considered size, shape and location of the presumed watershed infarctions. He differentiated between 'superficial borderline', 'deep borderline' and 'terminal zone' infarcts, and illustrated on CT templates 'typical watershed' changes, such as: triangular infarctions (figure 2.17a) at the frontoparietal and temporo-occipital borderline which could well be regarded as terminal zone or endzone infarcts; secondly, cystic infarcts in the head of the caudate nucleus (figure 2.17a), which could be regarded as deep borderzone infarcts; thirdly, striated and stained hypodense areas in the white matter (figure 2.17b), which could be regarded as deep borderzone infarcts; fourthly, striated hypodense areas in the white matter extending into adjacent supply areas of the anterior and middle cerebral arteries (figure 2.17c).

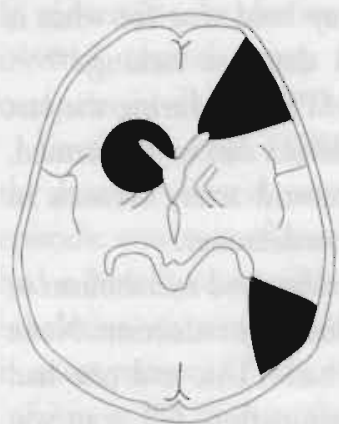

$2.17 a$

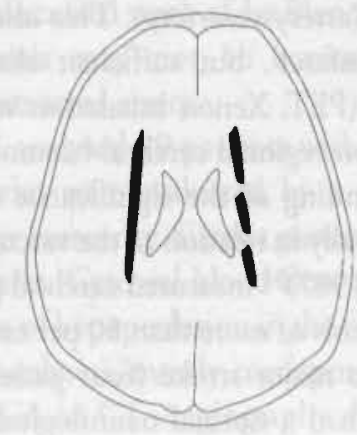

2.176

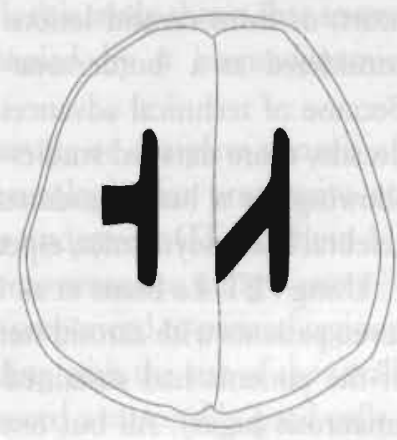

$2.17 c$

Figure 2.17a, 2.17b, 2.17c:

Schematic representation of axial CT-sections, indicating typical watershed changes.

2.17a: triangular infarction at frontoparietal and temporo-occipital borderline; cystic infarction in head of caudate nucleus.

2.17b: striated and stained hypodense areas in white matrer.

$2.17 \mathrm{c}$ : striated hypodense areas in white matter extending into adjacent supply areas of anterior and middle cerebral arteries.

Adapted from Wodarz $R$. Watershed infarctions and computed tomography. A topographical study in cases with stenosis or occlusion of the carotid artery. Neuroradiology 1980;19:245-248 (with permission).

In 40 per cent of the cases the author described changes in both the 'terminal' and 'borderline' zones, which he called 'watershed processes'. No further clinical details on these infarcts were given. In this study, site, size, shape and location of infarcts with 'watershed processes' were clearly described. Some of the infarcts, especially the 'terminal zone infarcts' however, may not be real 'borderzone' infarcts, but endzone infarcts. This would explain the high percentage ( $40 \%)$ of 'watershed infarctions' in this series. The lack of clinical data, and the lack of information about patient selection make an analysis of the presumed 'watershed' infarcts presented in this study hazardous. Obviously, neither topographical CT features, nor certain clinical features are available from this study to characterize infarcts as 'borderzone' or 'watershed'.

A 'significant' carotid obstruction may impair poststenotic flow. ${ }^{8}$ However, the concept of a 'haemodynamically significant' carotid stenosis is still controversial. Recent 
studies have not demonstrated a consistent relationship berween the severity of occlusive disease in the carotid artery and the haemodynamic status of the ipsilateral cerebral circulation. ${ }^{123}$ Intracerebral haemodynamic abnormalities and autoregulatory vasodilation were not found to correlate with the degree of carotid stenosis. ${ }^{93}$ On the other hand, some studies showed a strong relationship between the regional cerebral haemodynamics in the hemisphere distal to a carotid stenosis or occlusion and the angiographical pattern of collateral circulation. ${ }^{122}$ Therefore, with respect to the arterial borderzones distally to a carotid stenosis, a special haemodynamic compromise of these borderzones is not yet obvious. Factors such as syncope, collapse, hypotension or a sudden drop in blood pressure are supposed to worsen the haemodynamic status distally to a carotid stenosis. But, the clinical evidence of such a concept is weak, whereas hypoperfusion may be considered to play only a minor role in the origin of brain infarcts in general. ${ }^{162}$ Brain infarcts are much more likely to be the result of emboli, either from the heart, or from carotid lesions (artery-to-artery). This also may hold true for what is considered as a 'borderzone infarct', but sufficient clinical data are lacking. ${ }^{149,150}$ Because of technical advances (PET, Xenon inhalation with SPECT) during the last decade, more detailed studies on regional cerebral haemodynamics can be performed, allowing for a better understanding of the significance of carotid artery stenosis in cerebral haemodynamics, especially in relation to the vascular borderzones.

Using PET, Le Blanc et al. (1987) ${ }^{91}$ measured cerebral perfusion and metabolism in seven patients with carotid stenosis of more than 80 per cent diameter reduction. None of the patients had sustained a major stroke (four patients had TIAs, and one had amaurosis fugax). All but one had a normal neurological examination. CT scan was normal in all patients. The topographical location of the borderzone areas was not defined. In the patients in study a significant reduction in cerebral blood flow (CBF) and of haemodynamic reserve capacity in borderzone regions between the ACA and MCA was seen as compared with the 'normal ranges' of six neurologically sound elderly volunteers. No reduction was found in the MCA/PCA borderzone. The authors concluded that the anterior borderzone was selectively vulnerable to cerebral ischaemia in patients with severe carotid stenosis. The numbers of parients in this study were relatively low and it was not clear which anatomical areas were designated as borderzone territories, which makes it questionable as to which cerebral areas were in fact investigated. Nevercheless, the results may suggest haemodynamic compromise of the anterior territories presumably located in the vascular borderzone in patients with ipsilateral carotid stenosis.

To investigate the possible existence of chronic selective haemodynamic impairment in the 'arterial borderzone regions' of the brain Carpenter et al. (1990) $)^{38}$ performed a positron emission tomography (PET) study of 32 patients with either severe internal carotid artery stenosis or occlusion, and of eleven controls. Twenty-six patients were symptomatic (TIA, amaurosis fugax, or other ocular signs). None of the patients had clinical neurological signs or CT abnormalities. Regional cerebral blood volume (rCBV), regional cerebral blood flow (rCBF) and regional cerebral oxygen extraction were measured. The authors used a stereotactic co-ordinate system to define the regions of interest. The borderzone anatomy was chosen according to the anatomical descriptions of Van der Eecken: an anterior and a posterior corrical borderzone, respectively 
ACA/MCA and MCA/PCA.50.51 No evidence of selective haemodynamic impairment in the regions considered as borderzones between the MCA and either the ACA or PCA in the group of patients with severe occlusive carotid artery disease was found. The authors concluded that exacerbation of pre-existing selective borderzone haemodynamic impairment by small changes in perfusion pressure was not a common cause of selective borderzone infarction. They made the restriction that since they did not study any patient immediately prior to a borderzone infarct, they could not be completely sure about their conclusion. But the authors suggested that, with respect to the borderzone infarct pathophysiology, a significant drop in regional perfusion pressure may have caused an acute infarct in the borderzone territory. This may have been due to acute progression of the carotid artery stenosis, a sudden embolic occlusion, a sharp drop in systemic blood pressure, or showers of micro-embolic material. However, it is important to emphasize that these were all hypothetical possibilities rather than proven certainties. In contrast to the previously discussed work of Le Blanc ${ }^{91}$, this study shows that severe internal carotid artery stenosis may not be accompanied by a haemodynamic compromise distally to the obstructed artery.

Yanagihara et al. (1988) 161 analysed 19 patients with severe or complete stenosis of the internal carotid artery who were evaluated by a neurologist for progressive or episodic weakness of one lower extremity. Sixteen patients underwent CT, of whom 11 had a (small) compatible infarct. Cerebral blood flow measurements, using Xenon ${ }^{133}$ inhalation, showed a wide area of hypoperfusion in the frontoparietal to parietal regions in most patients ( 7 out of 8 analyses), mostly corresponding with the site of the small infarcts in the ACA or the MCA on CT. Angiography showed a reasonably good collateral perfusion to the ACA through the anterior communicating artery. The authors believed that the hypoperfusion was located in the anterior borderzone between the $\mathrm{ACA}$ and $\mathrm{MCA}$ and that the clinical syndrome was the consequence of haemodynamic alterations in this region. In this study patients with specific clinical syndromes were selected, most of them had 'ACA-syndromes'. Therefore it is not surprising to find the hypoperfusion in the ACA/MCA territory. Because the demarcation lines of the anterior borderzone were not described by the authors, it is questionable whether (all) zones of hypoperfusion were 'really' borderzones.

Using PET, Yamauchi et al. (1990) ${ }^{160}$ studied nine patients with minor stroke, unilateral internal carotid artery occlusion, and good collateral circulation through the anterior portion of the circle of Willis. Three patients had TIAs and five a minor stroke. Five patients had a small white matter infarct on CT and four had normal CT. The authors found significantly decreased $\mathrm{TCBF}$ in the MCA territory and the surrounding watershed areas' in the patient group compared with eight controls. They suggested haemodynamic vulnerability of the 'watershed areas' after internal artery occlusion in this patient group. However, it is questionable whether the $\mathrm{CBF}$ values in the presumed watershed territories have any specific significance: it cannot be excluded that these patients had a complete MCA territory hypoperfusion, rather than hypoperfusion restricted to the borderzone areas. From the studies of Yanagihara ${ }^{161}$ and Yamauchi ${ }^{160}$ it may be concluded that, at least in some patients with carotid occlusion or stenosis, specific haemodynamic compromise of the ipsilateral cortical arterial area may be present. However, controls in studies like these should consist of similar cerebral 
vascular disease patients with similar cerebral vascular compromise except for the presence of carotid obstruction, rather than healthy controls. So far, there are no strong arguments in favour of the idea that carotid disease significantly contributes to the risk of developing a 'borderzone' infarct, rather than a 'territorial' infarct. Large series of brain infarct patients containing different subtypes of brain infarcts including 'borderzone' infarcts are lacking. Up till now, it is not clear whether haemodynamic disturbances in the borderzone are the cause or the consequence of cerebrovascular compromise.

The next section deals with topographical CT studies of patients with and without a significant carotid lesion. Most CT studies differentiate between 'cortical borderzone' and 'subcortical borderzone'. With 'cortical borderzone' most authors are referring to the vascular borderzone between adjacent cortical branches of the three major cerebral arteries (territorial borderzone), whereas 'subcortical borderzone' refers to the deeply located vascular borderzone between the perforating medullary branches and the deep penetrators of the major cerebral arteries (deep borderzone).

Using Doppler sonography, CT scan, and cerebral angiography Ringelstein et al. $(1983)^{131}$ studied 107 patients with internal carotid artery occlusion and TIA or stroke, in order to relate clinical, angiographical and brain morphological findings. The authors distinguished four types of infarcts. Firstly, eight patients had 'typical' striated and triangular cortical 'watershed' or 'borderline' infarcts of the convexity: figure 2.18a. In these infarcts a haemodynamic cause was suggested. (One of the two infarcts illustrated in the figures could well be an 'endzone' or small territorial infarct of the MCA). Secondly, 36 patients had haemodynamically induced subcortical terminal supply area infarctions: figure $2.18 \mathrm{~b}$ (to our opinion some of these infarcts could well be classified as (subcortical) borderzone infarcts). Thirdly, 42 patients had 'pial artery territory infarction': figure $2.18 \mathrm{c}$. These infarcts were suspected to be of thromboembolic origin (one of the illustrated infarcts could also be classified as a terminal MCA or endzone infarct). Fourthly, one extended lentiform nucleus infarction: figure $2.18 \mathrm{~d}$ (the infarct shown as an example in the figure could also be classified as a partial subcorrical borderzone infarct). By combining angiographical findings with 'CT morphology' the authors aimed at differentiation berween haemodynamically induced infarcts ${ }^{132}$ and those caused by embolism of the major brain arteries. These findings could, according to the authors, provide a guideline for proper selection of patients for carotid endarterectomy. However, some of the infarcts in the described four infarct subgroups could also be classified differently. Therefore, it may be hazardous to relate such infarct localization on CT to possible pathophysiology and consequently to possible therapy. 


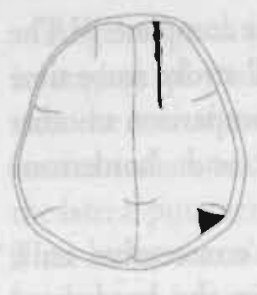

$2.18 a$

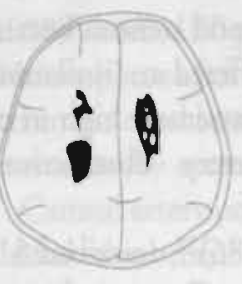

2.186
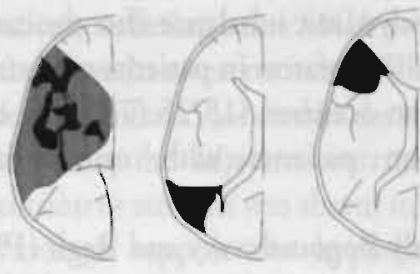

$2.18 \mathrm{c}$

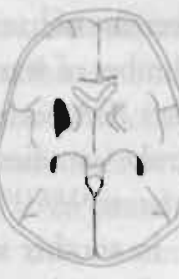

$2.18 d$

Figure 2.18a, 2.18b, 2.18c, 2.18d

Figure 2.18a: Haemodynamic, predominantly cortical, 'watershed' infarcrs.

Figure 2.18b: Subcortical terminal supply area infarcts.

Figure 2.18c: Thromboembolic territorial infarcts.

Figure 2.18d: Lentiform nucleus infarct.

Adapted from Ringelstein $B$, Zeumer $H$, Angelou $D$. The pathogenesis of strokes from internal carotid artery occlusion. Diagnostic and therapeutical implications. Stroke 1983;14:867-875 (with permission).

Bogousslavsky and Regli (1986) ${ }^{21}$ described 'watershed infarcts' on CT in 154 patients with either carotid transient ischaemic attack (TIA) or infarction, with an occlusion of the ipsilateral ICA on Doppler Ultrasound studies. The topography of the infarcts on CT was assessed using Damasio's templates. ${ }^{41}$ The authors distinguished infarcts in the borderzone berween the superficial territory of the MCA and ACA, in the borderzone between the superficial territory of the MCA and the PCA, and in the borderzone between the superficial and deep territory of the MCA (called subcortical 'watershed' infarcts). Initially in only eight (5.2\%) of the 154 patients 'watershed infarcts' were found. It is not clear how many patients initially had a non-watershed infarct on CT. After a mean follow-up period of 48 months 30 of the remaining 148 patients had suffered a stroke. Eighteen patients with an additional 'watershed' infarct were found, making up a total of 26 of the 154 patients $(17 \%)$ with one or more (symptomatic) 'watershed' infarcts. In 18 of these patients the infarct occurred in the follow-up period, which means after the occlusion of the 'ipsilateral' carotid artery had been demonstrated. Symptomatic heart disease with periods of hypotension and syncope, severe contralateral ICA disease, high haematocrit values, and heavy smoking were more frequent in patients with 'watershed' infarcts as compared to the remaining patients with 'ipsilateral' carotid occlusion and TIA or stroke. Among 27 patients with angiographically proven ICA occlusion who suffered a delayed ipsilateral infarct, an ulcerated stump and/or ulcerated or irregular stenosis in the collateral channels was more frequently found in infarcts in the territory of the main branches of the MCA (6/7) than in 'watershed' infarcts (3/16). This would suggest, according to the authors, that an embolic cause is less probable in 'watershed' infarcts. The authors concluded that in the 'watershed' infarct group a haemodynamic cause was most probable. They suggested that in patients with ICA occlusion and watershed infarcts appropriate treatment of all potential causes of systemic haemodynamic disturbances may be crucial in the longterm management of these patients. Although the authors found several "haemodynamic factors' which were more prominent in the watershed infarct group, most of the watershed infarcts $(18 / 26(69 \%))$ appeared only some time after the ipsilateral ICA had occluded. This is of particular interest because, other studies, in contrast, mentioned a 
decrease of haemodynamic inbalance after the carotid stenosis became complete. ${ }^{112}$ The number of watershed infarcts in patients who suffered an 'ipsilateral' stroke some time after ICA occlusion occurred (18/25 (72\%)) is extremely high in comparison to other stroke studies on patients with carotid artery obstruction and borderzone infarcts. ${ }^{43,84,110}$

In another study Bogousslavsky and Regli (1986) ${ }^{22}$ described 51 'consecutive' acute stroke patients with 'three types of watershed' infarcts: infarcts in the borderzone between MCA and ACA, infarcts in the borderzone between the MCA and PCA, and infarcts in the borderzone between the superficial and deep territories of the MCA (subcortical watershed infarcts). Also in this study the CT watershed areas were determined using the templates of Damasio ${ }^{41}$, and mapped according to Matsui and Hirano. ${ }^{100}$ The authors described different infarct shapes, such as striated and wedgelike without arguing why these configurations should be typical for 'watershed' infarcts. The aim of the study was to describe the characteristic clinical picture in patients with watershed infarcts. Frequent signs were loss of consciousness for a few minutes at onset in 37 per cent and focal myoclonic jerks in 12 per cent of the parients. Thirty-eight patients $(75 \%)$ had internal carotid artery occlusion or tight stenosis at the onset with 'cardiopathy', elevated haematocrit, or acute hypotension. The patients selected for this group possibly overlapped with those in a prior study. ${ }^{21}$ The authors concluded that 'most watershed infarcts are caused by haemodynamic events, typically when patients with severe ICA obstruction suffer a fall in systemic blood pressure'. They further suggested that in patients with severe ICA disease treatment of associated cardiopathy and polycythemia may prevent watershed infarcts. The studies of Ringelstein and Bogousslavsky $21,22,131$ did not demonstrate a sudden drop in systemic blood pressure in their patients, and lacked a comparison of 'watershed' infarcts with other infarct subtypes. Still they may suggest a haemodynamic stroke cause in 'cortical borderzone' infarcts related to carotid artery obstruction. These studies provided clear definitions of 'borderzone' territories, although the definitions are open to criticism. Other studies, however, contradict this 'haemodynamic theory' in watershed infarcts with associated carotid stenosis.

Graeber et al. (1992) ${ }^{70}$ described three patients with a CT confirmed infarct partially or exclusively located in 'watershed' territories. Two patients had angiographically demonstrated minimal carotid plaque. The third patient had high grade ICA stenosis but also an artery branch occlusion corresponding with the infarct territory. Because of the lack of an embolic source (severe carotid stenosis) in the first two patients and signs of 'embolic branch artery occlusion' in the third patient, combined with the absence of 'a history suggestive for a generalized cerebral hypoperfusion' the authors suggested that the described infarcts were of embolic origin. They concluded that patients in whom CTconfirmed 'watershed' infarcts do not occur during periods of systemic hypotension 'should not automatically be assumed to have haemodynamic infarction'. However, evidence of an 'embolic infarct' was only present in the third case. From the first two cases it may only be concluded that the infarcts did not relate to a significant carotid stenosis, which does not exclude a haemodynamic infarct cause. Moreover, clinical signs of hypoperfusion prior to an infarct are very difficult to register or to exclude (e.g. short periods of hypotension). However, this study was small and its significance is therefore limited. 
Angeloni et al. (1990) ${ }^{6}$ studied 36 patients suffering acute MCA occlusion confirmed by angiography within six hours after the ictus. In seven patients $C T$ scan three months after the ictus showed an 'internal borderzone infarct', located in the white matter of the corona radiata and occasionally extending into the 'adjacent centrum semi-ovale or in the lateral putamen'. Carotid artery occlusion or stenosis was absent in all seven patients. The authors concluded that their findings support the hypothesis that internal borderzone infarctions may arise from distal intracranial MCA branch occlusions and not necessarily from haemodynamic compromise secondary to proximal large vessel (carotid) occlusive disease. According to the authors a local haemodynamic effect may be part of the pathogenesis of internal borderzone infarctions, although limited to the distal fields due to isolated intracranial MCA branch occlusion, whatever the cause. The lack of CT scan descriptions in the first week after the stroke makes the interpretation of the 'late' CT scans somewhat speculative. It may be that in some of the seven 'internal borderzone infarcts' changes such as retraction phenomenon or density attenuation had led to CT misinterpretations. Furthermore, patients were selected on angiographically 'proven' MCA occlusion. We may conclude from this study that in some patients with normal carotid arteries distal 'internal borderzone infarcts' may arise in relation to MCA occlusion. This means that large intracerebral artery compromise, e.g. due to a cardiac embolus or due to slugging of the MCA, may be a cause of borderzone infarcts. Graeber $^{70}$ and Angeloni ${ }^{6}$ emphasized the possibility of large thromboembolism as a cause of borderzone infarcts in parients with either normal or abnormal carotid arteries.

Haemodynamic compromise, without carotid artery disease, may appear in perioperative states of cardiac surgery and after syncope or periods of orthostatic hypotension, sometimes related to autonomic failure, and in 'cardiac disease'. In cardiac surgery neurological complications of various aetiology have frequently been described. ${ }^{67.140}$ Howard et al. (1987) ${ }^{82}$ described four patients with borderzone ischaemia on CT (three of them bilateral) following cardiac surgery, and two patients with borderzone ischaemia after a severe period of hypotension. The authors described the demarcation lines of the different vascular territories according to Beevor. ${ }^{13}$ The authors suggested that periods of hypotension of various cause and duration may cause borderzone brain infarcts. Ross Russell and Bharucha $(1978)^{135}$ described four patients with bilateral 'borderzone' infarction following cardiovascular surgery. At least two of these lesions were located, on CT, mainly in the vascular territory of the PCA and were possibly only located for a small part in the vascular borderzones. The other two infarcts were located occipitally but probably also mainly in the territory of the MCA and consequently could be 'borderzone' infarcts. The infarct shape was trapezoid in two cases. All infarcts were difficult to distinguish from territorial infarcts. The authors suggested that generalized cerebral hypotension and suspected carotid obstructive lesions were the most likely infarct causes, but these were not substantiated. They also mentioned that hypocapnia, induced vasoconstriction or lowered perfusion pressure from raised intracranial pressure by venous obstruction during operation could be contributing factors, whereas embolism was considered unlikely. In this study on selected cases with borderzone infarcts the authors suggested that lowered cerebral perfusion pressure due to cardiac surgery may cause cerebral ischaemia in the vascular borderzones. In addition 
Malone et al. (1981) ${ }^{97}$ found infarcts along the 'cerebral arterial boundary zones' in a microscopic analysis of nine parients who died following cardiac surgery. From the studies of Howard, Ross Russell and Malone we conclude that cerebral damage related to cardiac surgery may occur in the arterial borderzones; however, it is not clear from these studies if there are specific aetiological factors which cause such damage.

\section{Possible 'autonomic failure' in borderzone brain infarcts}

Sloan and Clarke Haley (1990) ${ }^{142}$ described 54 patients with severe unilateral or bilateral carotid artery disease. Eight patients had signs of 'postural sensitivity', which means the occurrence of symptoms after positional changes. These symptoms were considered to be 'vertebrobasilar TIAs'. In all eight parients angiography showed unilateral or bilateral hypoperfusion zones 'between the distal fields of two or more cerebral arteries' or 'borderzones'. Arterial borderzones were located by CT or pathological data, however the CT scan findings were not described. In an attempt to explain the clinical signs, the authors suggested that subtle alterations in perfusion pressure in these patients with severe 'haemodynamic lesions' could have provoked (bilateral) borderzone ischaemia; they did not suggest autonomic failure as an explanation of these severe orthostatic/positional disturbances. Evaluating a group of patients with TIAs, Dobkin $(1989)^{47}$ selected 13 patients with brief repetitive stereotyped TIAs, large artery obstructions and orthostatic hypotension. The angiograms showed 'impaired collateral flow to a cortical perfusion borderzone'. Six patients had CT or MRI. One of these six patients had a cortical 'borderzone infarct' and in five cases confluent deep white matter lesions (some of them possibly located in the 'subcortical borderzone') were described. Eight of the 13 patients had diabetes mellitus and this was considered to be the cause of orthostatic hypotension. In the studies of Sloan and Dobkin patients with severe carotid and/or vertebrobasilar artery disease, and orthostatic changes were described. Most of them had signs of 'borderzone hypoperfusion or ischaemia'. The orthostatic changes, leading to cerebral perfusion alterations may cause infarcts in such 'borderzones'. The exacr cause of such orthostatic changes were, however, nor clear. Dobkin considered auronomic disturbances as a cause of orthostatic signs (in diaberics). Appenzeller $(1990)^{7}$ mentioned a study on cerebral blood flow with concomitant assessment of arterial pressure in a number of elderly subjects with postural hypotension. In this study it is concluded that these patients with neurological signs caused by hypotension had either unilateral or bilateral impairment of the cerebral autoregulation. Some patients with autonomic dysfunction had impairment of cerebral autoregulation because of abnormalities in the autonomic innervation of the cerebral blood vessels. ${ }^{7}$ In the studies of Dobkin and Sloan most patients had severe vascular disease; this is possibly another factor which dysregulates the cerebral autoregulation. We conclude that a combination of vascular risk factors such as atherosclerosis (carotid artery disease) and diabetes mellitus may cause cerebral autoregulation disturbances 7117,146 and may lead to cerebral ischaemia/infarcts to which the borderzone territories could be selectively vulnerable.

What other factors may contribute to possible autoregulatory dysfuncrion in 'borderzone territories'? Clinical syndromes with 'primary autonomic failure' such as olivopontocerebellar atrophy (OPCA), idiopathic orthostatic hypotension and 
Parkinson's disease are known to cause autoregulatory disturbances. Besides these, autonomic failure commonly occurs in diabetes mellitus, alcoholism, as well as in a large number of chronic, acute and subacute neuropathies.7 However, no data on 'diseases' with autonomic failure are specifically related to borderzone infarcts. Although the study of Dobkin suggests a relationship between 'borderzone ischaemia' and autoregulatory disturbances, few patients in that study had 'real' borderzone infarcts. Bogousslavsky ${ }^{21}$ mentioned that 23 per cent of the 26 patients with 'watershed' infarcts had diabetes. In another study the same author described 51 patients with "borderzone infarcts' of whom 37 per cent had syncope prior to the stroke. ${ }^{22}$ Unfortunately in this study the percentage of patients with diabetes was not mentioned. These two studies of Bogousslavsky only give indirect signs of possible autonomic dysregulation contributing to borderzone infarcts. There are no other clinical studies available.

Other factors that may influence local haemodynamics and possibly specifically the borderzone areas are: elevated haematocrit, the use of diuretics or other blood pressure lowering medication, dehydration states of various origins, aging, chronic hypercapnia (in chronic obstructive pulmonary disease), or combinations of these factors. The above-mentioned studies of Bogousslavsky ${ }^{21,22}$ show a possible relationship between borderzone infarcts and an elevated haematocrit. No further data on these issues are available from the literature.

\section{Deep (subcortical) borderzone infarctions}

The borderzones between the cortical branches of two or more adjacent major cerebral arteries may be regarded as 'classical' borderzones. However, the deeply located zone between the deep penetrators of the lenticulostriate and choroidal arteries, and the medullary branches of the major cerebral arteries may constitute another vascular 'borderzone', often called 'subcortical borderzone', 'deep borderzone', or 'internal borderzone'. Several studies suggest that infarcts in this region may have specific features, and may be regarded as a group of infarcts with a distinct pathophysiology. ${ }^{17,46,156}$ Others, however, exclude this region as a 'borderzone' because of the supposed lack of anastomosis or collaterals in these areas. ${ }^{26}$ Infarcts in the subcortical borderzone' are often small with characteristics of the so-called lacunar infarcts. ${ }^{65,154,156}$ Therefore, 'lacunar' or small deep infarcts at the junction of the deep penetrators and the medullary branches of the ACA, MCA or PCA may be called small deep borderzone infarcts or subcortical borderzone infarcts. Also the subcortical borderzone area may vary considerably, which introduces uncertainty when classifying small deep infarcts in this region as 'borderzone infarcts'.

Using SPECT, Weiller et al. (1991) ${ }^{156}$ studied cerebral haemodynamics in 37 patients with a first-ever stroke and documented infarct on CT in comparison with 49 controls. Seventeen parients had so-called haemodynamically induced 'low-flow infarcts', as judged from CT pattern. These infarcts were located in the distal territories perfused by the deep perforators. This type of low-flow infarct was also called 'terminal supply area infarct', or 'subcortical watershed infarct' and it was differentiated from 'true watershed infarct' which was supposed to be locared in the cortical borderzones, and with probably 
a different cause. The authors compared the 17 'haemodynamically induced' low-flow infarcts with the remaining 20 'territorial infarcts'. Sixteen 'low-flow infarcts' and 12 territorial infarcts had ICA occlusion. Cerebral haemodynamics (in particular cerebral perfusion reserve, which is a measure of local cerebral perfusion) were most compromised around the infarct areas in patients with low-flow infarcts, compared with infarct areas of patients with territorial infarcts and associated ICA occlusions. Similar perfusion reserve values were found in patients with territorial infarcts and normal ICAs as compared with the controls. All the low-flow infarcts had a characteristic pattern on SPECT images. This consisted of severely decreased cerebral perfusion reserve in an area which far exceeded the infarcted areas seen on MRI. In contrast, in all but three of the 20 territorial infarcts perfusion reserve changes on SPECT were almost exclusively restricted to the infarct area itself. The authors concluded that the haemodynamic compromise in patients with low-flow infarcts was much higher than in patients with territorial infarcts, and that the described type of low-flow infarct could be related to the 'distant haemodynamic effects of severe extracranial occlusive disease'. They also suggested that in addition to the occlusive extracranial lesion another factor may contribute to the decrease in perfusion pressure that caused the low-flow infarct. This could be a more chronic haemodynamic compromise due to an inadequate intracranial collateral blood supply caused by either contralateral ICA occlusion or abnormalities of the circle of Willis, rather than a sudden systemic hypotension. In this study the lowflow infarcts', many of which were probably located at the subcortical borderzone, may have had a haemodynamic cause in the presence of ipsilateral carotid occlusion. However, in this 'haemodynamic' study, cerebral perfusion measurements were done after obstruction of the carotid artery became complete, and after brain infarction had occurred, which leads to the possibility that the haemodynamic findings were the consequence rather than the cause of the infarction. Furthermore, with regard to the proportion of low-flow infarcts and the number of carotid occlusions, this study undoubtedly selected most of the patients because of the presence of one or more items of interest.

Bogousslavsky and Regli (1984) $)^{19}$ described in a group of 75 patients with internal carotid artery occlusion on angiography five patients with transient clinical neurological signs and small deep infarcts on CT scan, some of which were probably small deep borderzone infarcts. Waterston et al. (1990) $)^{154}$ investigated 100 patients with cerebral vascular disease over a two-year period and described 10 patients with a small deep infarct and ipsilateral carotid obstruction. Some of them even had contralateral carotid disease as well. Four of the parients had evidence of haemodynamic compromise as measured by CBF response to hypercapnia, suggesting a haemodynamic stroke mechanism. However, not all the infarcts were locared in the borderzone areas between the deep MCA perforators and the medullary branches. Del Sette et al. (1992) ${ }^{43}$ studied $1136 \mathrm{CT}$ scans of patients recruited by the North American symptomatic carotid endarterectomy trial (NASCET) using templates for the identification of deep and cortical vascular territories. The authors identified 413 ischaemic lesions with ipsilateral carotid stenosis, 138 were 'pure' small deep infarcts (SDI), and 108 small lesions in the internal borderzone (SBI), which is 44 per cent of the small deep infarcts, an amazingly high proportion. High-grade $(\geq 70 \%)$ stenosis was found in 63 per cent of the SBI and in 42 
per cent of the SDI. Stenosis of $\geq 90$ per cent was found in 18 per cent of the SBI opposed to 8 per cent of the SDI. After checking for risk factors the difference in the frequency of high-grade stenosis remained significant. The authors concluded that there is a subgroup of small deep infarcts, which they called small borderzone infarcts, that are associated with high-grade carotid stenosis, and may be mainly caused by embolism. It should be noted that the authors of this study regarded a high-grade carotid stenosis as an embolic stroke cause rather than a condition including low-flow infarction. Furthermore, it should be realized that all patients had been selected by the presence of a possible significant stenosis, making an association of any infarct type with carotid stenosis highly likely. A similar study done from the European Carotid Surgery Trial (ECST) data did not yield statistically significant results (Boiten 1994, personal communication). The studies of Weiller, Bogousslavsky, Waterston and Del Sette ${ }^{1,43,154,156}$ describe patients with subcortical borderzone infarcts and ipsilateral carotid artery obstruction. Of these, only those of Weiller and Waterston suggest a haemodynamic 'subcortical borderzone' infarct cause.

In a study on risk factors and presumed infarct causes in 100 consecutive patients with a first stroke and CT proven infarct in the territory of the deep perforators from the carotid artery system Ghika (1989) ${ }^{65}$ described four patients with 'watershed' infarcts. Although 28 of the 100 patients had ipsilateral carotid artery stenosis of more than 75 per cent, and carotid artery embolism was suggested as a possible cause of such infarcts, none of the four 'watershed infarcts' in this study had a carotid artery stenosis. Bogousslavsky and Regli (1992) ${ }^{26}$ described 36 patients with infarcts in the 'centrum ovale'. They distinguished large infarcts, that were associated with severe ipsilateral carotid artery disease and small round or ovoid infarcts associared with hypertension and diabetes, but not with carotid artery disease. Some of the described small deep infarcts may well be subcortical borderzone infarcts, apparently not related to carotid artery stenosis. These studies of Ghika and Bogousslavsky described parients with probable subcortical borderzone infarcts not related to carotid artery stenosis.

Mounier-Véhier et al. (1993) ${ }^{110}$ investigated the differences in cerebrovascular risk factors between patients in two subtypes of 'borderzone infarcts' on CT: those with 'watershed' and those with 'internal junctional' infarcts. In 493 consecutive patients with TIA (21.7\%) or stroke (78.3\%) 26 patients had 'watershed' infarcts (territorial borderzone), and $18 \mathrm{had}$ 'internal junctional' infarcts (deep borderzone) on CT. Internal carotid artery stenosis of $>50 \%$ and hypertension were more frequent in the 'watershed' group, whereas ischaemic heart disease was more frequent in the 'internal junctional' group when both groups were compared separately with all non-borderzone infarcts. The authors concluded that both subtypes of 'borderzone' infarcts probably have a different infarct cause. The authors compared both groups of borderzone infarcts separately with all remaining symptomatic infarcts, whether CT was abnormal or not, and whether these infarcts were territorial or deep. Therefore, the statistical analysis is questionable.

Bladin and Chambers (1993) ${ }^{17}$ described six patients with 'confluent internal watershed infarction' (CIWI), and 12 patients with 'partial internal watershed infarction' (PIWI). The authors stated that 'syncopal symptoms and/or documented periods of hypotension were prominent in both groups', but this was not substantiated. 
'Carotid disease', 'cardiac disease', and diabetes mellitus were significantly more frequent in the internal watershed infarcts (IWI) in comparison with an undefined 'stroke population as a whole'. The authors concluded that IWIs are characterized by different pathological mechanisms in comparison with other subcortical or lacunar infarcts. Although this study suggests a specific risk factor profile in 'internal watershed infarcts', several factors make the study results questionable: the authors did not consider the corrical borderzone infarcts in this stroke registry as a separate group; in only three watershed patients 'hypotension' was described, however, the blood pressure values were not provided; a carotid stenosis of more than 30 per cent whether or not compatible was regarded as 'carotid disease'; 'heart disease' was not exactly defined; IWIs were defined as infarcts in the paraventricular or supraventricular region adjacent to the lateral ventricular wall and in accordance with the topographical descriptions of Damasio, who only arbitrarily defines vascular borderzones; the IWIs were compared with more than 1000 patients, whereas the IWI patients were selected from a series of 300 patients; finally comparisons were not adjusted for the interactions of infarctrelated variables.

\section{Asymptomatic subcortical borderzone infarcts}

With the introduction of CT and later MRI scan several studies on asymptomatic lesions in the deep white matter and deep borderzones appeared. ${ }^{77,86,92,129}$ Kobayashi et al. (1991) ${ }^{86}$ studied the incidence of 'silent lacunar lesions' and the CBF in 246 neurologically normal adults. Thirteen per cent of the persons had 'possible silent lacunar lesions'. The 'watershed zone between the medullary branches and the perforating branches of the MCA or ACA was the most vulnerable region'. In this zone 14/32 (45\%) 'silent lacunes' were located. The rCBF measured with the Xenon ${ }^{133}$ inhalation method was significantly lower in subjects with silent lacunes than in those without. $\mathrm{CBF}$ was mildly reduced in patients with silent lacunes. Higher age, hypertension, higher mean arterial blood pressure and retinal artery sclerosis were more prominent in the 'silent lesion' group. This study suggests that asymptomatic white matter lesions ('lacunar infarcts') may often occur in the 'subcortical borderzone' areas and, according to the authors may reflect areas which are haemodynamically compromised. In addition to Kobayashi, Lechner et al. (1988)92 found many silent white matter lesions on MRI in normal volunteers. Sixty-five per cent of the lesions were located in the MCA watershed area'. Only 11 of the 155 silent white matter lesions described by Lechner on MRI could be detected by CT! In contrast to the findings of Kobayashi, Herholz et al. (1990) $)^{77}$ did not find a relationship between $\mathrm{CBF}$ reduction and asymptomatic white matter lesions in 'subcortical vascular borderzone territories', when studying 20 patients with atherosclerotic disease of the internal carotid artery. Révèsz et al. (1989) ${ }^{129}$ found a good correlation berween the subcortical 'MRI lesions' and pathological changes corresponding with the histological signs of lacunar infarcts. In summary, MRI may detect asymptomatic lacunar infarcts much more frequently than CT, whereas many of these infarcts are mainly located in areas considered as subcortical borderzones, and may have a haemodynamic cause. However, definite conclusions await sufficient data. 


\section{SPECT and borderzone infarcts}

Using T T ${ }^{9 \%}$ HMPAO SPECT Sullivan et al. (1991) ${ }^{147}$ studied 'warershed infarers' in five parients with focal neurological symptoms, and made a comparison with C.I. Good correlation was found in two patients. In the remaining three patients only the $\mathrm{Tc}^{90} \mathrm{HMPAO}$ SPECT revealed abnormalities in watershed areas, whereas CT was normal. The authors concluded that $\mathrm{Tc}^{99} \mathrm{HMPAO}$ SPECT may be more sensitive than CT in the detection of 'infarctions' in the watershed areas. In this study of cortical 'watershed' infarcts the uptake defects may have reflected zones of hypoperfusion extending into the 'borderzone territories' around the middle cerebral artery. However, these uptake defects may not always reflect infarcts in these territories. HMPAO SPECT may indicate corrical zones of hypoperfusion which may be larger than the infarcted zone on CT. ${ }^{127}$ Moreover, subcortical areas can less reliably be studied, because regional $\mathrm{CBF}$ is much lower in the subcortical white matter than in the cortex. Therefore, perfusion disturbances in 'borderzone territories' on SPECT may reflect different pathophysiological mechanisms than infarcts seen on CT. One should avoid the term 'watershed infarct' to describe an abnormality on SPECT because an uptake defect reflects a perfusion disturbance, which does not necessarily include tissue necrosis. 


\section{PART 4 SUMMARY OF POSSIBLE PATHOPHYSIOLOGICAL MECHANISMS IN BORDERZONE INFARCTS}

The significance of distinguishing borderzone infarcts from other infarct subtypes is related to the possible cause of borderzone infarcts which, if it could be identified, may offer possibilities for specific treatment, prevention of eventual recurrences or both. Before characterizing different features of borderzone infarcts, one should be convinced that the infarcts under study are indeed infarcts in the borderzone territory of two major arterial supply areas, otherwise one may deal with distally located territorial infarcts or (small) deep infarcts. The border between two adjacent arteries is often considered as a rather straight line, whereas consequently, an infarct largely configurated along the course of this line is presumed to be a borderzone infarct. However, one can never be sure that an infarct fitting such a description is located in two separate vascular territories, because the supply areas of the major cerebral arteries vary widely in individual cases.

With the introduction of computed tomography more clinically orientated descriptions of 'borderzone infarcts' appeared. In these studies the variability of the vascular borderzone territories is often not taken into account, and the authors elaborated mostly on the hypothetical concept of Zülch of 'a haemodynamic stroke cause'. ${ }^{162,163}$ Factors that may aggravate such a haemodynamic - low - perfusion state such as periods of hypotension, carotid stenosis, states after cardiac surgery, heart disease and elevated haematocrit were therefore studied. The hypothesis of Zülch was based on a logical concept of low perfusion in the most distal vascular areas, the terminal zones, or the borderzones between two vascular areas. In accordance with this concept many studies report on the relation of carotid artery stenosis or occlusion to infarcts in borderzone territories. $17,21,65,112,131,142,156$ In many of these studies patients were selected according to the presence of priorly presumed causes such as carotid stenosis, whereas they were not compared with those with non-borderzone infarcts. In none of the studies were all patients prospectively registered. Therefore, there is no clear evidence of a typical 'borderzone pattern' regarding pathophysiological characteristics and location of the infarcts.

The hypothesis that infarcts along supposed arterial borderzones, or located exclusively inside the area of vascular variability, may constitute a separate infarct subtype, may only be confirmed if such infarct patients differ from other infarct patients in vascular risk factor profile, presumed underlying stroke mechanisms, and natural history. Such a study has not yet been performed.

\section{Conclusions}

'Borderzone brain infarcts' are ischaemic lesions along the arterial borderzones between the supply areas of two (or three) major cerebral arteries, or between two major cerebellar arteries (territorial borderzone infarcts), or infarcts located at the demarcation line between the deep penetrators and the medullary branches of the ACA, MCA or PCA (deep borderzone infarcts). The terminology used to indicare such infarcts is confusing. The pathophysiology of these infarcts is unclear. In imaging studies, the 
borderzone territories are difficult to define, mainly because of the large inter-individual variation of the major cerebral arteries. So far, a specific nosological entity of 'borderzone infarcts' has not been defined.

Several clinical risk factors have been related to 'borderzone infarcts'. The significance of such findings is questionable because of the lack of comparison of 'borderzone infarcts' with other infarct subrypes.

\section{Questions for this study}

1. Are there any 'specific' characteristics of territorial 'borderzone infarcts', when studied in the 'classical' way (defined as infarcts located on CT in territories at the demarcation lines of two major cerebral arteries according to the current CT topography) with respect to vascular risk factors, presumed pathogenesis, natural history and CT findings. (chapter 4)

2. When defining a 'borderzone' as a territory of variable vascular supply of adjacent major cerebral arteries as described by Van der Zwan et al., do infarcts confined to such a territory differ from 'borderzone infarcts' as defined in question one; and if they do, what are their characteristics? (chapter 5)

3. When considering the deep borderzone infarcts, do they have any specific characteristics with respect to vascular risk factors, presumed pathogenesis, natural history, and CT findings; and are they different from (small) deep infarcts in general, e.g. the well-defined clinical entity of an AChA infarct. (chapter 3, 4 and 6)

4. Are borderzone infarcts that occur in states of hypoperfusion (e.g. during cardiac surgery), specifically related to cerebral haemodynamic compromise? (chapter 7) 


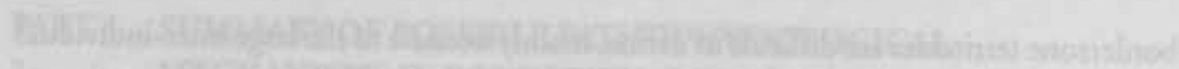

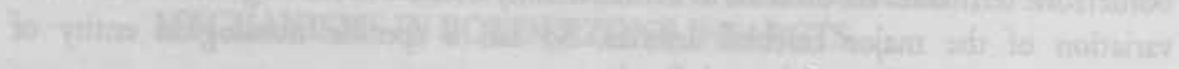

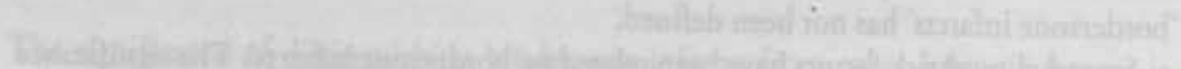

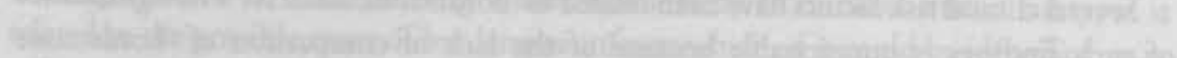

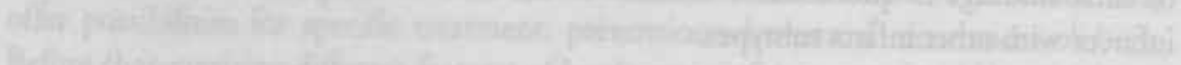

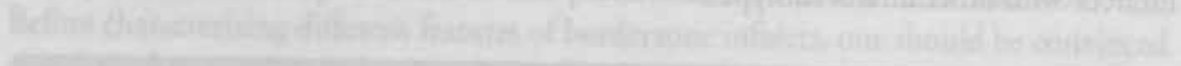

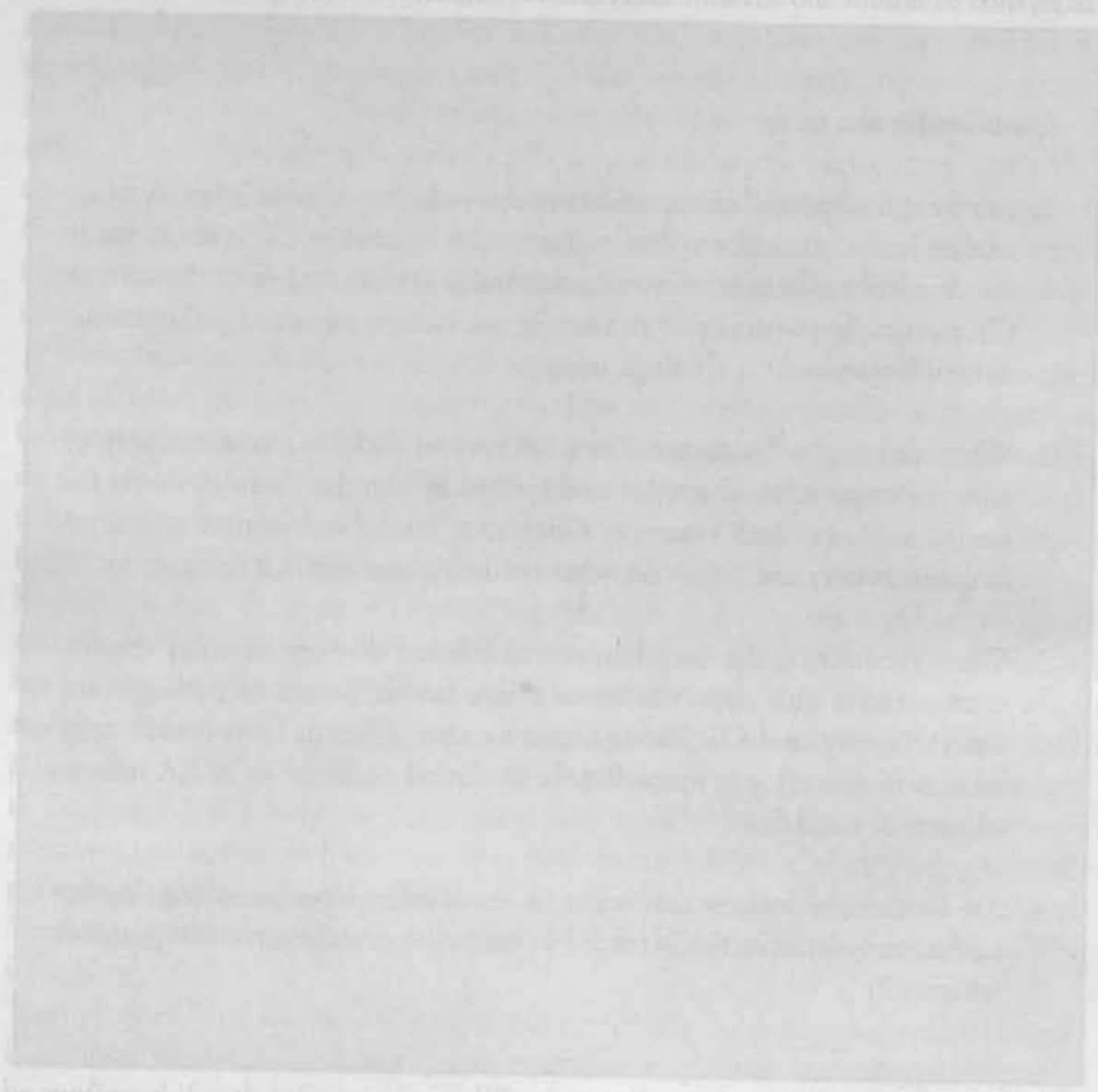

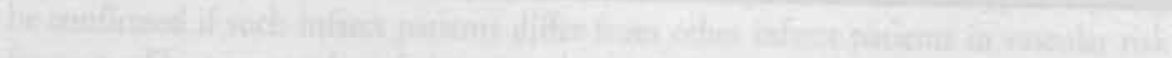
W.

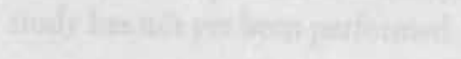

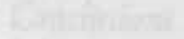

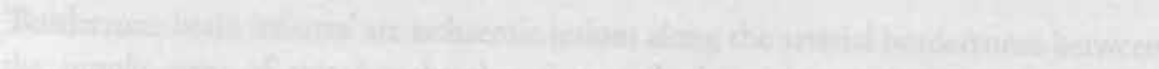

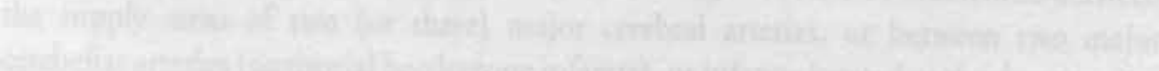

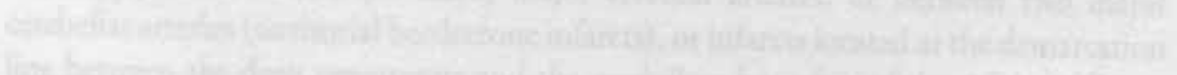
axt

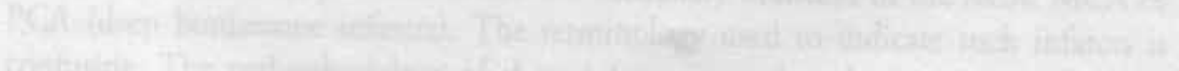

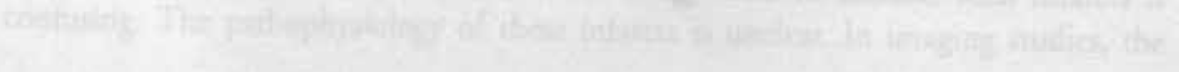




\section{Chapter 3}

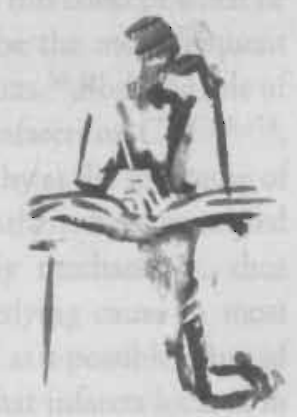

Haemodynamic mechanism in small deep borderzone infarcts?!

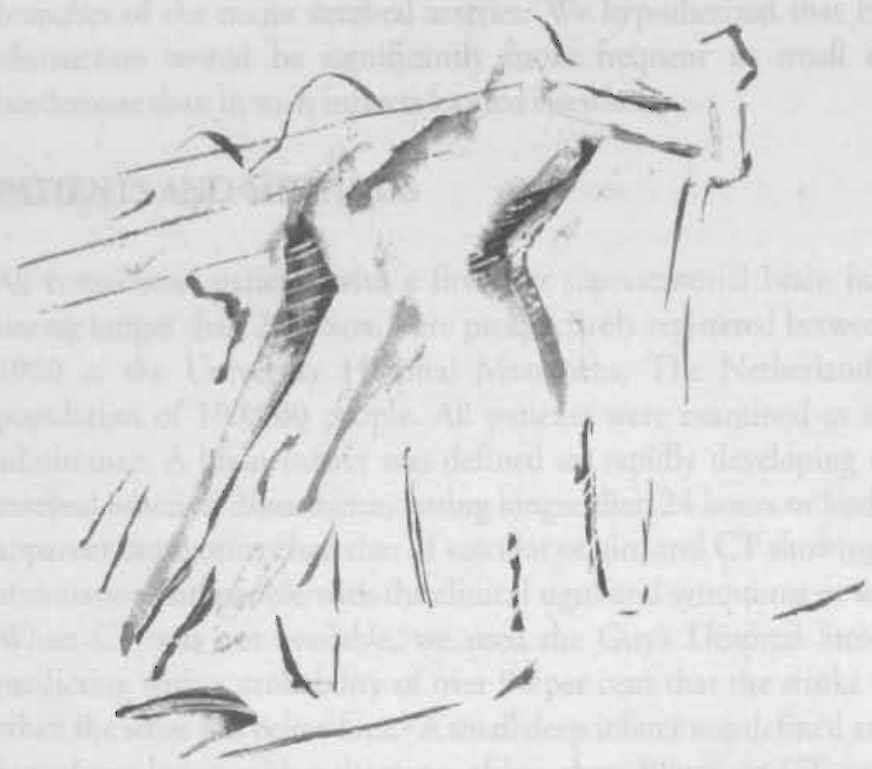

1. Adapted from: Haemodynamic mechanism in small subcortical borderzone infarcts? RMM Hupperts, J Lodder, J Wilmink, J Boiten, EPM Heuts-van Raak. Cerebrovascular Diseases 1993, 3:231-235. 


\section{[ 19 tosit)}

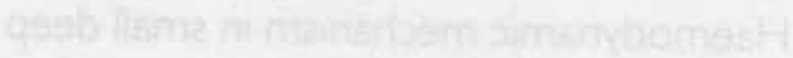

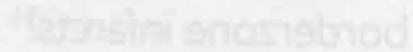

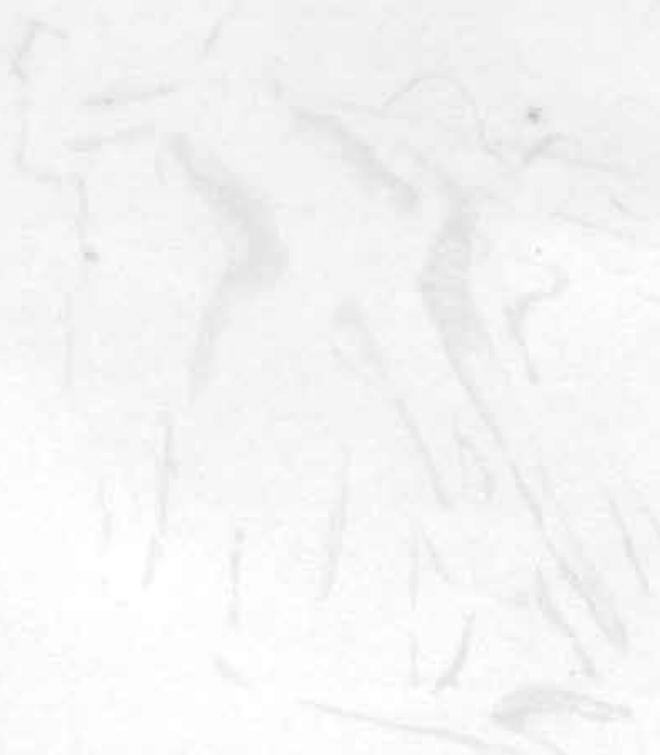

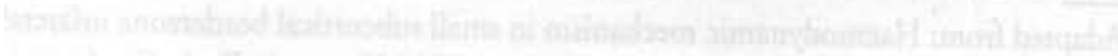

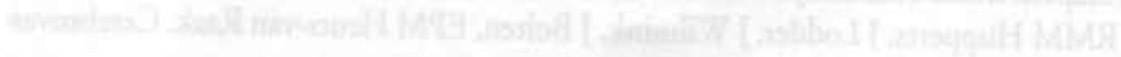

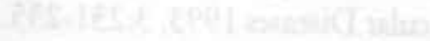




\section{INTRODUCTION}

Originally, Fisher hypothesized that lacunar infarcts result from small-vessel lipohyalinosis secondary to the effects of hypertension. ${ }^{54.55}$ Later, he revised this concept when he found small-vessel atherosclerosis rather than lipohyalinosis to be the most frequent underlying vasculopathy in most of the symptomatic lacunar infarcts. ${ }^{56}$ Both the role of hypertension as a single, specific risk factor for small subcortical infarcts on CT $27,95,114$, as well as local obstruction resulting from a small-vessel vasculoparhy as the sole cause of such an infarct, have been questioned. $23,89,104$ However, we, like orhers, have presented evidence that cardiac and carotid embolism are also unlikely mechanisms, thus supporting the view that small-vessel vasculopathy is the underlying cause in most patients. ${ }^{27,85,95,114,136,148} \mathrm{~A}$ mechanism hitherto not fully explored as a possible cause of small deep infarcts is a haemodynamic one. The classic view is that infarcts located in vascular borderzone areas most likely result from brain hypoperfusion in the presence of significant obstruction in the ipsilateral internal carotid artery (see chapter 2).22.25 In considering such a mechanism as a possible cause of CT-verified small deep infarcts, we looked for these infarcts in the vascular borderzone between the deep and the superficial branches of the major cerebral arteries. We hypothesized that internal carotid artery obstruction would be significantly more frequent in small deep infarcts in the borderzone than in such infarcts located elsewhere.

\section{PATIENTS AND METHODS}

All consecutive patients with a first-ever supratentorial brain infarct with symptoms lasting longer than 24 hours, were prospectively registered between July 1987 and July 1990 at the University Hospital Maastricht, The Netherlands, with an adherent population of 180,000 people. All parients were examined as soon as possible after admitrance. A brain infarct was defined as: rapidly developing clinical signs of focal cerebral function disturbance, lasting longer than 24 hours or leading to death, with no apparent cause other than that of vascular origin, and CT showing either an area of low attenuation compatible with the clinical signs and symptoms or with no specific lesion. When CT was not available, we used the Guy's Hospital Stroke Diagnostic Score, predicting with a probability of over 90 per cent that the stroke was due to an infarct when the score was below four. ${ }^{5} \mathrm{~A}$ small deep infarct was defined as a sharply marginared hypodense lesion with a diameter of less than $20 \mathrm{~mm}$ on CT, or with no specific CT lesion but clinically one of the following lacunar syndromes: pure motor syndrome (PMS), sensorimotor syndrome (SMS), pure sensory syndrome (PSS), and dysarthriaclumsy hand syndrome including ataxic hemiparesis cases (DCHS/AH), as defined elsewhere. ${ }^{9.27}$ In cases with multiple small deep infarcts on the symptomatic side, the one most likely to relate to the presenting symptoms from a radiological and anatomical point of view was identified as symptomatic. CT scans were independently reviewed by two neurologists without any knowledge of the clinical data. When the two reviewers were not in agreement about the presence or location of an infarct, a neuroradiologist acted as arbitrator. Routine investigations included standard blood and urine tests, electrocardiogram, chest X-ray, non-invasive carotid studies, and CT. Echo- 
cardiography, 24-hours ECG monitoring and cerebral angiography were done in selected cases. Non-invasive carotid studies were performed using either multi-gate pulsed Doppler with spectral frequency analysis, Duplex equipment, or continuous wave Doppler, all of which reliably detect carotid obstructive lesions with a diameter reducrion of more than 50 per cent, which was considered as significant stenosis. ${ }^{37}$

The following risk factors were recorded: Age and sex; hypertension: known hypertension regardless of ongoing anti-hypertensive treatment, or two or more blood pressure recordings with a diastolic of more than $90 \mathrm{~mm} \mathrm{Hg}$, and/or systolic more than $160 \mathrm{~mm} \mathrm{Hg}$, or both, on different occasions before or at least one week after the stroke; hypotension: blood pressure recording on admission with a diastolic of less than $60 \mathrm{~mm}$ $\mathrm{Hg}$ and/or a systolic of less than $90 \mathrm{~mm} \mathrm{Hg}$. Diabetes mellitus: known diabetes being treated with either diet, medication or both, or a fasting serum glucose of more than $6 \mathrm{mmol} / \mathrm{l}$ measured on at least two separate occasions. Ischaemic heart disease: a history of angina pectoris, myocardial infarct or coronary bypass operation. Cardioembolic source: persistent or intermittent atrial fibrillation, rheumatic heart disease, mitral stenosis, mitral or aortic valve prosthesis, left ventricular myocardial infarct within the preceding six weeks, left ventricular aneurysm, endocarditis, cardiac myopathy, ventricular septum defect.

The vascular borderzone between the territory of the deep penetrating arteries and the medullary branches of the major cerebral arteries was defined according to the templates of Ghika et al. ${ }^{66}$ We compared clinical and CT features in patients with a symptomatic small deep borderzone lesion, and those with a CT verified symptomatic small deep infarct elsewhere. Differences between groups were analysed using odds ratios (OR) with $95 \%$ confidence interval $(\mathrm{CI})$, and chi-square $\left(\chi^{2}\right)$, both with Yates' correction. ${ }^{115}$

\section{RESULTS}

One hundred and forty-three patients with a first-ever supratentorial small deep infarct were registered. All underwent CT-scanning, 92 (64\%) in the first week, $123(86 \%)$ within the first two weeks, and $131(92 \%)$ within the first three weeks. Ninety-one patients showed a compatible small deep infarct on CT, 16 of which were located in the borderzone between the areas supplied by the deep penetrators and the medullary branches of the major cerebral arteries, whereas 75 small deep lesions were located elsewhere. Seventy-four of these 91 patients with a CT-confirmed small deep lesion had carotid artery testing by continuous wave Doppler: $n=9$, multi-channel pulsed Doppler: $n=33$, and Duplex: $n=32$. Two of the 16 patients with a small deep borderzone lesion underwent angiography, as did 13 of the 75 with a small deep lesion elsewhere. All 15 patients who underwent angiography had non-invasive testing yielding compatible results. Twelve of the 16 patients with a borderzone infarct underwent carotid studies, and four of these were shown to have a $>50 \%$ ipsilateral carotid stenosis. Sixty-two of the 75 patients with a small deep infarct outside the borderzone also underwent carotid studies, and three of these also had such a carotid lesion (OR: 9.83; 95\% CI: 1.70-57.04; $\mathrm{p}<0.01$ ) (Table 3.1). The groups did not differ with respect to several other vascular risk factors, or the presence of a potential 
cardioembolic source. The four borderzone infarcts with carotid stenosis are illustrated in Figure 3.1.

Table 3.1 Different features in patients with a small deep infart in the vascular borderzone between deep and superficial major cerebral artery territories $(n=16)$, and in those with a non-bonderzone small deep infarct on $C T(n=75)$. $O R=$ odds ratio. $C I=$ confidence interval. $O R>l=$ more frequent in borderzone infarcts.

\begin{tabular}{|c|c|c|c|c|c|}
\hline 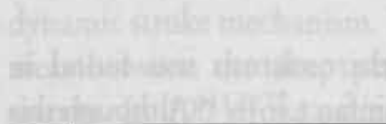 & $\begin{array}{l}\text { borderzo } \\
\text { infarcts } \\
(n=16)\end{array}$ & $\begin{array}{l}\text { other small } \\
\text { deep infarcts } \\
(n=75)\end{array}$ & OR & $95 \% \mathrm{CI}$ & $\mathrm{p}$-value \\
\hline age & 68 & 69 & & & \\
\hline male/female & $8 / 8$ & $43 / 32$ & 0.74 & $0.08-6.95$ & \\
\hline diabetes mellitus & 2 & 11 & 0.83 & $0.10-7.13$ & \\
\hline ischemic heart disease & 2 & 10 & 0.93 & $0.59-1.47$ & \\
\hline hypertension & 8 & 39 & 0.77 & $0.05-10.94$ & \\
\hline cardiac embolism & 2 & 9 & 1.05 & $0.82-1.34$ & \\
\hline carotid stenosis & 4 & 3 & 9.83 & $1.70-57.04$ & $<0.01$ \\
\hline nr. non-invasive tests & 12 & 62 & 0.63 & $0.05-7.79$ & \\
\hline$\geq 1$ asympt. small deep infarct & 10 & 38 & 1.62 & $0.32-8.22$ & \\
\hline cortical syndrome & 3 & 13 & 1.10 & $0.48-2.52$ & \\
\hline pure motor syndrome & 8 & 27 & 1.78 & $0.40-7.81$ & \\
\hline sensorimotor syndrome & 1 & 19 & 0.20 & $0.02-2.12$ & \\
\hline pure sensory syndrome & 0 & 2 & & & \\
\hline DCHS/AH & 4 & 13 & 1.59 & $0.13-19.69$ & \\
\hline
\end{tabular}

DCHS/AH= dysarthria clumsy hand syndromelataxic bemiparesis syndrome.

The specific syndrome was unknown in one non-borderzone infarcr case.

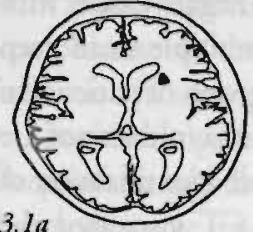

3.1a
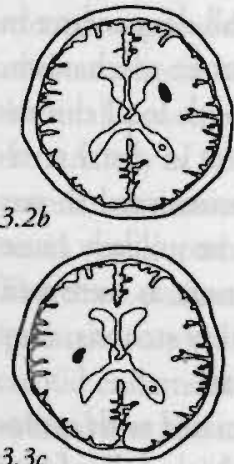

$3.3 c$

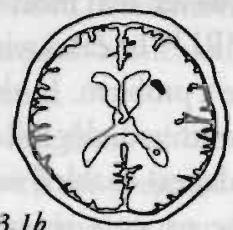

3.16
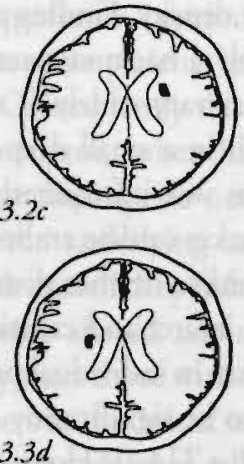

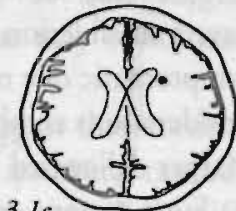

3.1c
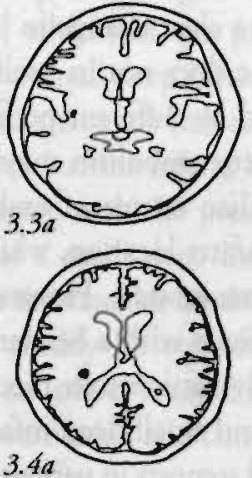

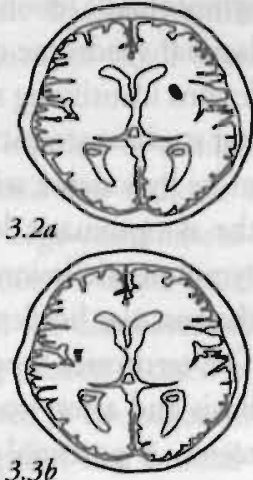

3.36

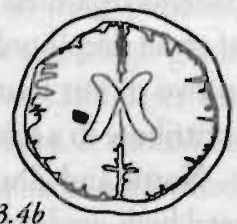

Schematic CT templates (in the orbitomeatal line) of four patients with ipsilateral high grade carotid stenosis and a small deep infarct in the borderzone between the deep penetrators and the medullary branches of the major cerebral arteries. 


\section{DISCUSSION}

Part of Fisher's lacunar hypothesis proclaims that lacunar infarcts are due to a distinct small-vessel disease related to hypertension. ${ }^{55}$ From his parhological series Fisher suggested that this small-vessel vasculopathy was lipohyalinosis. ${ }^{54,55}$ Later, Fisher found small-vessel atheromathosis to be the most frequent underlying vasculoparhy in six of the ten parhologically studied cases. ${ }^{56}$ Not all small deep infarcts may be the result of local obstructive disease.

Ipsilateral carotid stenosis as a sign of large vessel atherosclerosis was found in approximately $10-15$ per cent of patients with a small deep infarct. ${ }^{27,95,114}$ Although this is significantly less compared with infarcts involving the cortex, some argue that such lesions act as an embolic source. ${ }^{23}$ Even if severe carotid stenosis could cause small deep infarcts by means of embolism, it remains unclear how often this occurs, and how often such lesions are a coincidental finding merely reflecting a more advanced stage of generalized atherosclerosis. Another, hitherto not fully explored possible cause of small deep infarcts related to severe carotid obstructive lesions, is a haemodynamic mechanism. Infarcts located in the vascular borderzone are generally suspected to be the result of a haemodynamic or local low flow mechanism, which is considered more likely in the presence of obstructive carotid disease. ${ }^{25}$ Others, however, state that the degree of carotid stenosis does not consistently relate to a haemodynamic infarct mechanism, and they stress the importance of disturbed local haemodynamics. ${ }^{123}$

We compared the frequency of ipsilateral carotid stenosis more than 50 per cent in patients with a first symptomatic small deep infarct in the vascular borderzone between deep and superficial major cerebral artery territories, with that in those who had a CTconfirmed small deep infarct elsewhere. CT is not sensitive enough to visualize all symptomatic lesions. An MRI study showed, however, that most CT-negative cases with lacunar syndrome did have a small lesion on $M R I .^{80}$ In cases with multiple small deep lesions identifying the symptomatic one may be a problem. In this group of patients in our study anatomical considerations combined with radiological criteria (old lesions are more hypodense with sharper delineated boundaries) enabled reliable identification of the symptomatic lesion. Furthermore, in some patients repeated CT visualized the symptomatic lesion by a clear change in lesion density. Finding a small deep infarct in the vascular borderzone does not in itself imply a haemodynamic stroke mechanism. The territories supplied by different perforators vary widely ${ }^{57}$, and both local thrombosis and artery-to-artery embolism may result in a small deep infarct in distal territories. A potential cardiac source of embolism was infrequently documented in our patients regardless of infarct location, which makes cardiac embolism an unlikely cause of small deep borderzone infarcts. However, cardiac rhythm disturbances, as were seen in two of our four patients with a borderzone infarct and carotid artery stenosis, may contribute to a haemodynamic stroke mechanism in individual patients.

Norris and Zhu found small deep infarcts to be significantly associared with ipsilateral high-grade carotid stenosis in patients with a TIA. ${ }^{113}$ However, whether all infarcts in their patients with a TIA were symptomatic remains unclear and, therefore, the association they found may merely support the idea that high-grade stenoses relate to (mainly) asymptomatic small deep infarcts. Moreover, it was not mentioned whether 
these infarcts were located in a vascular borderzone area. Some of the selected patients in the study of Weiller et al could be regarded as having small deep borderzone infarcts. ${ }^{156}$ These authors found not only ipsilateral carotid stenosis, but also signs of a cerebral lowflow state suggesting a haemodynamic stroke mechanism. Waterston et al described ten patients with a small deep infarct and ipsilateral carotid obstruction, and some even had contralateral carotid disease as well. ${ }^{154}$ Four of these patients had evidence of haemodynamic compromise as measured by CBF response to hypercapnia, suggesting a haemodynamic stroke mechanism. However, not all the infarcts were located in the borderzone areas between the deep penetrators and medullary branches of the major cerebral arteries. In 100 stroke patients with CT-proven small deep lesions Ghika et al. found four lesions in borderzone areas. ${ }^{65}$ Although 28 patients had ipsilateral carotid stenosis of more than $75 \%$, and carotid embolism was suggested as a possible cause of such infarcts, none of the four borderzone small deep infarcts in that study had carotid stenosis. Some of the five small deep infarcts with ipsilateral carotid occlusion and presenting with transient clinical signs in the series of Bogousslavsky, were probably in the vascular borderzone area. ${ }^{19}$ Recently, Bladin and Chambers described 18 patients with 'internal watershed infarctions' and compared them with an undefined population of more than 1000 stroke patients. ${ }^{17}$ They found significantly more patients with a carotid stenosis in the borderzone group. The authors did not mention if a carotid stenosis was compatible or not, whereas a stenosis of more than 30 per cent was regarded significant in their analysis; furthermore, although their total series was large, they did not account for possible interaction of variables, such as differences in age, sex, frequency of hypotension, etc., which in fact were not even mentioned. Therefore, the results of this study remain questionable. Nevertheless, although these studies were not performed using prospective clinical series comparing small deep borderzone infarcts with such infarcts located elsewhere, they at least suggest that haemodynamic compromise in the vascular borderzone areas may constitute a cause of small deep infarction in some patients.

Our data together with those of others suggest that borderzone location of a small deep infarct together with the presence of an ipsilateral carotid stenosis may indicate a haemodynamic stroke mechanism, but does not prove it. Significant large-vessel atherosclerosis may add to perfusion compromise, which, in the presence of small-vessel atheromathosis, may in some patients lead to a small deep infarct in the distal areas of the small penetrators. Consequently this means that such lesions are infarcts located in the territory of one penetrator, rather than a borderzone infarct located in two adjacent vascular territories. Our findings do not disagree with the presumption that a smallvessel vasculopathy is the underlying cause of a small deep infarct in most patients. Therefore, patients with a small deep infarct in the vascular borderzone and a high-grade ipsilateral carotid stenosis should not more readily be considered as candidates for carotid endarterectomy than those with such an infarct located elsewhere. It should be stressed that the numbers in this initial series were small and comparisons as performed in chapter 4 and 5 may produce more reliable results. 


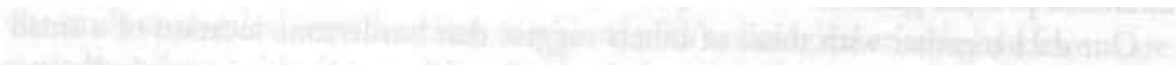

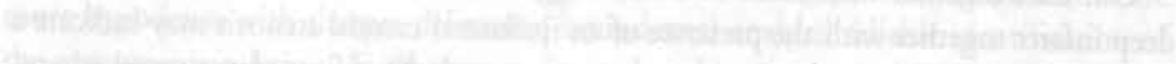

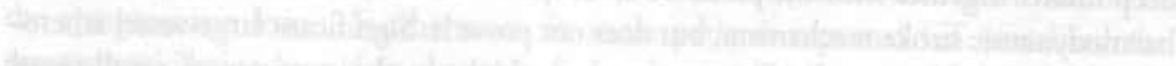

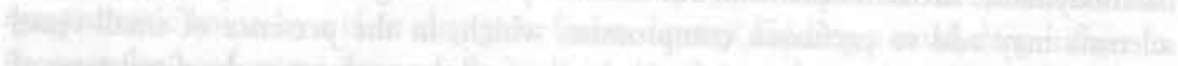

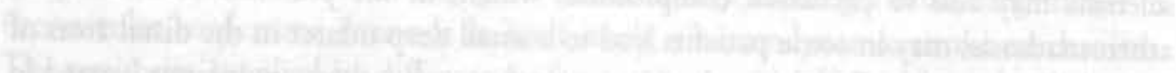

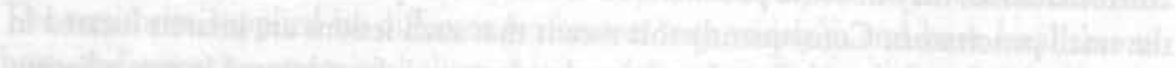

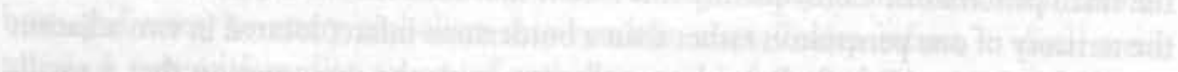

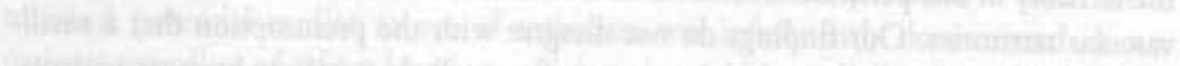

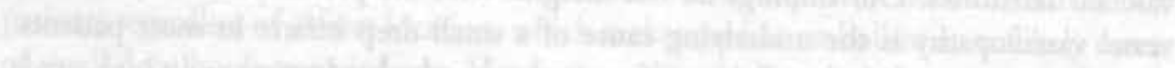

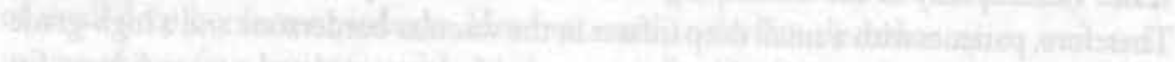

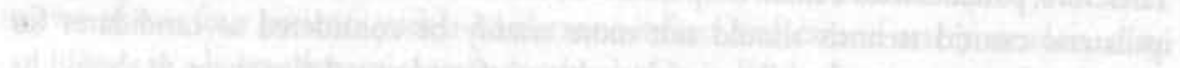

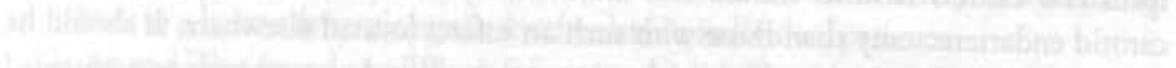

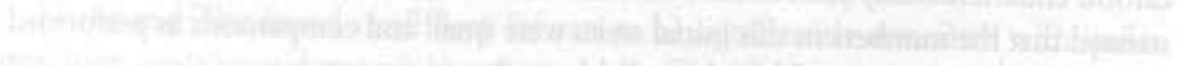

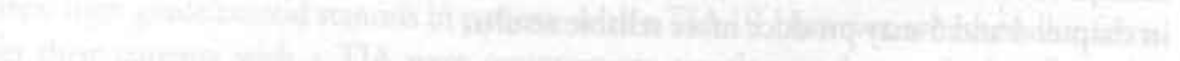

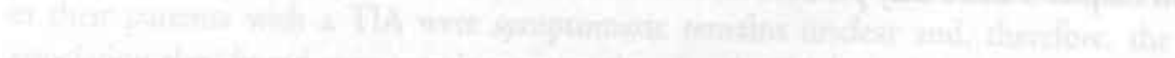

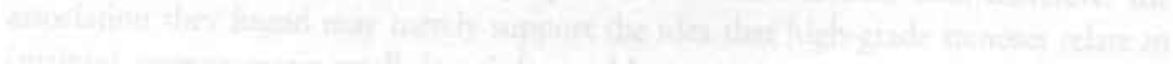

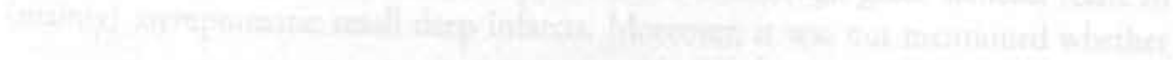




\section{CHAPTER 4}

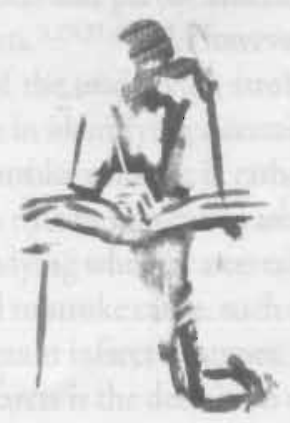

CT-defined borderzone brain infarcts; relationship with clinical features among stroke subgroups

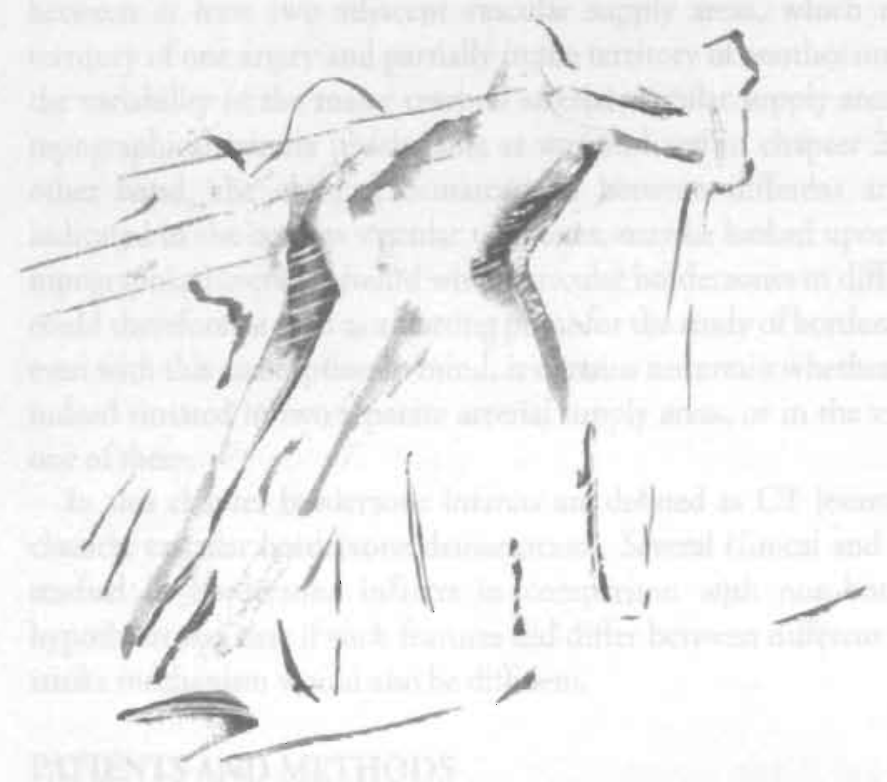





\section{INTRODUCTION}

Using CT, different brain infarct types have been distinguished, such as infarcts involving the cortex, lacunar infarcts, striatocapsular infarcts, total and partial anterior or posterior circulation infarcts, etc., and also borderzone infarcts. ${ }^{929.37 .49,155}$ However, CT morphological criteria are not invariably good predictors of the underlying stroke mechanism. Pathological data are, without doubt, of major value in identifying a certain infarct cause, but are often hard to collect, especially when a stroke subtype is rather infrequent. Moreover, the cause of fatal infarcts may differ from that in non-fatal cases. Therefore, clinical data, although indirectly, may be useful in studying whether a certain stroke cause is more or less likely; especially when features related to stroke cause, such as carotid stenosis or cardiac embolism, are compared in different brain infarct subtypes.

A major problem in the clinical study of borderzone brain infarcts is the definition of such infarcts, as outlined in chapter 1 of this thesis. An a priori presumptive stroke mechanism, such as for example a carotid stenosis-related hypoperfusion, should not be included in the infarct definition if borderzone infarcts are distinguished by $\mathrm{CT}$ or MRI topographical features. Borderzone infarcts are supposed to be located in the borderzone between at least two adjacent vascular supply areas, which means partially in the territory of one artery and partially in the territory of another one. But then, because of the variability of the major cerebral arterial vascular supply areas, the validity of these topographical criteria is debatable as was outlined in chapter 2 of this thesis. On the other hand, the classical demarcations between different arterial supply areas as indicated in the current vascular templates, may be looked upon as reflecting a kind of topographical average around which vascular borderzones in different subjects vary, and could therefore be used as a starting point for the study of borderzone infarcts. However, even with this assumption in mind, it remains uncertain whether a borderzone infarct is indeed situated in two separate arterial supply areas, or in the vascular endzone of just one of them.

In this chapter borderzone infarcts are defined as CT lesions compatible with the classical vascular borderzone demarcations. Several clinical and CT scan features were studied in borderzone infarcts in comparison with non-borderzone infarcts. The hypothesis was that if such features did differ between different brain infarct subtypes, stroke mechanism would also be different.

\section{PATIENTS AND METHODS}

All consecutive patients with a first-ever supratentorial ischaemic stroke with symptoms lasting longer than 24 hours were registered prospectively between July 1987 and July 1992 at the University Hospital Maastricht as described in chapter 3. Routine investigations and the definition of brain infarction were described in chapter 3 . Of the first 813 consecutive patients 25 had a rare stroke cause such as fibromuscular dysplasia, carotid dissection, vasculitis or haematological disorders and were considered as a separate category and therefore not included in the study. Of the remaining 788 patients 752 underwent CT. Five hundred and thirty-nine of these had a compatible infarct on CT, and were included in the study. CT scans were reviewed by two neurologists with 
specific interest in cerebrovascular disorders and by a neuroradiologist, without knowledge of the clinical data. In case of disagreement about the presence or location of an infarct, CT was scored as negative for that particular item. A small deep infarct (SDI) was defined as a sharply marginated hypodense lesion with a diameter of less than 20 $\mathrm{mm}$ on CT. A territorial infarct (TI) was defined as a hypodense lesion compatible with a territory supplied by the main stem, the corrical, or medullary branches of one of the three large cerebral arteries. Large subcortical lesions were included in the territorial infarct group, because of similar pathogenesis. 29,155 The territorial infarcts were divided into small, moderate, or large infarcts. Large subcortical infarcts were considered as moderate-sized territorial infarcts. A CT lesion was considered 'compatible' if located in the hemisphere where the signs and symptoms originated from, and if the radiologically estimated age was consistent with the beginning of the stroke (old lesions being more hypodense, more sharply delineated, or showing signs of retraction of brain structures towards the lesion site). According to this classification CT scans were re-evaluated without any knowledge of clinical data or previously collected CT data, in order to indicate whether infarcts were locared in a vascular borderzone area. Territorial and deep borderzone areas were distinguished by the following criteria: the superior frontal sulcus demarcated the anterior from the middle cerebral artery territory; the occipito-transversal sulcus demarcated the posterior from the middle cerebral artery territory; and the pariero-occipital sulcus demarcated the posterior from the anterior cerebral artery territory. Infarcts in these three borderzone areas were called territorial borderzone infarcts (see figures 4.1-4.5). The borderzone between the deep penetrating arteries and medullary branches of the major cerebral arteries (deep borderzone area) was considered according to Ghika et al. (see figures 4.1-4.3) ${ }^{66}$ Any infarct situated across the above indicated demarcation lines was called a borderzone infarct, regardless of its size, shape, or extension. If the infarct areas were approximately the same size on both sides of the border, the infarct was considered as 'total' borderzone, whereas an infarct was called 'partial' borderzone if these areas differed largely in size. With regard to the CT appearance of borderzone infarcts we distinguished slirlike, right-angled, and triangular or trapezoid, round or oval, and undefined shape. Borderzone infarcts with a slitlike or right-angled shape were considered as 'typical' borderzone infarcts. The extension of borderzone infarcts was expressed in numbers of CT slices (of $10 \mathrm{~mm}$ thickness) at which the infarct was visible; those 'typical' borderzone infarcts with an extension of more than 2 slices and territorial location were considered separately. An asymptomatic infarct was defined as a low-density area on CT compatible with infarction but without a history of stroke. We distinguished between asymptomatic small deep and asymptomatic territorial infarcts, and noted whether these were borderzone, using the same criteria as used in symptomatic infarcts.

Subsequent data were recorded: sex, age in three categories: $\leq 65,65<a g e \leq 75$, and $>75$. The use of diuretics. The haematocrit on admission in three categories: $\leq 40 \%, 41$ $45 \%$, and $>45 \%$. The haematocrit was analysed in all patients and because the haematocrit is lower in females than in males, it was analysed separately in both sexes. Hypertension, hypotension, diabetes mellitus, ischaemic heart disease, cardioembolic source, and non-invasive carotid studies were recorded according to the definitions given in chapter 3. Chronic obstructive pulmonary disease (COPD): a history of chronic 
obstrucrive pulmonary disease treated with medicarion. Handicap on admission was measured using the modified Rankin scale." Thircy-day case farality and one-year mortality were registered. Clinical and CT features in different subsets of borderzone infarct patients were compared with those of patients with non-borderzone infarcts. Categorical variables were analysed in a univariate analysis by means of Yates' correcred $\chi^{2}$-test and (crude) odds ratios ((c)OR) with $95 \%$ confidence interval (CI), or by the Fisher exact test. ${ }^{138}$ Subsequent multivariate logistic regression analysis statistically adjusted the estimated effect of each variable for differences in the distribution of the other independent variables, resulting in adjusted odds ratios ((a)OR) with $95 \%$ confidence interval.

\section{RESULTS}

Two hundred and eighty-five males and 254 females with a median age of 71 (range: $24-$ 96) years were included in the study. Median time from stroke onset until CT was 5 (range: 0-566) days; 59 per cent had CT within one week, 84 per cent within two, and 90 per cent within three weeks following stroke. There were 164 (31\%) small deep infarcts, and $375(69 \%)$ territorial infarcts. In $69(13 \%)$ patients symptomatic infarcts were considered as borderzone infarcts; 26 of these were territorial borderzone infarcts, and 43 were deep borderzone infarcts. Two territorial infarcts (one large deep and one small territorial), were classified as deep borderzone infarcts, but because they were initially regarded as territorial infarcts they were confined to the territorial borderzone infarct group with regard to further analysis. Thus, 28 territorial borderzone infarcts, and 41 (small) deep borderzone infarcts remained for statistical analysis. Of the 28 territorial borderzone infarcts 18 were located on the border berween ACA and MCA, six between PCA and MCA, and two berween ACA and PCA, whereas two were located deeply. Table 4.1 shows the CT findings in the 69 borderzone infarcts. One of the 28 territorial borderzone infarcts, and five of the 41 deep borderzone infarcts had a slitlike shape, whereas seven of the territorial borderzone infarcts and one of the deep borderzone infarcts had a right-angled shape, which gives a total of 14 borderzone infarcts with a 'typical' shape. Considering only the 'typical' territorial borderzone infarcts with an extension over more than two slices six infarcts were left. These were analysed separately.

Table 4.2 compares clinical and CT features between the 69 borderzone and 470 nonborderzone infarcts. Univariate comparison showed in the borderzone infarct group a significantly lower frequency of cardiac embolism and atrial fibrillation, and a significantly higher frequency of COPD, the combination of COPD and DM, and of patients with any type of asymptomatic infarcts. Afrer multivariate regression comparison with the variables: age, sex, DM, hypertension, IHD, significant carorid stenosis, cardiac embolism, COPD, the use of diuretics, and asymptomatic infarcts in the model, COPD and asymptomatic infarcts remained significantly associated with borderzone infarcts. If COPD and DM were included in the model as one variable instead of both conditions separately, this appeared to be highly significantly associated with borderzone infarcts ((a)OR):10.2; 95\%CI: 3.11-33.2; $\mathrm{p}<0.0001)$. A compatible carotid stenosis was not 

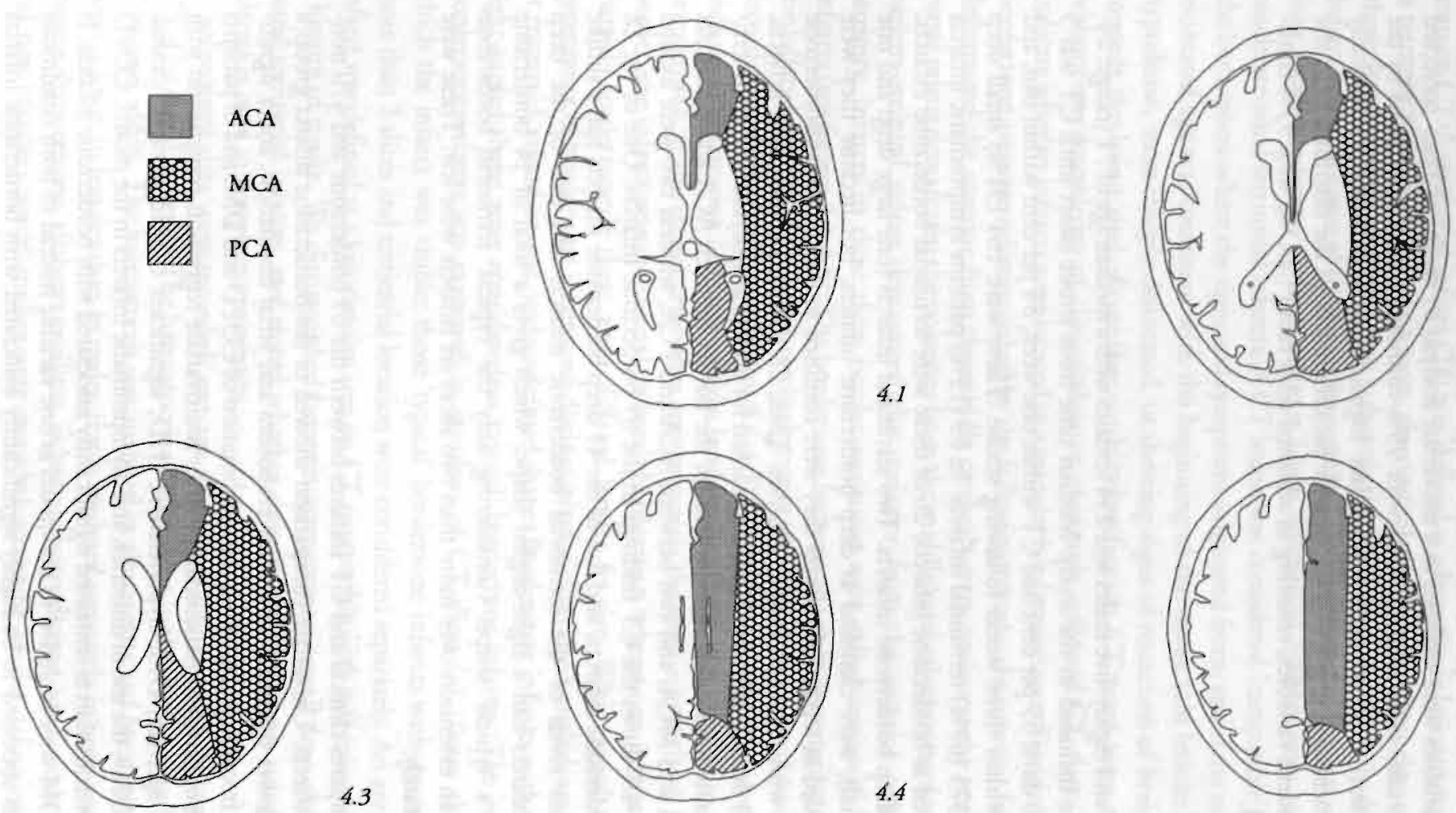

4.5

Figures 4.1-4.5: Schematic CT templates of the vascular territories of the ACA, MCA and PCA

Territorial borderzones: demarcation lines drawn from the superior frontal sulcus to the anterior horn of the lateral ventricle and from the occipito-transversal sulcus to the posterior horn of the lateral ventricle. The paricto-occipital sulcus demarcates the posterior from the anterior cerebral artery.

Deep borderzones: a line parallel to the cerebral convexity drawn from the anterior horn of the lateral ventricle to the posterior horn of the lateral ventricle. 
Table 4.1 CT scan features of 69 borderzone infarcts.

$\begin{array}{ll}\text { Territorial } & \text { Deep } \\ \text { borderzone } & \text { borderzone } \\ \text { infarcts } & \text { infarcts } \\ \mathrm{n}=28 & \mathrm{n}=\mathbf{4 1}\end{array}$

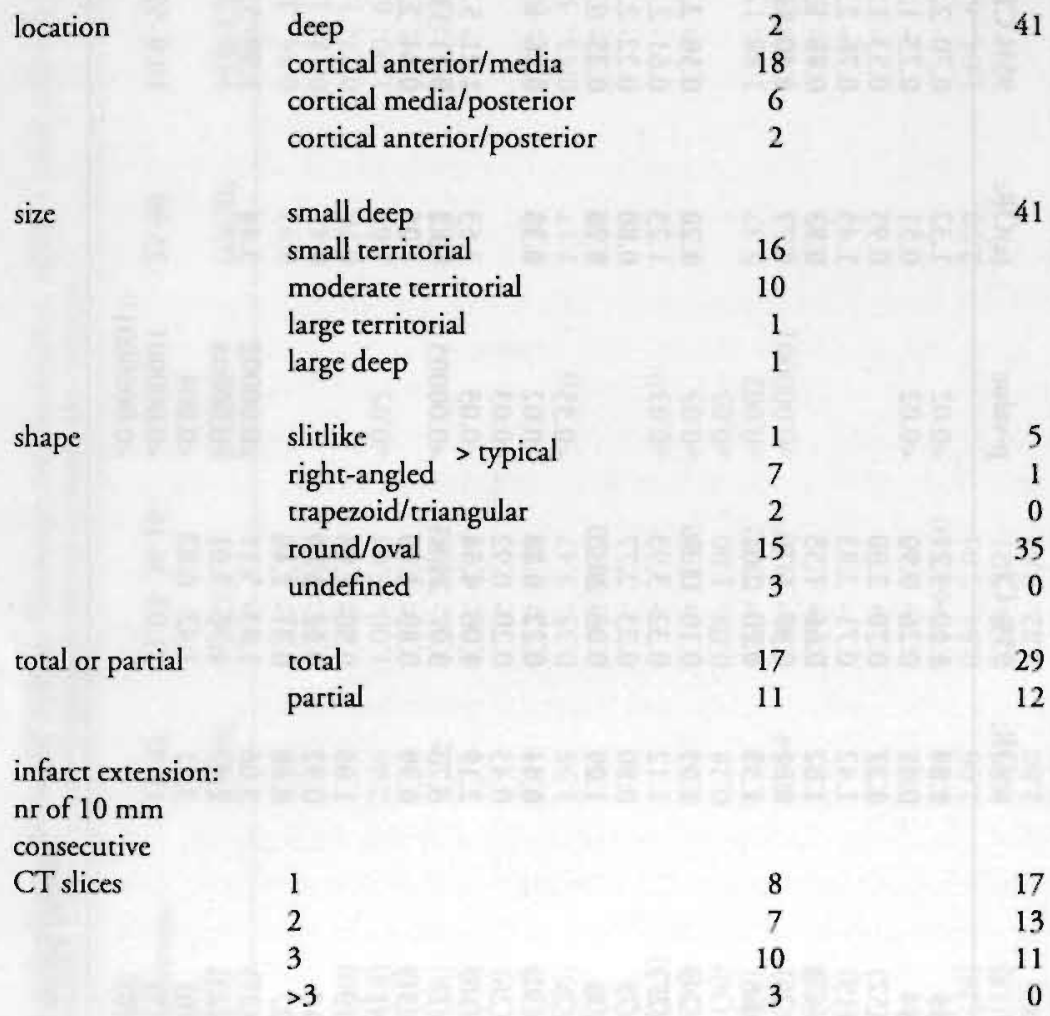

slitlike or

right-angled

and $>2$ slices deep

6

seen more frequently in borderzone infarcts than in the remaining infarcts. When this variable was replaced by a significant right- or left-sided carotid stenosis whether or not compatible ((a)OR:1.23; 95\%Cl:0.61-2.46), or by right- plus left-sided carotid stenosis ((a)OR:0.8; 95\%Cl:0.22-2.87), or by a compatible stenosis and diabetes mellitus in the model as one variable ((a)OR:1.26;95\%CI:0.25-6.14) no statistical differences could be detected. The simultaneous presence of a compatible carotid stenosis and COPD did not occur in the borderzone group. When the haematocrit was added to the model, an elevated versus a low haematocrit was not seen more frequently in the borderzone infarcts compared with the remaining infarcts: $40<\mathrm{Ht} \leq 45$ versus $\mathrm{Ht} \leq 40$ : (a)OR:1.15; 95\% CI:0.58-2.25, and $\mathrm{Ht}>45$ versus $\mathrm{Ht} \leq 40$ : (a) OR:0.86; 95\% CI:0.39-1.90. When 


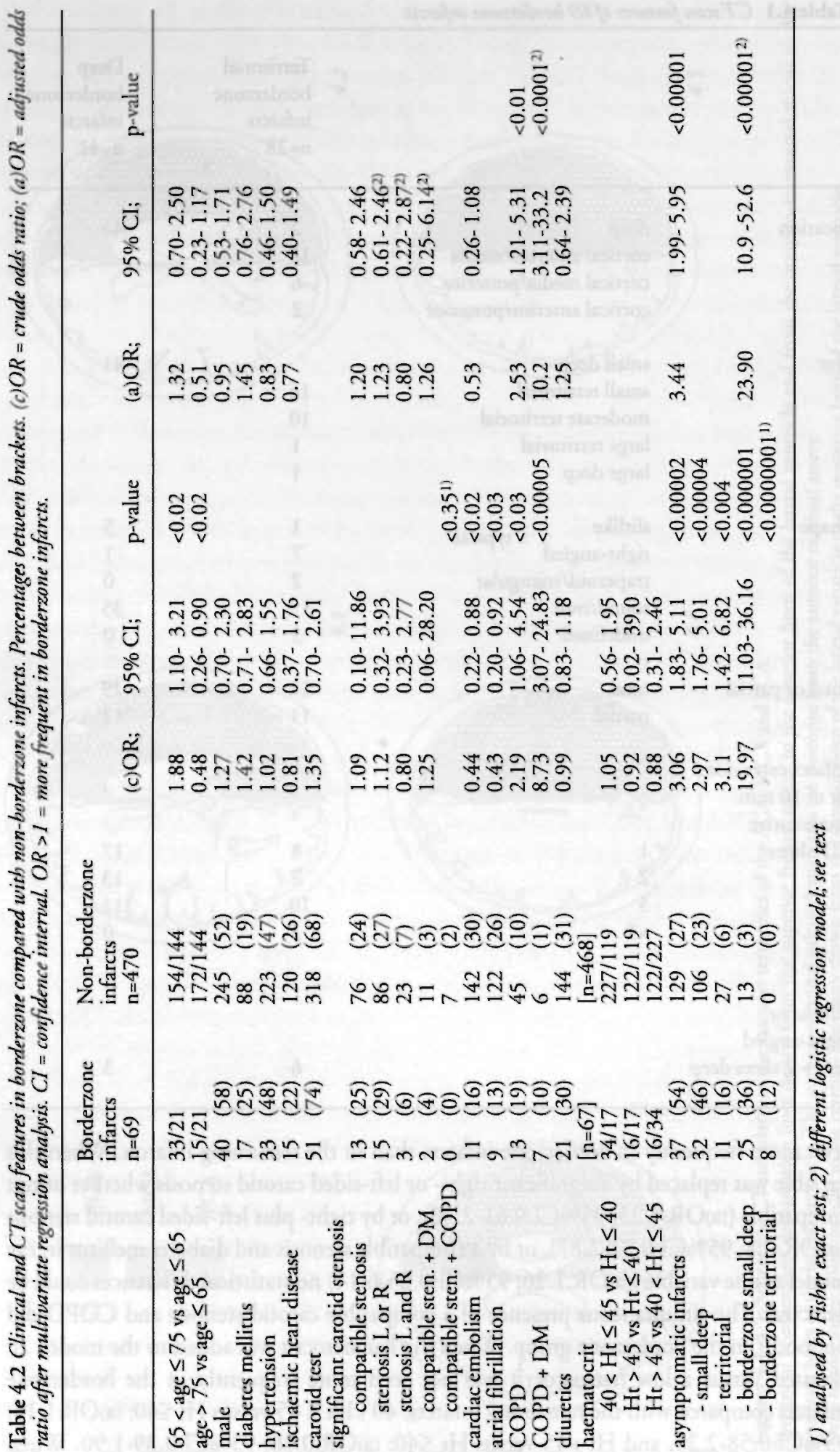




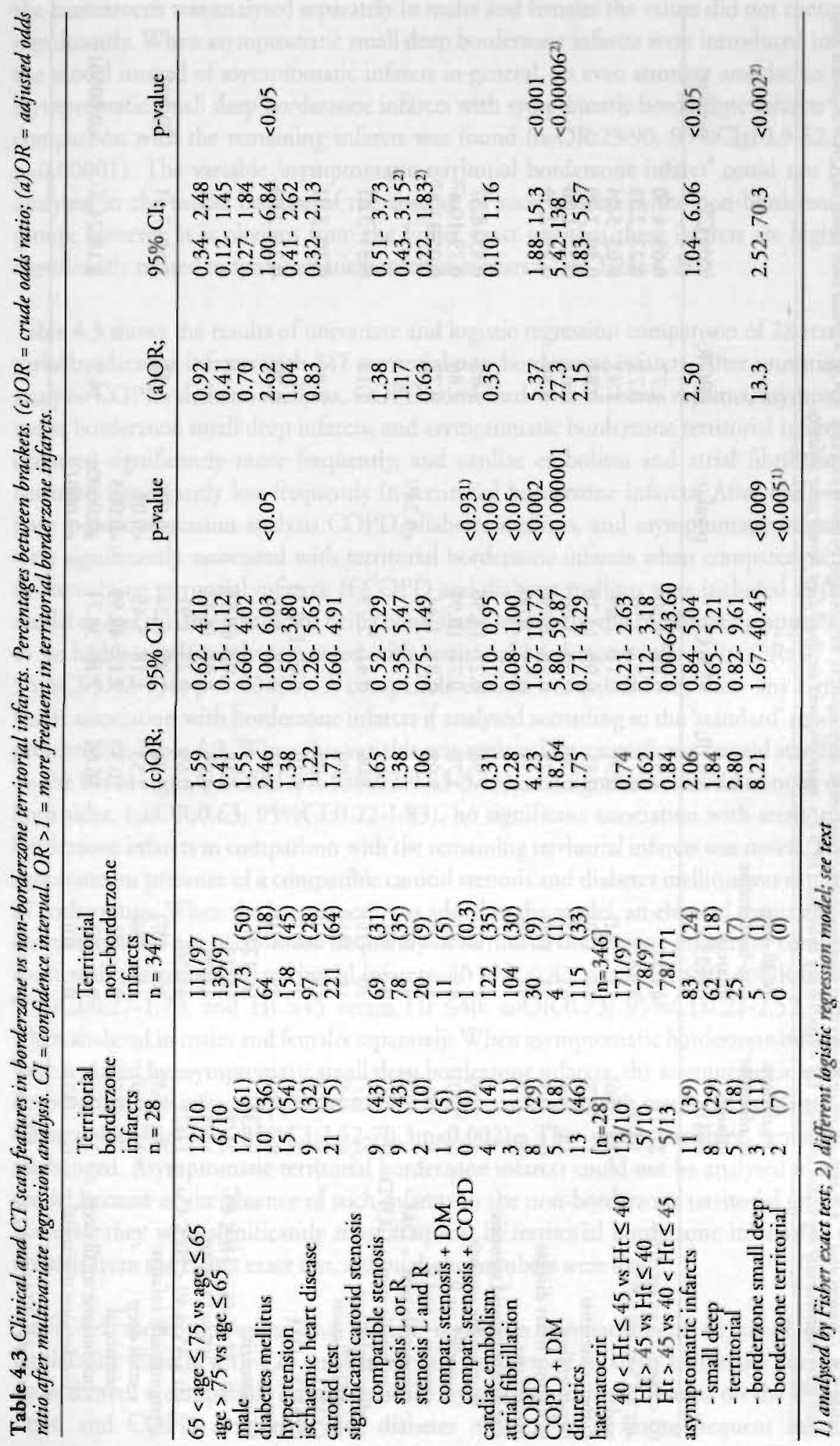


Table 4.4 Clinical and CT scan features in borderzone and non-borderzone small deep infarcts. Percentages between brackets. $(c) O R=c r u d e$ odds natio; $(a) O R=$ adjusted odds ratio after multivariate regression analysis. $C I=$ confidence interval. $O R>I=$ more frequent in small deep borderzone infarcts.

\begin{tabular}{|c|c|c|c|c|c|c|c|c|}
\hline 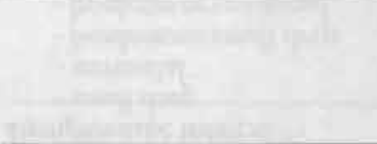 & $\begin{array}{l}\text { Small deep } \\
\text { borderzone } \\
\text { infarcts } \\
n=41\end{array}$ & $\begin{array}{l}\text { Small deep } \\
\text { non-borderzone } \\
\text { infarcts } \\
n=123\end{array}$ & (c) $\mathrm{OR}$; & $95 \% \mathrm{Cl}$ & p-value & (a) OR: & $95 \% \mathrm{Cl}_{i}$ & p-value \\
\hline $\begin{array}{l}65<\text { age } \leq 75 \text { vs age } \leq 65 \\
\text { age }>75 \text { vs age } \leq 65 \\
\text { male } \\
\text { diabetes mellitus } \\
\text { hypertension } \\
\text { ischaemic heart disease } \\
\text { carotid test } \\
\text { significant carotid stenosis } \\
\text { compatible stenosis } \\
\text { stenosis } \mathrm{L} \text { or } \mathrm{R} \\
\text { stenosis } \mathrm{L} \text { and } \mathrm{R} \\
\text { compatible sten. + DM } \\
\text { compatible sten. + COPD } \\
\text { cardiac embolism } \\
\text { atrial fibrillation } \\
\text { COPD } \\
\text { COPD + DM } \\
\text { diuretics } \\
\text { haematocrit } \\
40<\mathrm{Hr} \leq 45 \text { vs } \mathrm{Ht} \leq 40 \\
\text { Ht }>45 \text { vs Ht } \leq 40 \\
\text { Ht }>45 \text { vs } 40<\mathrm{Ht} \leq 45 \\
\text { asymptomatic infarcts } \\
\text { - small deep } \\
\text { - territorial } \\
\text { - borderzone small deep } \\
\text { - borderzone territorial }\end{array}$ & $\begin{array}{ll}21 / 11 \\
9 / 11 \\
23 & (56) \\
7 & (17) \\
18 & (44) \\
6 & (15) \\
30 & (73) \\
& \\
4 & (13) \\
6 & (20) \\
1 & (3) \\
1 & (0.2) \\
0 & (0) \\
7 & (17) \\
6 & (15) \\
5 & (12) \\
2 & (5) \\
8 & (20) \\
{[n=39]} \\
21 / 7 \\
11 / 7 \\
11 / 21 \\
26 & (63) \\
24 & (59) \\
6 & (15) \\
22 & (54) \\
6 & (15)\end{array}$ & $\begin{array}{ll}43 / 47 \\
33 / 47 \\
72 & (51) \\
24 & (20) \\
65 & (53) \\
23 & (19) \\
97 & (79) \\
& \\
7 & (7) \\
8 & (8) \\
3 & (3) \\
0 & (0) \\
0 & (0) \\
20 & (16) \\
18 & (15) \\
15 & (12) \\
2 & (2) \\
29 & (24) \\
{[n=122]} \\
56 / 22 \\
44 / 22 \\
44 / 56 \\
46 & (37) \\
44 & (36) \\
2 & (1) \\
8 & (6) \\
0 & (0)\end{array}$ & $\begin{array}{l}1.06 \\
1.00 \\
1.00 \\
3.10 \\
0.79 \\
\\
1.18 \\
0.79 \\
0.69 \\
2.90 \\
2.53 \\
10.37 \\
16.64\end{array}$ & $\begin{array}{l}0.89-4.30 \\
0.22-2.70 \\
0.11-7.69 \\
0.05-13.70 \\
0.29-1.66 \\
0.15-3.79 \\
0.23-2.28 \\
0.27-14.56 \\
0.71-10.95 \\
0.81-1.44 \\
0.41-2.73 \\
\\
0.07-138.21 \\
0.18-3.38\end{array}$ & $<0.24^{11}$ & $\begin{array}{l}1.13 \\
0.96 \\
0.70 \\
3.33 \\
24.7\end{array}$ & $\begin{array}{l}0.69-4.50 \\
0.22-2.33 \\
0.63-3.24 \\
0.30-2.30 \\
0.27-1.50 \\
0.25-2.59\end{array}$ & 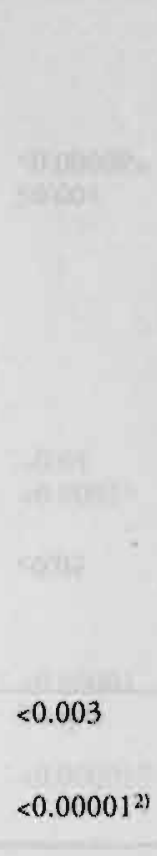 \\
\hline
\end{tabular}

1) analysed by Fisher exact test; 2) different logistic regression model; see text 
the haematocrit was analysed separately in males and females the values did not change significantly. When asymptomatic small deep borderzone infarcts were introduced into the model instead of asymptomatic infarcts in general, an even stronger association of asymptomatic small deep borderzone infarcts with symptomatic borderzone infarcts in comparison with the remaining infarcts was found ((a)OR:23.90; 95\%Cl:10.9-52.6; $\mathrm{p}<0.00001$ ). The variable 'asymptomatic territorial borderzone infarct' could not be analysed in the model because of the absence of such infarcts in the non-borderzone group; however, it is obvious from the Fisher exact test that these infarcts are highly significantly related to symptomatic borderzone infarcts (see Table 4.2).

Table 4.3 shows the results of univariate and logistic regression comparison of 28 territorial borderzone infarcts with 347 territorial non-borderzone infarcts. After univariate analysis COPD, diabetes mellitus, COPD combined with diabetes mellitus, asymptomatic borderzone small deep infarcts, and asymptomatic borderzone territorial infarcts occurred significantly more frequently, and cardiac embolism and atrial fibrillation occurred significantly less frequently in territorial borderzone infarcts. After multivariate logistic regression analysis COPD, diabetes mellitus, and asymptomatic infarcts were significantly associated with territorial borderzone infarcts when compared with the remaining territorial infarcts. If COPD and diabetes mellitus were included in the model as one variable instead of being considered separately, the combination appeared to be highly significantly associated with territorial borderzone infarcts ((a)OR: 27.3; 95\%CI:5.42-138; $\mathrm{p}<0.00006$ ). A compatible carotid stenosis did not show any significant association with borderzone infarcts if analysed according to the 'standard' model presented in Table 4.3. When this variable was replaced by a significant carotid stenosis on the left or right, ((a)OR:1.17; 95\%CI:0.43-3.15), or a significant carotid stenosis on both sides, ((a)OR:0.63; 95\%CI:0.22-1.83), no significant association with territorial borderzone infarcts in comparison with the remaining territorial infarcts was noted. The simultaneous presence of a compatible carotid stenosis and diabetes mellitus was similar in both groups. When the haematocrit was added to the model, an elevated versus a low haematocrit did not occur more frequently in territorial borderzone infarcts in comparison with the remaining territorial infarcts: $40<\mathrm{Ht} \leq 45$ versus $\mathrm{Ht} \leq 40$ : (a) OR:0.69; 95\%Cl:0.27-1.79, and $\mathrm{Ht}>45$ versus $\mathrm{Ht} \leq 40:$ (a) OR:0.73; 95\%Cl:0.21-2.52, nor when analysed in males and females separately. When asymptomatic borderzone infarcts were replaced by asymptomatic small deep borderzone infarcts, the asympromatic small deep borderzone infarcts appeared to be strongly associated with territorial borderzone infarcts ((a)OR:13.3; 95\%CI:2.52-70.3;p<0.002). The other variables remained unchanged. Asymptomatic territorial borderzone infarcts could not be analysed in the model because of the absence of such infarcts in the non-borderzone territorial group; however, they were significantly more frequent in territorial borderzone infarcts as is obvious from the Fisher exact test, although the numbers were low.

Table 4.4 shows univariate and logistic regression comparison of 41 small deep borderzone infarcts with 123 small deep non-borderzone infarcts. Univariate comparison showed a compatible carotid stenosis, a significant carotid stenosis on the left or right, and COPD combined with diaberes mellitus to be more frequent in the 
In Table 4.5 Clinical and CT scan features in 'typical' borderzone and remaining infarcts. Percentages between brackets. (c) $O R=$ crude odds matio; (a) $O R=$ adjusted odds matio after multivariate regression analysis. $C I=$ confidence interval. $O R>I=$ more frequent in typical' borderzone infarcts.

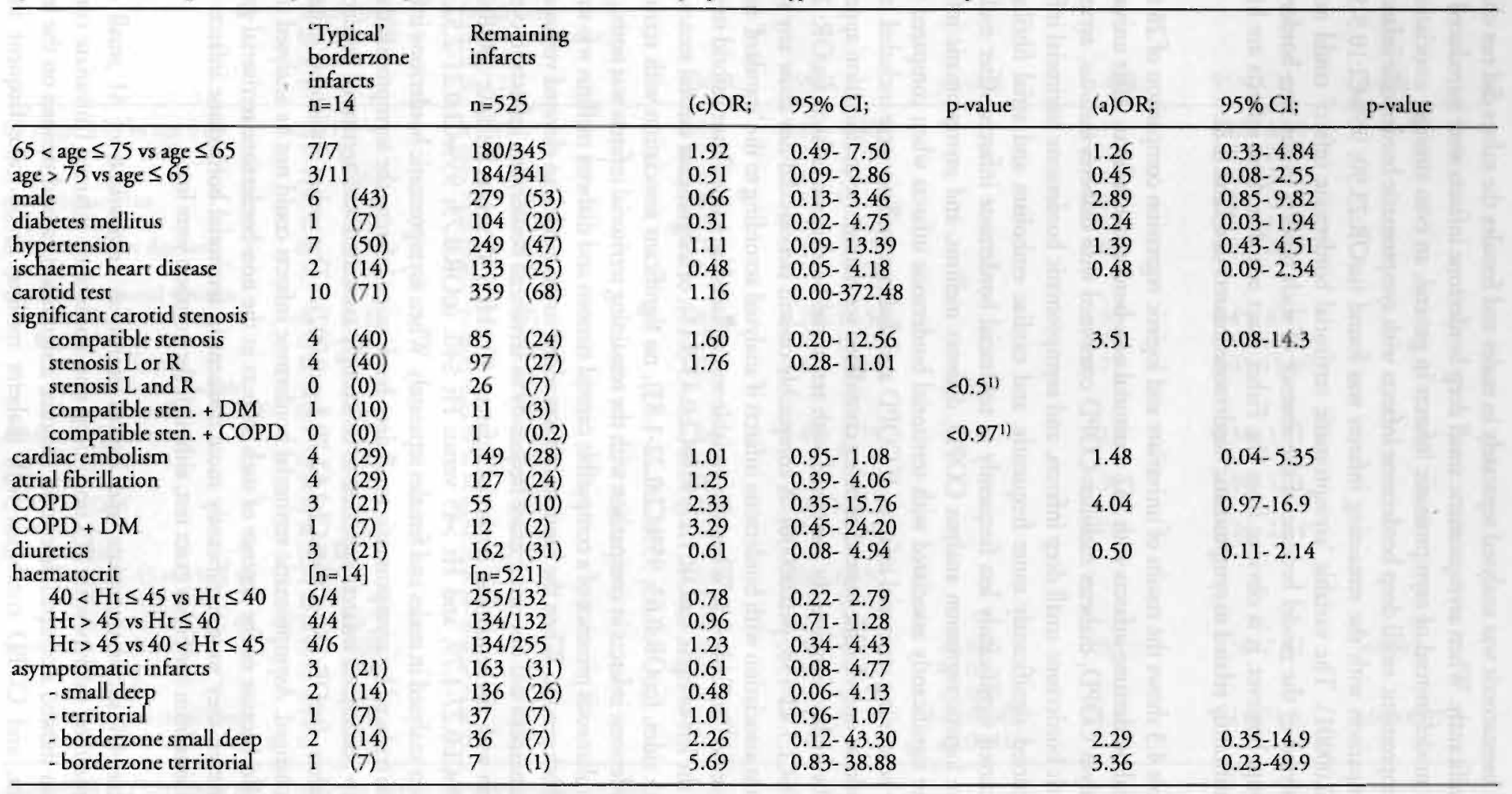

1) analysed by Fisher exact test 
borderzone infarct group, but the differences were not statistically significant. All subtypes of asymptomatic infarcts were seen significantly more frequently in the borderzone infarct group. Logistic regression analysis only revealed a significant association of small deep borderzone infarcts with asymptomatic infarcts, which was even more obvious when asymptomatic infarcts were replaced by asymptomatic small deep borderzone infarcts ((a)OR:24.7; 95\%CI:8.18-74.5; $\mathrm{p}<0.00001$ ). Asymptomatic territorial borderzone infarcts could not be statistically analysed in the model because of the absence of these infarcts in the non-borderzone small deep infarcts, but they were significantly more frequent in small deep borderzone infarcts as is obvious from the Fisher exact test. A compatible carotid stenosis did not show a significant association with small deep borderzone infarcts in comparison with the remaining small deep infarcts if analysed according to the model of Table 4.4. When a compatible carotid stenosis was replaced by a carotid stenosis on the left or right, ((a)OR:2.86; 95\% CI:0.79-10.4), or by a significant carotid stenosis on both sides, ((a)OR:0.77; 95\%Cl:0.05-11.4), no significant associations of carotid stenosis with small deep borderzone infarcts in comparison with the remaining small deep infarcts were found. When the haematocrit was added to the model, an elevated versus a low haematocrit was not more frequent in small deep borderzone infarcts in comparison with the remaining small deep infarcts: $40<\mathrm{Ht} \leq 45$ versus $\mathrm{Ht} \leq 40$ : (a) OR: $1.50 ; 95 \% \mathrm{Cl}: 0.50-4.49$, and $\mathrm{Ht}$ $>45$ versus $\mathrm{Ht} \leq 40$; (a) OR:0.88; 95\% Cl:0.26-3.0. When haematocrit was analysed in males and females separately the values did not change significantly.

Table 4.5 shows univariate and logistic regression analysis of 14 'typical' borderzone infarcts (slitlike or right-angled in shape), compared with the remaining infarcts $(\mathrm{n}=525)$. Univariate analysis did not show any significant difference, although COPD, the combination of COPD and diabetes mellitus, and asymptomatic borderzone infarcts were more frequent in the 'typical' borderzone group. After multivariate logistic regression analysis with sex, age, IHD, hypertension, COPD, diabetes mellitus, compatible stenosis, cardioembolic stroke cause, use of diuretics, and asymptomatic infarcts in the model, no significant associations of risk factors, or CT features of 'typical' borderzone infarcts in comparison with the remaining infarcts were found, although a carotid stenosis, COPD, and asymptomatic borderzone infarcts were more frequent in the typical borderzone infarct group. Four out of six patients with even more 'typical' borderzone infarcts (slitlike or right-angled territorial borderzone infarcts with extension of more than 2 slices on CT) had a carotid occlusion, which was seen more frequently in this group than in the remaining territorial infarcts, although not statistically significant: (OR:4.38;95\%Cl:0.54-35.37). After logistic regression analysis using the model of Table 4.5, these six infarcts did not differ from the remaining territorial infarcts in that a carotid stenosis was significantly associated with borderzone infarcts ((a)OR:2.99; 95\%CI:0.45-19.7).

Table 4.6 shows the univariate analysis of initial Rankin score 4 or 5 , the 30-day case fatality and the one-year mortality in borderzone infarcts in comparison with the remaining infarcts. Multivariate analysis with the 30-day case fatality and the one-year mortality as respectively dependent, and using the model of independent variables as 
Table 4.6 Initial Rankin score 4 or 5 , the 30-day case fatality, and the one-year mortality in borderzone infarcts compared with the remaining infarcts, and comparison of the diverse infarct subtypes. Percentages between brackets. (c) OR = crude odds ratio. $C I=$ confidence interval.

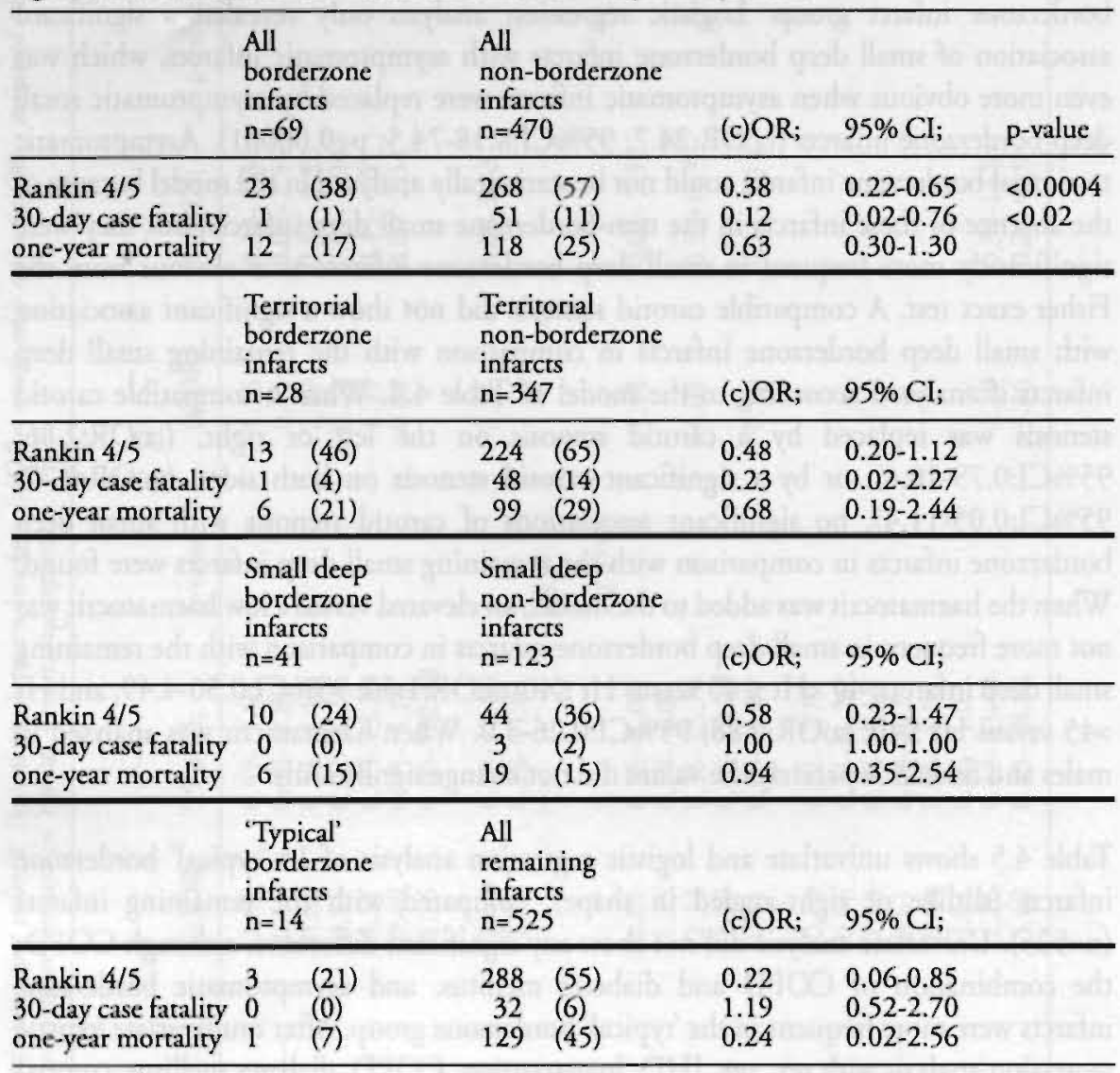

Table 4.7 Association (OR) of the 30-day case fatality and the one-year mortality with multiple variables after multivariate logistic regression analysis in all patients. (a) $O R=$ adjusted odds ratio after multivariate regression analysis. $C I=$ confidence interval. $O R>1$ more frequent in patients death within 30 days or death within one year respectively.

\begin{tabular}{|c|c|c|c|c|c|c|}
\hline & \multicolumn{3}{|c|}{$\begin{array}{l}\text { 30-day case } \\
\text { fatality }\end{array}$} & \multirow{2}{*}{$\begin{array}{l}\text { one-year } \\
\text { mortality } \\
\text { (a)OR; }\end{array}$} & \multirow[b]{2}{*}{$95 \% \mathrm{CI}$} & \multirow[b]{2}{*}{$\mathrm{p}$-value } \\
\hline & (a) $\mathrm{OR}$; & $95 \% \mathrm{CI}$ & $\mathrm{p}$-value & & & \\
\hline male & 0.49 & $0.22-1.10$ & & 0.85 & $0.51-1.41$ & \\
\hline $65<$ age $\leq 75$ vs age $\leq 65$ & 0.18 & $0.05-0.59$ & $<0.004$ & 1.14 & $0.57-2.25$ & \\
\hline age $>75$ vs age $\leq 65$ & 0.82 & $0.31-2.16$ & & 3.86 & $1.98-7.52$ & $<0.00007$ \\
\hline ischaemic heart disease & 1.51 & $0.71-3.19$ & & 1.19 & $0.70-1.99$ & \\
\hline hyperrension & 1.44 & $0.71-2.92$ & & 1.02 & $0.64-1.63$ & \\
\hline COPD & 0.50 & $0.14-1.76$ & & 1.08 & $0.52-2.25$ & \\
\hline compatible stenosis & 1.02 & $0.24-4.38$ & & 1.86 & $0.93-3.71$ & \\
\hline diabetes mellitus & 1.42 & $0.63-3.20$ & & 1.44 & $0.82-2.55$ & \\
\hline cardiac embolism & 2.52 & $1.23-5.17$ & $<0.01$ & 1.92 & $1.17-3.15$ & $<0.009$ \\
\hline Rankin $4 / 5$ & 10.2 & $2.94-35.1$ & $<0.0002$ & 2.78 & $1.65-4.67$ & $<0.0001$ \\
\hline borderzone infarcts & 0.19 & $0.02-1.66$ & & 1.00 & $0.46-2.16$ & \\
\hline asymptomatic infarcts & 0.97 & $0.46-2.05$ & & 1.31 & $0.79-2.15$ & \\
\hline
\end{tabular}


presented in Table 4.7, revealed that the 30-day case fatality was negatively associated with the borderzone infarcts and positively associated with a high initial handicap score, a higher frequency of cardiac embolism and a lower number of patients in the middleaged group. The one-year mortality was associared with a higher number of parients with a higher age, a less favourable Rankin score and a higher frequency of cardiac embolism. No association between the one-year mortality and borderzone infarcts was found. When the model of Table 4.7 was used for only territorial infarcts, the variables remained almost unchanged. When this model was used for only small deep infarcts no significant associations were found.

\section{DISCUSSION}

We hypothesized that if the frequency of certain features as we studied them differed between borderzone and non-borderzone infarcts, so would the underlying stroke cause. Although univariate comparison of 69 borderzone infarcts with 470 non-borderzone infarcts revealed several differences, logistic regression comparison accounting for interaction between different variables only showed that COPD was more than 2.5 times as frequent in borderzone infarcts, and that prior asymptomatic infarcts were more than three times as frequent. At least two subrypes of brain infarcts should a priori be distinguished because of different pathogenesis: territorial infarcts, in which cardiac or carotid embolism are the most frequent causes, and small deep (lacunar) infarcts, most of which are due to small vessel obstruction. ${ }^{125,126}$ Looking at the territorial infarcts it appeared that neither a compatible carotid stenosis with a diameter reduction of more than 50 per cent, nor such a stenosis regardless of the side of brain infarction, or a bilateral stenosis were more frequent among borderzone infarcts. This finding makes a carotid stenosisrelated cause as a specific factor unlikely. According to our findings a carotid stenosis may have a similar function in territorial borderzone infarcts as it has in territorial infarcts in general, which is a potential cause of embolism. These findings contradict other studies which suffer from various shortcomings in methodology and analysis as discussed in chapter 2 of this thesis. ${ }^{17,21,22,43,156}$ The same applies to cardiac embolism. Sludging of blood in a distal vascular bed as a possible specific cause of borderzone infarcts is also unlikely. Not only were the borderzone and non-borderzone territorial infarct groups similar with regard to $\mathrm{Ht}$ values, but also the use of diuretics as a possible cause of hypovolaemia did not differ between groups. In one study an elevated haematocrit was described as being strongly related to borderzone infarcts ${ }^{22}$, however, the borderzone infarcts in this study were not compared with other infarct subtypes. Diabetes mellitus emerged as the only vascular risk factor seen significantly more frequently in borderzone territorial infarcts, as it did in several other studies. ${ }^{17,21,22}$ The factor most strongly associated with territorial borderzone infarcts, however, was COPD. Particularly the combination of diabetes mellitus and COPD appeared to occur highly significantly more frequently in territorial borderzone infarcts. However, the number of patients was low, so that random variation might have played a role. These differences may point at a possible underlying mechanism in territorial borderzone infarcts: diabetes may render cerebral autoregulation less effective in order to counteract variations in local perfusion pressure by whatever cause: systemic hypotension or local 
hypoperfusion in the case of thromboembolism. Diaberes mellitus may also induce orthostasis. ${ }^{47.142}$ Although frequently reported in the literature, we only found one(!) patient with documented hyporension prior to the stroke in the territorial brain infarct group; ${ }^{21,22,82,135}$ so this mechanism is an unlikely cause of territorial borderzone infarction. The role of surgery-related hypotension was studied separately in chapter 7. Many COPD patients are chronically hypercapnic to some degree. Although we did not have blood gas analysis results in our patients, we assume that chronic hypercapnia will be present in many of the COPD patients. Chronic states of hypercapnia may cause autoregulatory disturbances even in discrete lowering of the blood pressure. ${ }^{17.159)}$ The combination of COPD and diabetes mellitus may render a patient susceptible to infarction in a borderzone area in situations of low flow, such as thromboembolism, because the cerebral blood flow in the cerebral white matter is approximately four times lower than in the cortex ${ }^{169}$, and because the vascular borderzone areas are mainly located in the white matter.

Whether territorial brain infarcts are located in two arterial supply areas instead of being restricted to one, remains unproven. However, considering the above discussion, it would seem most likely that territorial borderzone infarcts are located in one vascular endzone. Not only does a simultaneous thrombotic occlusion in two separate main arterial branches seem an unlikely phenomenon, but in the case of embolism it was demonstrated that even recurrent emboli are likely to lodge in the same arterial branch. ${ }^{140}$

Another significant finding was that asymptomatic infarcts were more frequent in territorial borderzone infarcts as compared with non-borderzone territorial infarcts, and furthermore, that such infarcts were often locared in a borderzone territory, which is also described by others. ${ }^{46,77,86,92,110.129}$ This finding may indicate a consistency in the cause of recurrent infarction after a prior asymptomatic infarct, and that borderzone areas are more 'neurologically silent' compared to other brain regions.

Considering small deep borderzone and small deep non-borderzone infarcts separately, no differences between these two groups emerged, except for the significantly higher frequency of asymptomatic infarcts in the borderzone group. Most asymptomatic infarcts were located in the vascular borderzone as reported previously. $77,86,92,129$ This suggests that the stroke mechanism in small deep borderzone infarcts is also rather consistent, and not different from the stroke mechanism in small deep infarcts in general, which is small-vessel disease. This finding also suggests that the deep borderzone is also a neurologically silent area. However, the number of prior asymptomatic territorial infarcts (15\%), all of which were located in the vascular borderzone, was surprisingly high in the borderzone small deep infarct group.

Also in the case of small deep borderzone infarcts it is by no means evident that such infarcts are located in two different arterial territories. Their size in combination with the most likely underlying stroke mechanism, which is small vessel occlusion, favours the view that small deep borderzone infarcts are located in the territory supplied by only one (penetrating) artery. The results from chapter 6 support this view.

One could argue against our definition of borderzone infarcts, that it was too liberal, and that only infarcts of a certain size and shape, like those that are more or less slit-like, should be included. Fourteen (3\%) of such infarcts were identified in our series. Neither 

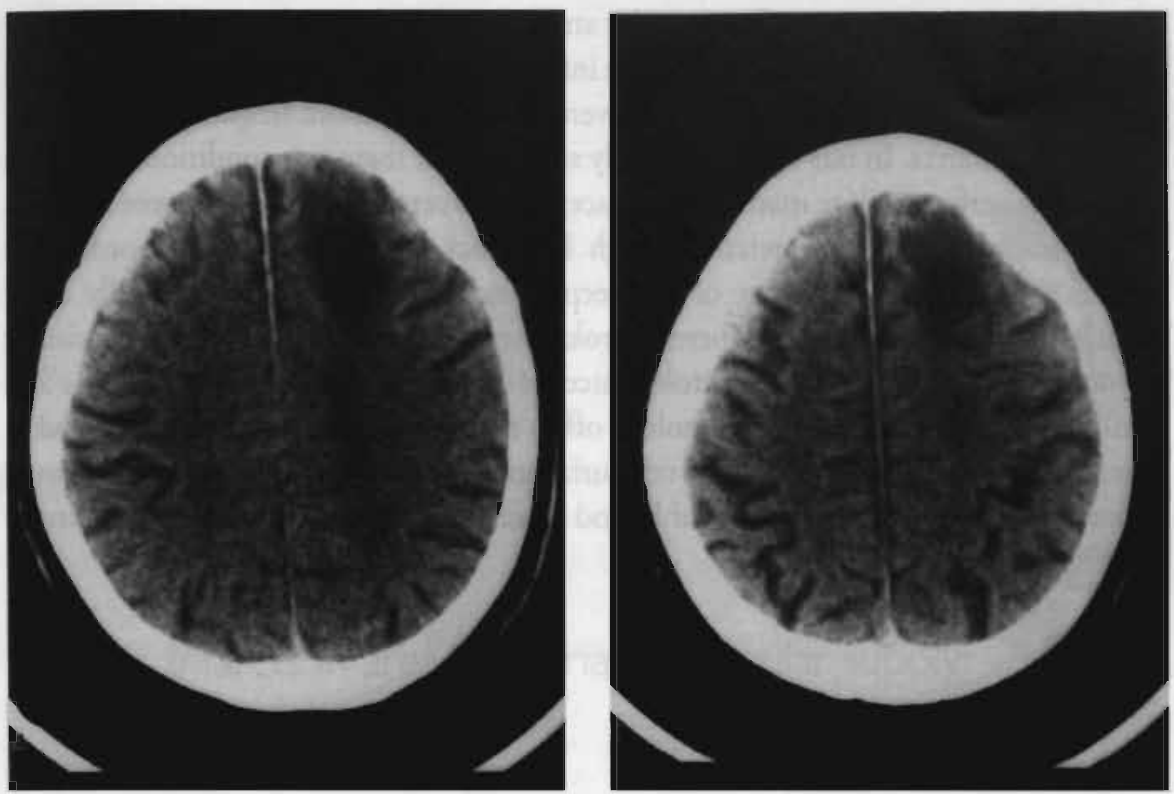

Figures 4.6a-4.6b:

CT-scan two days after stroke shows an infarct in the borderzone between the ACA and MCA of the left hemisphere in a 71-year-old man. On admission the patient had a right-sided cortical sensory motor syndrome. Duplex sonography showed an occlusion of the left-sided internal carotid artery. The patient was known to have hypertension.

univariate nor multivariate comparison with the remaining infarct group revealed any statistical significant difference (see Table 4.5). In six of these infarcts extending along two or more CT slices, a compatible significant carotid stenosis occurred about three times more often than in the remaining territorial infarcts, although not statistically significant. Moreover, the number of such infarcts appears to be small. Our data could not confirm that a carotid lesion in such cases is more often associated with bordertone than with non-borderzone infarcts. Moreover, there is no evidence that a carotid lesion causes post-stenotic hypotension rather than acting as a source of embolism. Obviously a carotid stenosis cannot be regarded as a predictor of borderzone infarcts as is frequently stated in the literature. $17.21,22,154,156,158$

When we looked at the degree of early handicap as indicated by a score of 4 or 5 on the Rankin scale (Table 4.6), this was less severe in borderzone infarcts. But the difference was no longer significant when the subgroups territorial and small deep infarcts were considered separately. Findings concerning the 30-day case fatality and the one-year mortality did not differ between groups. In a multivariate logistic regression model with the 30-day case fatality and the one-year mortality respectively as independent variables, borderzone infarction was not significantly associated with either of these variables (Table 4.7). Obviously, borderzone infarcts do not differ in early and the one-year outcome compared with non-borderzone infarcts. Also, this finding does not show any evidence in favour of the idea that borderzone infarcts should be considered as a separate brain infarct entity.

Our study does not support the view that borderzone infarction is significantly 
relared to carotid obstructive disease, prior stroke hypotension, or both. This applies for both territorial and small deep borderzone infarcts. Only diaberes mellitus, COPD, and especially the combination of these two were significantly more frequent in territorial borderzone infarcts. In our view this merely suggests that these two conditions make the already less perfused white matter more susceptible to cerebrovascular compromise such as thromboembolism. The relatively high frequency of silent lesions in borderzone infarcts may indicate that some of the deep white matter regions are clinically more silent than other brain areas, whereas stroke mechanism may be a rather consistent phenomenon in repeated stroke. Stroke outcome did not differ between borderzone and non-borderzone infarcts. CT morphology offers no evidence that an infarct is located in two adjacent instead of one separate territorial endzone. Therefore, the clinical concept of borderzone infarction is questionable, and at least does not appear to have any clinical significance so far. 


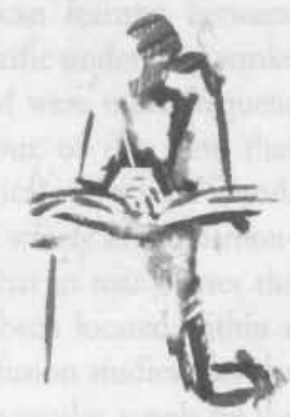

Infarcts in areas of variable vascular supply: borderzone infarcts?

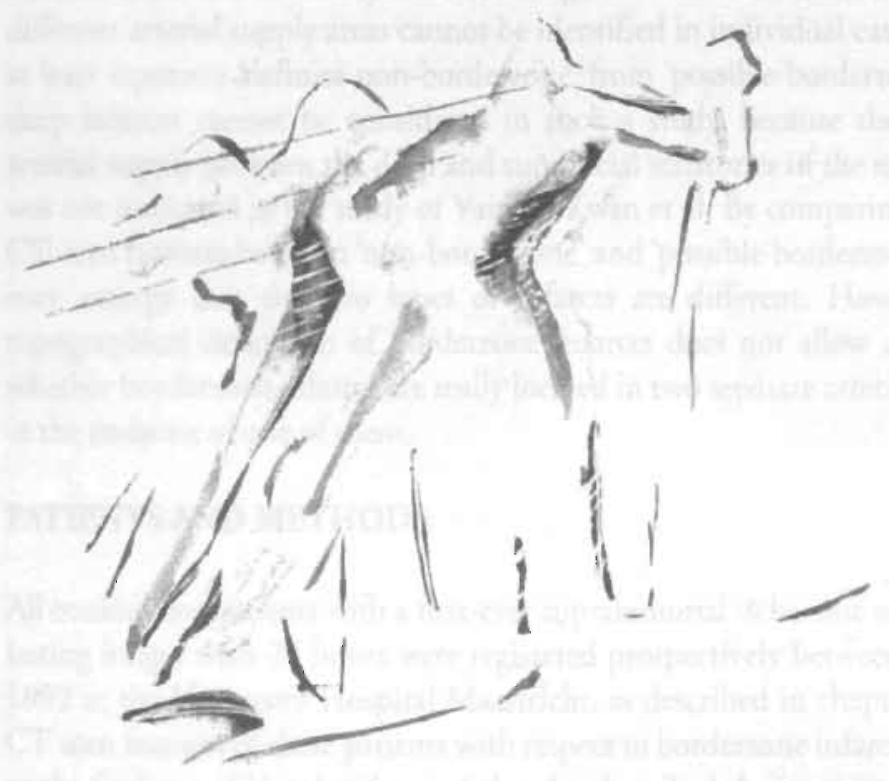




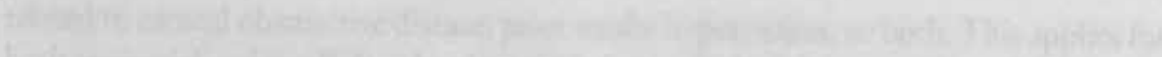

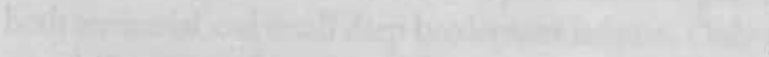

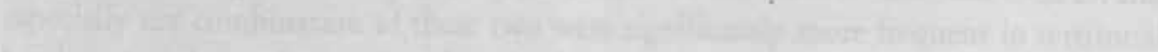

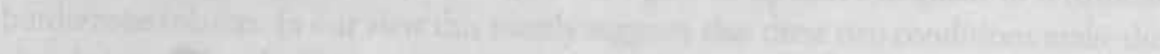

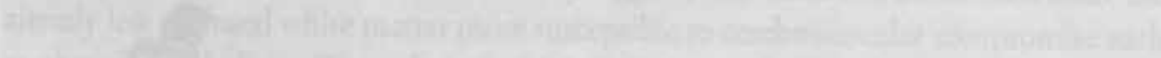

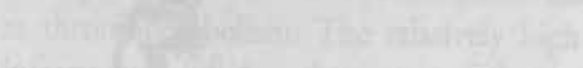

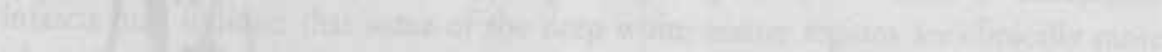

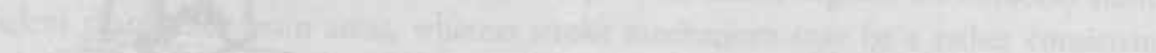

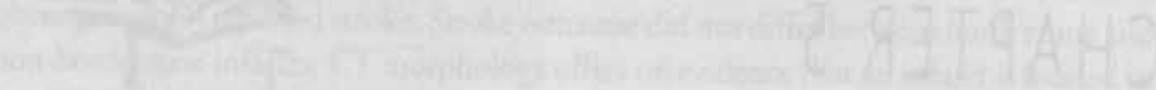

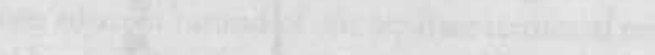

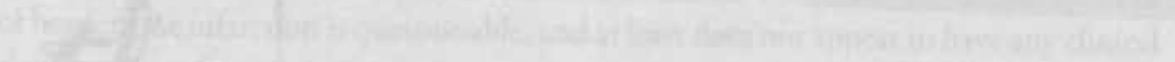
(1)

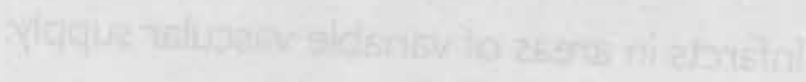

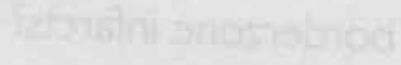
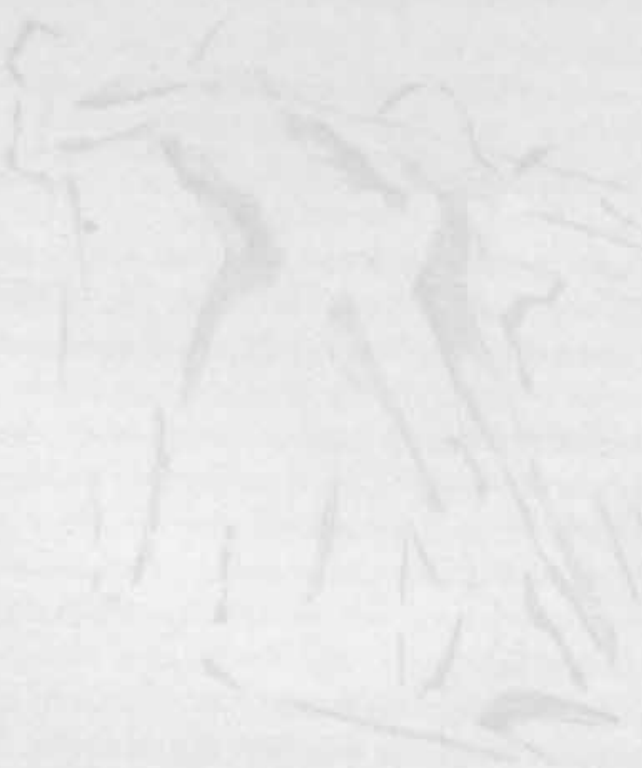


\section{INTRODUCTION}

In the previous chapter the vascular borderzones between the major cerebral arteries were defined according to the classical topographical demarcations between these arteries. $41,66.88,100$ Comparison of different clinical and CT scan features between borderzone and non-borderzone infarcts did not suggest any specific underlying stroke mechanism in borderzone infarcts, except that COPD and DM were more frequent among territorial borderzone infarcts. No arguments in favour of the view that borderzone infarcts represent a distinct clinical or parhophysiological entity were found.

The areas supplied by the different major cerebral arteries vary widely as was demonstrated in the study of Van der Zwan et al. ${ }^{166,168}$ This means that in many cases the classical demarcations between the different arteries may have been located within a vascular supply area rather than at the edge of it. From their infusion studies Van der Zwan et al. constructed templates representing areas of variable vascular supply by the major cerebral arteries, and areas that were consistently supplied by one and the same artery, as indicated in chapter 2 of this thesis. Infarcts located in the areas with variable arterial supply may represent borderzone infarcts, whereas those located in the nonvariable areas are definitely not. Although the exact location of the borders of the different arterial supply areas cannot be identified in individual cases, such a distinction at least separates 'definite non-borderzone' from 'possible borderzone' infarcts. (Small) deep infarcts cannor be considered in such a study, because the exact variability in arterial supply between the deep and superficial territories of the major cerebral arteries was not indicated in the study of Van der Zwan et al. By comparing several clinical and CT scan features between 'non-borderzone' and 'possible borderzone' infarcts, evidence may emerge that the two types of infarcts are different. However, even this CTtopographical definition of borderzone infarcts does not allow any conclusion as to whether borderzone infarcts are really located in two separate arterial systems, or merely in the endzone of one of them.

\section{PATIENTS AND METHODS}

All consecutive patients with a first-ever supratentorial ischaemic stroke with symptoms lasting longer than 24 hours were registered prospectively between July 1987 and July 1992 at the University Hospital Maastricht, as described in chapter 3. We studied the CT scan features of these patients with respect to borderzone infarcts, defined according to the findings of Van der Zwan et al., who described the inter-individual variability in supply areas of the ACA, MCA and PCA. ${ }^{166,168}$ We constructed CT templates by indicating the maximal minus the minimal vascular supply areas of the ACA, MCA and PCA, resulting in the areas of variability of vascular supply of these arteries (see Figures 5.1-5.6). These areas were considered as possible borderzone areas. Infarcts confined to such territories were defined as 'borderzone infarcts'. The territories of minimal supply of each artery were constructed, and infarcts in these territories were considered as nonborderzone infarcts. The topographical location of the borders of the vascular territories are indicated in the Figures 5.1-5.6. Reviewing the infarcts, we distinguished between infarcts restricted for more than 90 per cent to a borderzone territory, those restricted for 

more than 90 per cent to a non-borderzone territory, and infarcts located in both abovementioned territories. We called these infarcts respectively borderzone, non-borderzone and mixed infarcts. We compared clinical and CT features between the three infarct subtypes.

The demarcation lines of the deeply located arterial systems were not described by Van der Zwan et al. ${ }^{166,168}$ Therefore, we excluded the small deep $(n=164)$ and large deep $(\mathrm{n}=40)$ infarcts. Routine and selected investigations, definitions of infarct types, clinical features, non-invasive carotid studies, and CT lesions were used as described in chapter 4. Univariate and multivariate logistic regression analyses were performed as described in the previous chapter.

\section{RESULTS}

Seven hundred and fifty-two patients with a first-ever supratentorial brain infarct who underwent CT were registered. Three hundred and thirty-five patients had a symptomatic territorial brain infarct on CT. Two patients could not be analysed because of missing patient data, leaving 333 parients in the study. Using the above-outlined vascular templates 42 patients (13\%) had a borderzone infarct, $216(65 \%)$ a nonborderzone infarct, and in $75(22 \%)$ the infarct was categorized as mixed. Sixty-three per cent of the CTs were performed in the first week, 84 per cent within the first two weeks, and 91 per cent within the first three weeks. CT delay did not differ significantly between the infarct subtypes. The mean CT delay was 10 days (median 4; range 0-219). Twenty of the 42 borderzone infarcts also fulfilled the criteria of borderzone infarcts as defined in the previous chapter.

Table 5.1 compares clinical features and CT findings between the borderzone infarcts $(n=42)$ and the remaining infarcts $(n=291)$. Univariate analysis showed that cardiac embolism and atrial fibrillation were significantly less frequent in the borderzone infarct group. COPD and DM, considered as one variable, and asymptomatic borderzone infarcts occurred significantly more frequently in the borderzone group when compared with the remaining infarcts. A carotid test had been significantly more frequently performed in the borderzone group. After multivariate logistic regression analysis with the variables age, sex, DM, hypertension, ischaemic heart disease, cardiac embolism, compatible carotid stenosis, COPD, use of diuretics, and asymptomatic infarcts in the model, no differences between borderzone infarcts and the remaining infarcts were found. When COPD and DM were included in the model as one variable instead of both variables separately, this combination was seen significantly more frequently in the borderzone infarct group: ((a)OR:11.9; 95\%Cl:2.24-63.4; $\mathrm{p}<0.003$ ). Asymptomatic infarcts when replaced in the model by asymptomatic borderzone infarcts were significantly more frequent in the borderzone infarct group: ((a)OR:7.98; 95\%CI:1.38-46.2; $\mathrm{p}<0.001)$.

A compatible carotid stenosis did not show any significant association with borderzone infarcts in comparison with the remaining infarcts. Replacing the variable compatible carotid stenosis by a significant carotid stenosis regardless of which side was sympto- 
matic ((a)OR:1.55; 95\%CI:0.69-3.47), or replacing a compatible carotid stenosis by a significant carotid stenosis on both sides ((a)OR:1.24; 95\%Cl:0.40-3.82) did not yield any differences between groups. When a compatible carotid stenosis and DM were added to the model as one variable instead of both variables separately, the combination of DM and a compatible carotid stenosis was not more frequent in borderzone infarcts in comparison with the remaining infarcts ((a)OR:0.56; 95\% CI:0.06-4.72). Adding haematocrit to the model, showed that an elevated versus a low haematocrit was not more frequent in borderzone infarcts in comparison with the remaining infarcts: $40<\mathrm{Ht}$ $\leq 45$ versus $\mathrm{Ht} \leq 40$ : (a)OR:0.88; 95\%Cl:0.39-1.96, and $\mathrm{Ht}>45$ versus $\mathrm{Ht} \leq 40$ : (a) OR:0.87; $95 \% \mathrm{Cl}: 0.32-2.34$, nor when analysed in males and females separately.

Table 5.2 compares clinical features and CT findings of borderzone infarcts $(n=42)$ with definite non-borderzone infarcts ( $\mathrm{n}=216$ ). After univariate analysis, cardiac embolism and atrial fibrillation were significantly less frequent in the borderzone group. COPD and DM when simultaneously present were significantly more frequent in the borderzone group $(p<0.004)$. Asymptomatic infarcts were more frequent in the borderzone group, although not statistically significant, whereas asymptomatic borderzone infarcts were significantly more frequent in the borderzone group, but the numbers are low. A carotid test was significantly more frequently performed in the borderzone infarct group in comparison with the definite non-borderzone infarcts. After multivariate logisric regression analysis with the variables age, sex, DM, hypertension, ischaemic heart disease, a compatible carotid stenosis, cardiac embolism, COPD, the use of diuretics, and asymptomatic infarcts in the model, only DM was significantly more frequent among borderzone infarcts. When the variable asymptomatic infarcts was replaced by asymptomatic borderzone infarcts in the model, the asymptomatic borderzone infarcts were significantly associated with symptomatic borderzone infarcts in comparison with non-borderzone infarcts ((a)OR:7.50; 95\%Cl:1.09-51.7; $\mathrm{p}<0.04$ ), whereas the other variables remained unchanged. When COPD and DM were considered in the model as one variable instead of both variables separately, this combination was significantly associated with borderzone infarcts ((a)OR:14.4; 95\%Cl:2.00-104; $p<0.007$ ), whereas the other variables remained unchanged. A compatible carotid stenosis did not show any significant association with borderzone infarcts in comparison with the non-borderzone infarcts. When a comparible carotid stenosis was replaced by a significant carotid stenosis left or right ((a)OR:1.84; 95\%Cl:0.79-4.29) in the model, or when a compatible carotid stenosis was replaced by a significant carotid stenosis on both sides ((a)OR:1.13; 95\%CI:0.35-3.66), there were no differences between the groups. When adding haematocrit to the model, an elevated haematocrit versus a low haematocrit was not more frequent in borderzone infarcts in comparison with the non-borderzone infarcts: $40<\mathrm{Ht} \leq 45$ versus $\mathrm{Ht} \leq 40$ : (a)OR:0.68; 95\%CI:0.29-1.60, and $\mathrm{Ht}>45$ versus $\mathrm{Ht} \leq 40$ : (a) OR:0.65; 95\% CI:0.22-1.88, nor when analysed separately in males and females. Univariate comparison of an initial Rankin score of 4 or 5 on the Rankin scale, the 30-day case fatality and the one-year mortality between borderzone infarcts $(n=42)$ and 'definite' non-borderzone infarcts ( $n=216)$, and between borderzone infarcts and all the remaining infarcts $(n=291)$, shows that only the Rankin score of 4 or 5 was significantly less frequent in the borderzone group (see Table 5.3). 


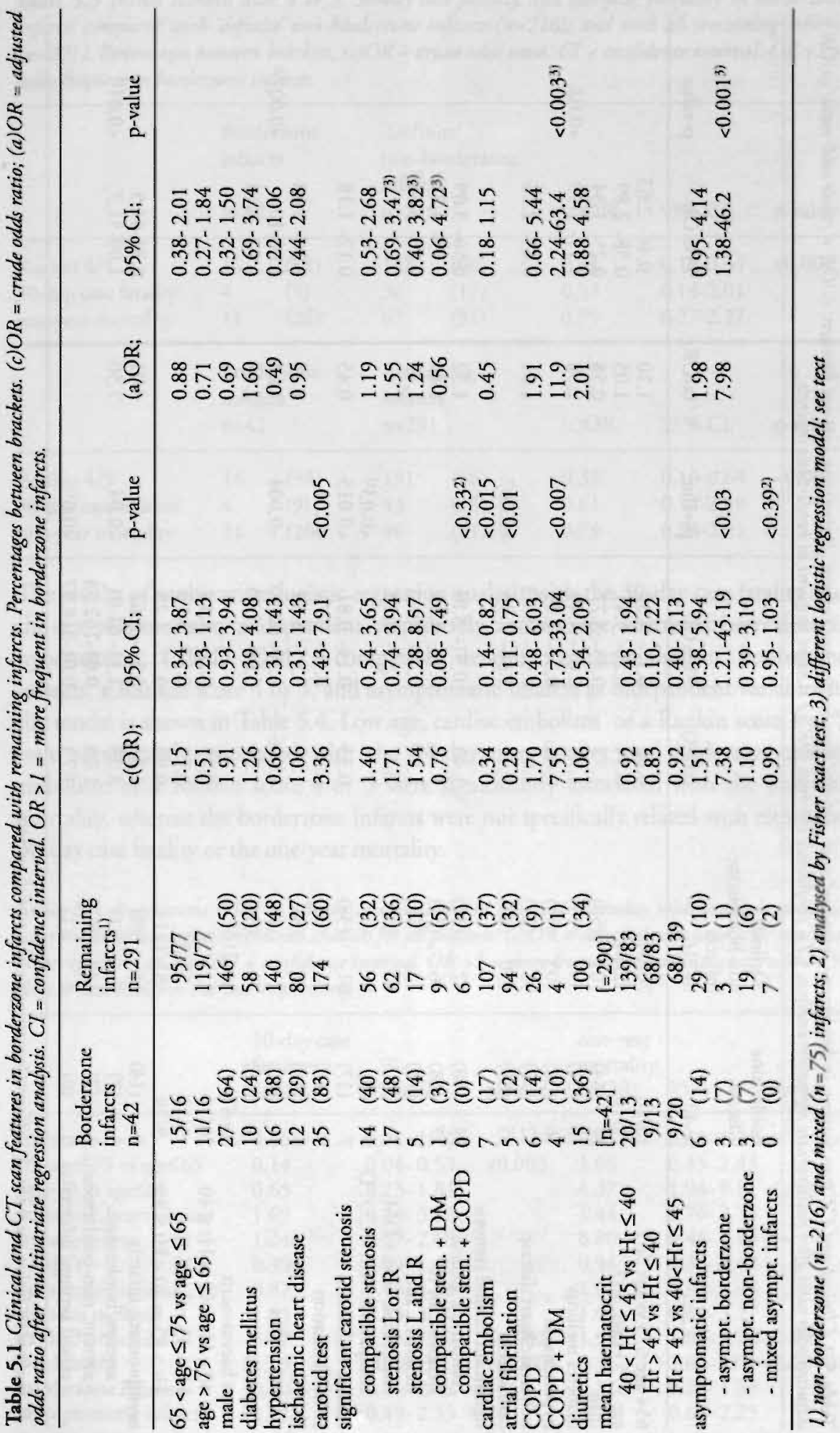


O̊̊

હ̊̊.

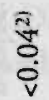

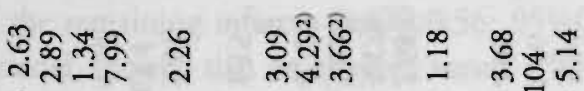

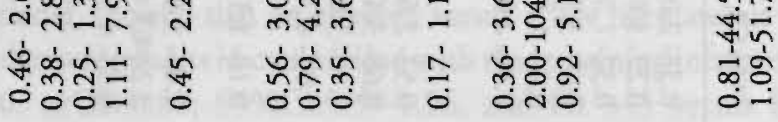

$\stackrel{2}{3}$

ฉั้

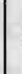

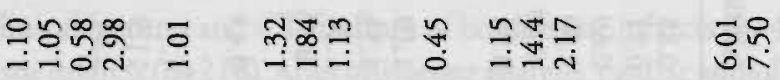

冚

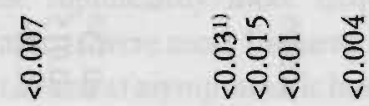

$\begin{array}{ll}\Delta & \bar{u} \\ \dot{0} & 0 \\ v & v\end{array}$

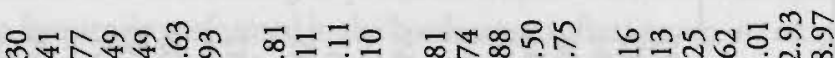

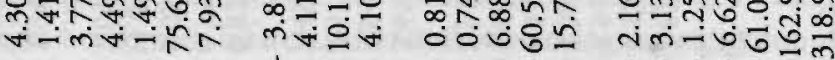

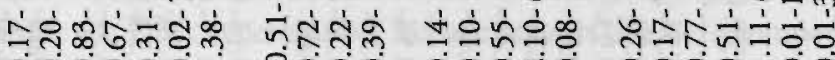

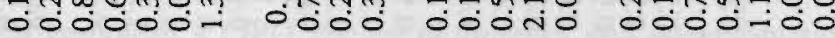

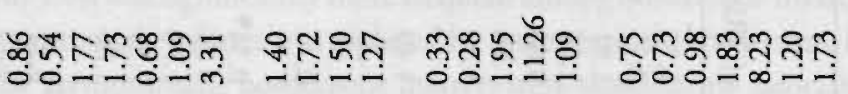

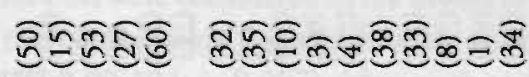

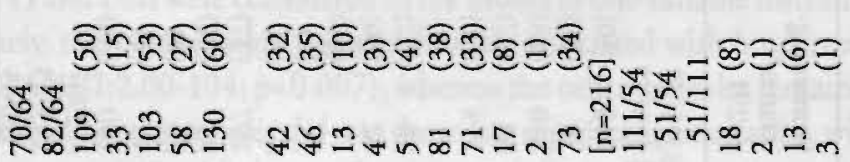

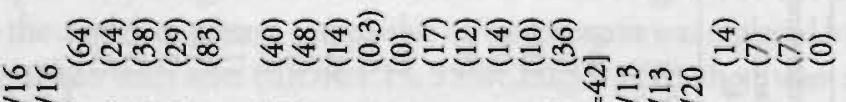

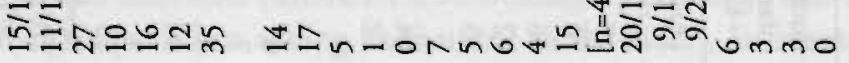

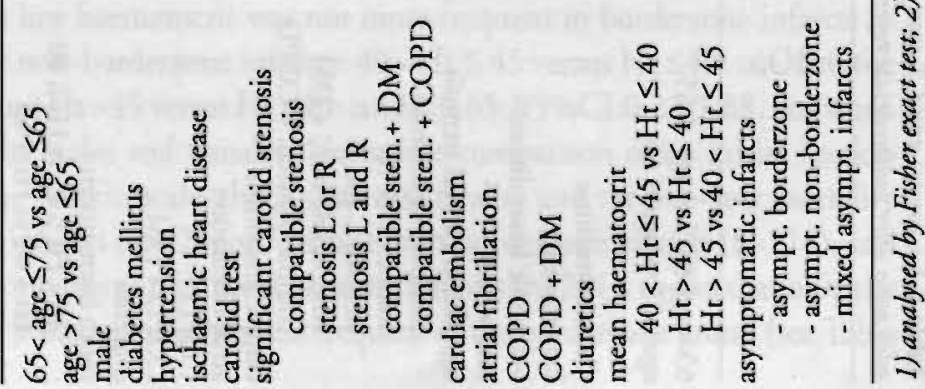


Table 5.3 Initial Rankin score 4 or 5, 30-day case fatality, and one -ycar mortality in borderzone infarces compared with 'definite' non-borderzone infarts $(n=216)$, and with all remaining infarcts $(n=291)$. Percentages berween brackets. (c) $O R=$ crude odds ratio. $C I=$ confidence interval. $O R>I=$ more frequent in borderzone infarcts.

\begin{tabular}{|c|c|c|c|c|c|c|c|}
\hline \multirow{4}{*}{$\begin{array}{l}\text { Rankin } 4 / 5 \\
\text { 30-day case fatality } \\
\text { one-year mortality }\end{array}$} & \multicolumn{2}{|c|}{$\begin{array}{l}\text { Borderzone } \\
\text { infarcts } \\
\mathrm{n}=42\end{array}$} & \multicolumn{2}{|c|}{$\begin{array}{l}\text { 'Definite' } \\
\text { non-borderzone } \\
\text { infarcts } \\
n=216\end{array}$} & \multirow{2}{*}{$\frac{\text { (c) } \mathrm{OR} \text {; }}{0.32}$} & \multirow{2}{*}{$\frac{95 \% \mathrm{Cl}}{0.16-0.64}$} & \multirow{2}{*}{$\frac{p \text {-value }}{<0.001}$} \\
\hline & 16 & (38) & 142 & (66) & & & \\
\hline & & (9) & & (17) & 0.53 & $0.14-2.01$ & \\
\hline & & (26) & 67 & (31) & 0.79 & $0.27-2.27$ & 1 \\
\hline & \multicolumn{2}{|c|}{$\begin{array}{l}\text { Borderzone } \\
\text { infarcts } \\
n=42\end{array}$} & \multicolumn{2}{|c|}{$\begin{array}{l}\text { Remaining } \\
\text { infarcts } \\
n=291\end{array}$} & (c)OR; & $95 \% \mathrm{CI}$ & $\mathrm{p}$-value \\
\hline Rankin 4/5 & 16 & (38) & 191 & (66) & 0.32 & $0.16-0.64$ & $<0.001$ \\
\hline 30-day case fatality & 4 & (9) & 43 & (15) & 0.61 & $0.14-2.58$ & \\
\hline one-year mortality & 11 & (26) & 90 & (31) & 0.79 & $0.28-2.21$ & \\
\hline
\end{tabular}

The results of multivariare logistic regression analysis with the 30-day case fatality and the one-year mortality as dependent, respectively, and sex, age, ischaemic heart disease, hypertension, COPD, DM, a compatible stenosis, cardiac embolism, borderzone infarcts, a Rankin score 4 or 5 , and asymptomatic infarcts as independent variables in the model is shown in Table 5.4. Low age, cardiac embolism or a Rankin score 4 or 5 were significantly associated with the 30-day case fatality, and high age, cardiac embolism or a Rankin score 4 or 5 were significantly associated with the one-year mortality, whereas the borderzone infarcts were not specifically related with either the 30-day case fatality or the one-year mortality.

Table 5.4 Associations (OR) of 30-day case fatality and one-year mortality with multiple variables afier multivariate logistic regression analysis for all patients. (a) $O R=$ adjusted odds ratio after multivariate regression analysis. $C I=$ confidence interval. $O R>1=$ more frequent in patients death within 30 days or death within one year respectively.

\begin{tabular}{llllll}
\hline & $\begin{array}{l}\text { 30-day case } \\
\text { fatality } \\
\text { (a)OR; }\end{array}$ & $95 \% \mathrm{CI} ;$ & p-value & $\begin{array}{l}\text { one-year } \\
\text { mortality }\end{array}$ \\
& (a)OR; & $95 \% \mathrm{CI}$; p-value \\
\hline male & 0.60 & $0.25-1.40$ & & 0.91 & $0.48-1.71$ \\
65<age $\leq 75$ vs age $\leq 65$ & 0.14 & $0.04-0.53$ & $<0.003$ & 1.05 & $0.45-2.43$ \\
age>75 vs age 565 & 0.65 & $0.23-1.84$ & & 4.37 & $1.94-9.81<0.0003$ \\
ischaemic heart disease & 1.69 & $0.74-3.88$ & & 1.44 & $0.76-2.73$ \\
hypertension & 1.24 & $0.57-2.69$ & & 0.80 & $0.45-1.44$ \\
COPD & 0.39 & $0.09-1.66$ & & 0.94 & $0.37-2.42$ \\
compatible stenosis & 0.87 & $0.18-4.08$ & & 1.90 & $0.81-4.44$ \\
diabetes mellitus & 1.35 & $0.55-3.36$ & & 1.63 & $0.81-3.27$ \\
cardiac embolism & 3.47 & $1.53-7.90$ & $<0.002$ & 1.99 & $1.06-3.76<0.03$ \\
Rankin 4/5 & 13.9 & $3.05-63.1$ & $<0.0006$ & 5.36 & $2.60-11.1<0.00001$ \\
borderzone infarcts & 0.60 & $0.15-2.42$ & & 0.51 & $0.20-1.33$ \\
asymptomatic infarcts & 1.11 & $0.49-2.53$ & & 1.18 & $0.62-2.25$ \\
\hline
\end{tabular}



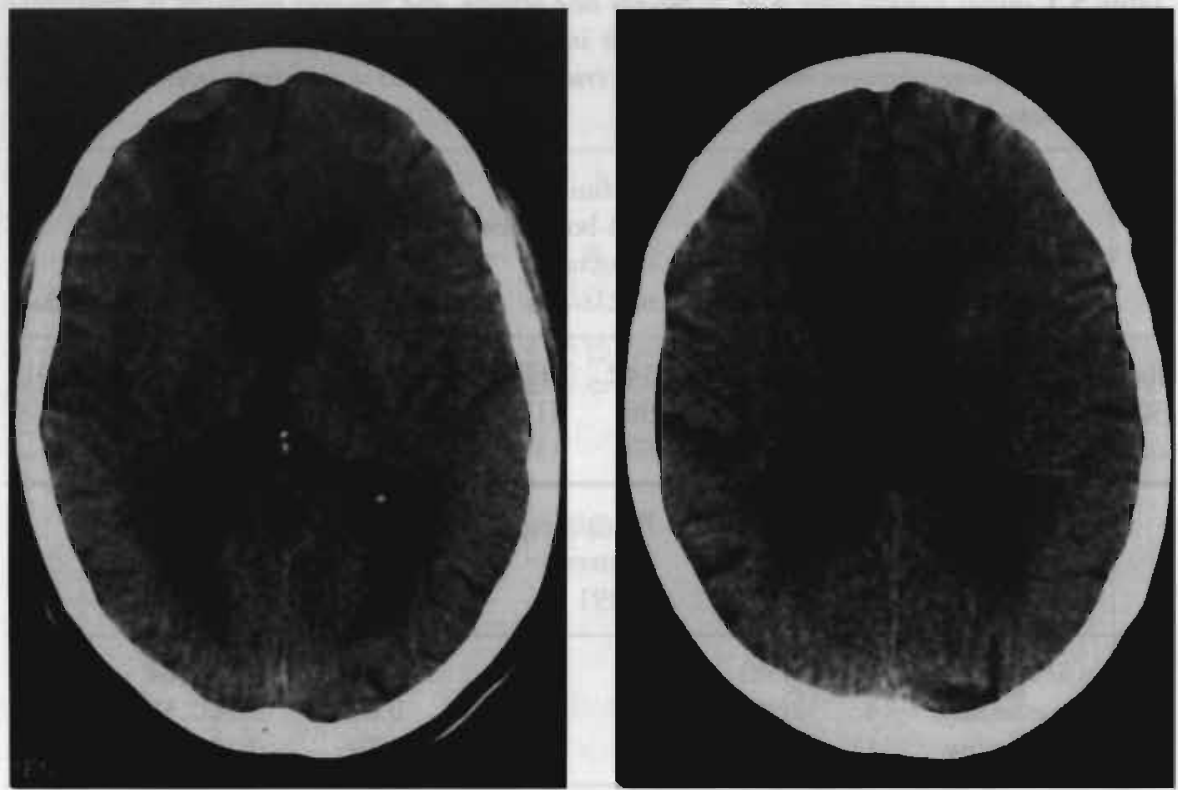

Figures 5.7A-5.7B: $\mathrm{CT}$ scan on the day of admission of a 60-year-old man with a left-sided cortical sensorimotor syndrome showing an infarct in the right hemisphere in the borderzone between the ACA and MCA. Duplex sonography showed an occlusion of the left internal carotid artery. The patient was known to have severe general atherosclerosis.

Reviewing the CT scan, the infarct was assessed as a borderzone infarct according to the criteria of borderzone areas as described in chapter 4 , as well as those of chaprer 5 .
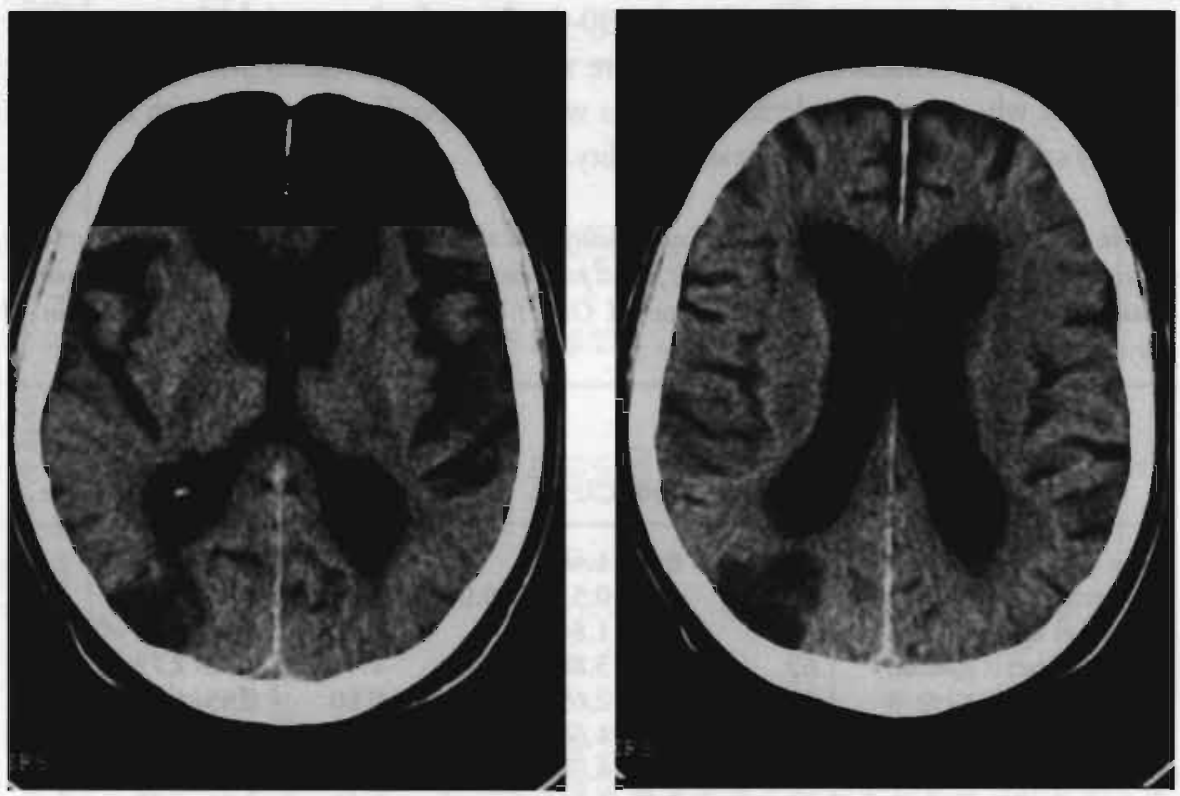

Figures 5.8A-5.8B: CT scan of an 80-year-old man five days after stroke onset showing an infarct in the right hemisphere in the borderzone between the PCA and MCA. On admission the patient had a leftsided hemianopia.

Reviewing the CT scan we assessed the infarct not as borderzone but as endzone with regard to the criteria of borderzone areas as described in chapter 4 . However, with regard to the criteria of chapter 5 the infarct was assessed as a borderzone infarct. 


\section{DISCUSSION}

As was shown in chapter 4 no evidence emerged that borderzone infarcts constirute a separate brain infarct entity with a specific underlying stroke cause. Also, the short term outcome in terms of 30-day case fatality and one-year mortality in such infarcrs did not differ from that in the remaining infarcts. Only DM, COPD, and especially the combination of these two risk factors were significantly associated with territorial borderzone infarcts. However, these features are more likely to be regarded as factors that compromise cerebral perfusion in case of a cerebrovascular event, rather than aetiological factors in themselves. We considered in chapter 4 that borderzone infarcts were those infarcts which were located across what has classically been regarded as the demarcation lines between the three different major brain arteries, as is often displayed in modern $\mathrm{CT}$ vascular templates. In the present chapter borderzone infarcts were defined taking into account the significant variability in the different arterial supply areas, as was demonstrated by Van der Zwan et al. ${ }^{166,168}$ Definite borderzone infarcts were those located for at least 90 per cent within an area of variability, and definite non-borderzone infarcts were those that for more than 90 per cent were confined to an area consistently supplied by one and the same major brain artery. Multivariate logistic regression showed that in particular the combination of DM and COPD was significantly more frequent among borderzone infarcts, whether they were compared with the definite nonborderzone infarcts or with all the remaining infarcts. This finding is similar to that of chapter 4 , but may merely reflect that the borderzone infarcts as defined in either way showed large topographical overlap. In fact, 20 of the 42 infarcts assessed as being borderzone according to the present chapter's definition, were also considered as territorial borderzone infarcts according to the classical topographical criteria used in chapter 4 . The fact, that more borderzone infarct patients had a carotid test is unlikely to have biased results towards a stronger association of borderzone infarction with a carotid stenosis, but rather towards the opposite: most of the patients who did not have such a test were older, and therefore more likely to have more severe carotid disease. The contribution of DM and COPD to the occurrence of borderzone infarcts as defined in this chapter may therefore be similar to that discussed in the previous chapter. No other variables appeared to be significantly related to borderzone infarcts. Therefore, our data do not offer any evidence in favour of the idea of a specific stroke cause underlying the infarcts defined as borderzone infarcts, even if one takes into account the variability in arterial vascular supply areas of the three major cerebral arteries. The higher frequency of asymptomatic infarcts in the borderzone group, most of them also located in a borderzone area, may again indicate a consistent stroke mechanism within individual patients regarding recurrent brain infarcts, however the numbers in the present study were small.

We conclude that clinically there are no arguments to consider borderzone infarcts as an infarct type different from infarcts in a territory of only one major cerebral artery. Also in this study it is not clear whether borderzone infarcts were indeed located in two adjacent arterial endzones. In individual cases this seems hard to verify. No evidence could be found to support the view that a specific stroke cause, such as the often proposed combination of systemic hypotension and a significant carotid obstruction, is 
related to borderzone infarcts. The study described in this chapter also lends no support to the existence of a separate brain infarct entity that could be assigned as "borderzone infarction'. 


\section{CHAPTER 6}

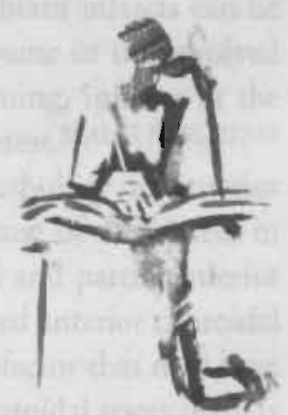

Infarcts in the anterior choroidal artery territory; anatomical distribution, clinical syndromes, presumed pathogenesis, early outcome and relationship with the 'deep borderzone'.'

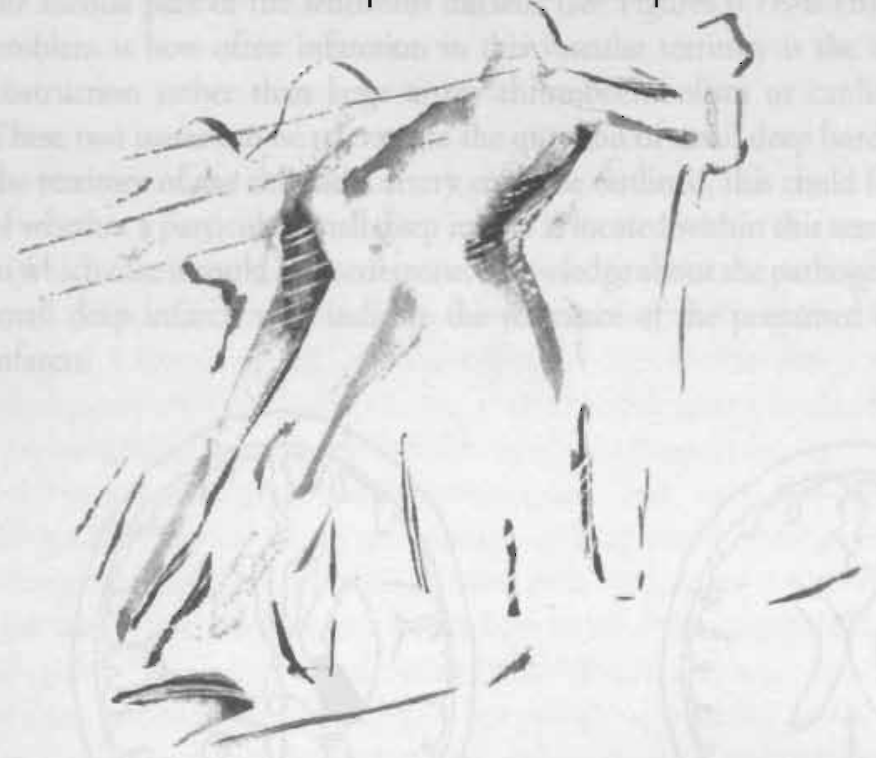

1 Adapted from: RMM Hupperts, J Lodder, EPM Heuts-van Raak, F. Kessels. Infarcts in the anterior choroidal artery territory; anatomic distribution, clinical syndromes, presumed pathogenesis and early outcome. Accepted for publication in Brain, 1994. 


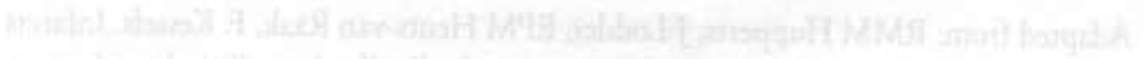

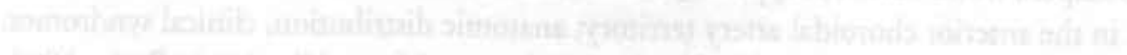

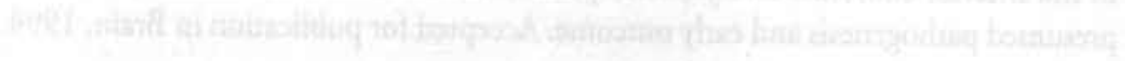




\section{INTRODUCTION}

Distinction between different subtypes of brain infarction may be relevant with regard to treatment and prevention of recurrences. ${ }^{12}$ Characteristics of brain infarcts can be studied from different points of entry, such as the clinical syndrome or the involved vascular territory. Following the introduction of brain CT scanning, infarcts in the territory of the anterior choroidal artery have received renewed interest. ${ }^{34,42,65,74-76,107,145}$ Symptomatology, risk factor profile and presumed vascular pathology in anterior choroidal artery infarcts differed between studies, probably because of differences in patient selection. Most studies did not distinguish between total and partial anterior choroidal artery territory infarcts, and none of the studies compared anterior choroidal artery infarcts with infarcts in other vascular territories. Another factor that may have influenced the differences in study results regarding the anterior choroidal artery infarcts is the variability in supply area as described in several pathological-anatomical studies. ${ }^{1,13}$ Two issues have been in dispute in particular. One is whether besides the posterior leg of the internal capsule the anterior choroidal artery also supplies the posterior paraventricular part of the corona radiata, the lateral part of the thalamus, and the medial part of the lentiform nucleus (see Figures 6.1A-6.1B). ${ }^{34,75,107}$ The second problem is how often infarction in this vascular territory is the result of small vessel obstruction rather than large artery thromboembolism or cardiac embolism. ${ }^{33,60,102}$ These two issues can be relevant to the question of small deep borderzone infarction. If the territory of the choroidal artery could be outlined, this could facilitate the decision of whether a particular small deep infarct is located within this territory or just outside, in which case it could be borderzone. Knowledge about the pathogenesis of this group of small deep infarcts may indicate the relevance of the presumed cause of borderzone infarcts.
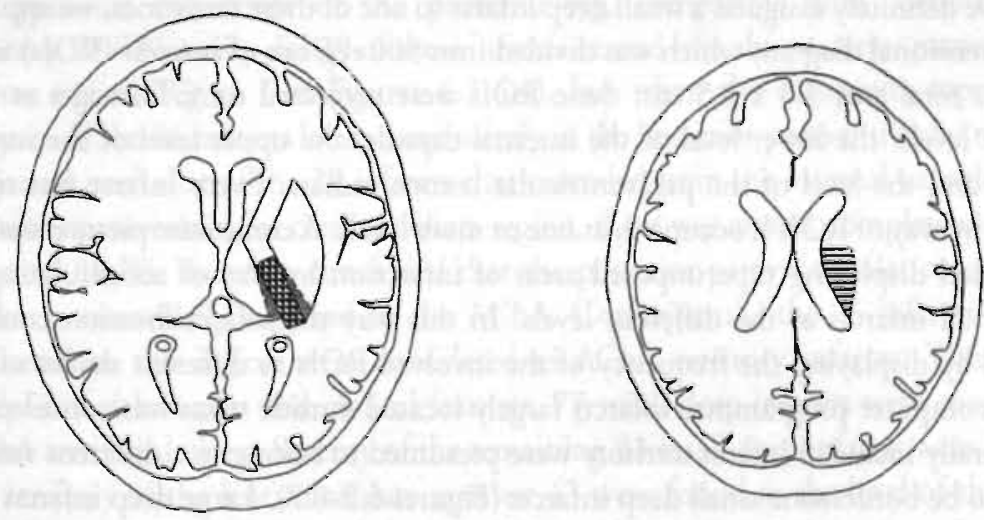

Figures 6.1A-6.1B: Schematic CT templates of presumed AChA territories according to the literature. Area agreed upon: 'definite' AChA (triangular), area of some disagreement (dotted), and contentious area (striated).

Therefore, in a prospective registry of all consecutive parients with a first-ever supratentorial brain infarct we studied the anatomical distribution on CT of infarcts in the presumed anterior choroidal artery territory. Furthermore, we studied the clinical 
syndrome, vascular risk factor profile, and signs of large vessel disease or cardiac embolism in patients with a small (less than $2 \mathrm{~cm}$ diameter) infarct in the presumed anterior choroidal artery territory, in comparison with small deep infarcts in other vascular regions, and also with territorial infarcts. These features were also studied in larger AChA infarcts.

\section{PATIENTS AND METHODS}

Patients were registered in a prospective registry at the University Hospital Maastricht, The Netherlands, of all parients with a first-ever supratentorial brain infarct with symptoms lasting longer than 24 hours, as described in chapter 3. Infarcts with rare causes (as defined in chapter 4), were considered as a separate category and were not included in the study. We distinguished small deep infarcts (as defined in chapter 3), large deep infarcts: a lesion larger than $20 \mathrm{~mm}$ on CT, and territorial infarcts (as defined in chapter 4). Large deep infarcts were included in the territorial infarct group because of similar pathogenesis. ${ }^{29,155,157} \mathrm{CT}$ scans were independently reviewed by two neurologists with specific interest in cerebrovascular disorders, without knowledge of clinical data. In case of disagreement about the presence or location of an infarct, the opinion of a third investigator was decisive. CT was studied to assess the vascular territory in which the symptomatic small deep infarct was located. We distinguished the territories of: anterior choroidal artery $(\mathrm{ACh} A)$, lenticulostriate artery, thalamoperforating artery, posterior choroidal artery $(\mathrm{PChA})$ and Heubners' artery, according to Ghika et al ${ }^{66}$ and Damasio $^{41}$. We defined the posterior two-thirds of the posterior leg of the internal capsule as 'definite' AChA territory. 1,261,75,107 Subsequently we assessed how often the posterior paraventricular region, the lateral part of the thalamus and the medial part of the lentiform nucleus were continuous with the 'definite' AChA territory infarcts. Before we definitely assigned a small deep infarct to one of these territories, we applied a two-dimensional diagram which was divided into 500 regions of interest (ROIs) representing a total area $3.5 \times 3.5 \mathrm{~cm}$; these ROIs were projected on CT images at three different levels: the lower level of the internal capsule, the upper level of the internal capsule, and the level of the paraventricular corona radiata. Every infarct was reconstructed by way of ROIs it occupied, at one or more levels. A composite picture was then constructed displaying superimposed areas of infarction by way of accumulating the ROIs of all infarcts at the different levels. In this way the infarct location could be analysed by displaying the frequency of the involved ROIs in different shades of grey using a computer programme. Infarcts largely located outside what was considered as the generally included infarct territory were presumed to belong to a different vascular area or to be borderzone small deep infarcts (Figures 6.2-6.7). Large deep infarcts were considered separately as to whether the AChA territory was involved. Routine investigations, included standard blood and urine tests, electrocardiogram and chest X-ray. Echocardiography, 24 hours ECG monitoring and cerebral angiography were done in selected cases. The following risk factors were recorded: age and sex, cardioembolic source, ischaemic heart disease, diabetes mellitus, hypertension, and hypotension, as defined in chapter 3. Non-invasive carotid studies were performed as described in chapter 3. Handicap on admission was measured using the modified Rankin scale. ${ }^{11}$ 
We compared different clinical features and non-invasive carotid test results between patients with a small infarct in the presumed $A C h A$ territory and the remaining patients with a small deep infarct on CT, and also with territorial infarct patients. Large AChA infarcts were compared with remaining territorial infarcts. Categorical variables were analysed in an univariate analysis by means of Yates' corrected chi-square $\left(\chi^{2}\right)$ and (crude) odds ratios ((c)OR) with $95 \%$ confidence interval (CI), or by the Fisher exact test. ${ }^{138}$ Subsequent multivariate logistic regression analysis statistically adjusted the estimated effect of each variable for differences in the distribution of and the associations among other independent variables. Adjusted odds ratios will be presented with ((a)OR) with $95 \%$ confidence interval.

\section{RESULTS}

We registered 755 parients with a first-ever supratentorial ischaemic stroke, 499 of which had resulted from a territorial infarct, and 256 from a small deep infarct. CT was performed within one week in 53 per cent, within two weeks in 81 per cent, and within three weeks in 88 per cent. The mean CT delay was 17 (median 6; range 0-912) days. CT delay did not significantly differ between the infarct subgroups. Three hundred and eighty-four (including 42 large deep infarcts) of the 499 territorial infarcts (77\%) and 160 of the 256 small deep infarcts (62\%) had a compatible lesion visualized on CT, and were included in the study. Twelve infarcts that initially, after reviewing the CT scans, were considered as possible AChA territory infarcts were assigned to a different vascular territory (thalamoperforator group: 2, posterior choroidal artery: 2, lenticulostriate group: 8), after studying the composite reconstruction diagrams, because they were largely located outside the area shared by the majority of the remaining infarcts (see Figures 6.2-6.7). At the level of the internal capsule, 51 infarcts were located mainly in the posterior two-thirds of the posterior leg, compatible with 'definite' AChA territory. ${ }^{75,107}$ Not only did 29 of these infarcts extend into the posterior paraventricular corona radiata region (see Figures 6.2-6.4), but when the composite topographical diagram of the 26 infarcts located exclusively in the posterior paraventricular region was projected onto that of the 29 infarcts that extended from the internal capsule into the posterior paraventricular corona radiata region, there was almost complete overlap (see Figure 6.8). We therefore concluded that the posterior paraventricular corona radiata region is most likely supplied by the AChA. Consequently, the 26 infarcts that were restricted to this region were considered as AChA territory infarcts. Thus, for the analysis of risk factors and clinical features, 77 small deep infarcts were considered as AChA territory lesions. Seventy of the remaining 83 small deep infarcts were located in the territory of the lenticulostriate arteries: 43 were found at the level of the internal capsule, seven of which extended upwards into the anterior, and one into the posterior paraventricular corona radiata region; 27 infarcts were restricted to the anterior paraventricular corona radiata region. Ten infarcts were located in the area supplied by the thalamoperforator group, two were located in the posterior choroidal artery area, and one in Heubners' artery area. 


\section{Figures 6.2-6.8:}

Composite reconstruction diagrams of small infarcts presumably located in AChA territory, at three different levels on CT. The diagonally dotred areas represent infarcts largely located outside the gencrally included infarct territory. These were finally assigned to a different vascular territory. (See text for further explanation).

\section{Figures 6.2-6.4:}

Twenty-nine infarcts in 'definite' AChA territory with upwards extension to the paraventricular corona radiata region. Six infarcts were finally assigned to a different vascular territory (striated area).

\section{Figures 6.5-6.6:}

Twenty-two infarcts in 'definite' AChA territory confined to the internal capsule region. Four infarcts were finally assigned to a different vascular territory (striated area). 


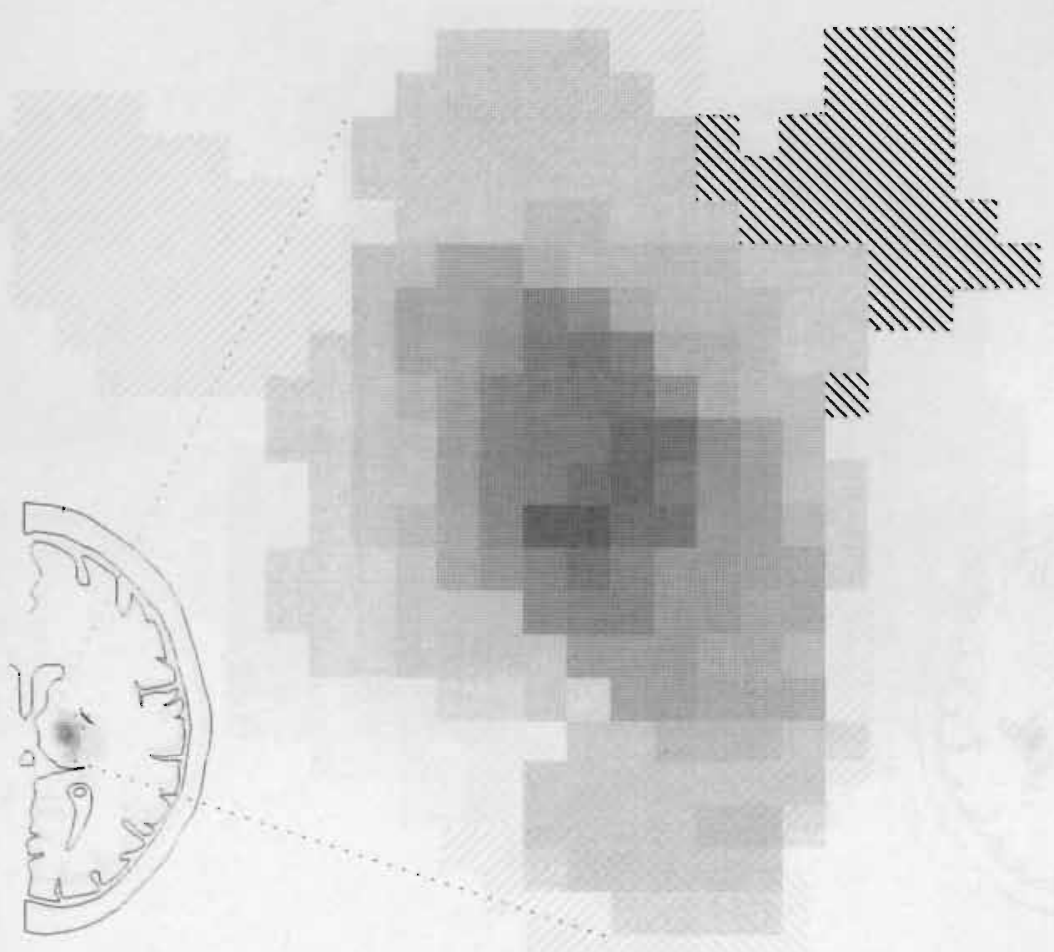

Fig. 6.2: Lower level internal capsule, 


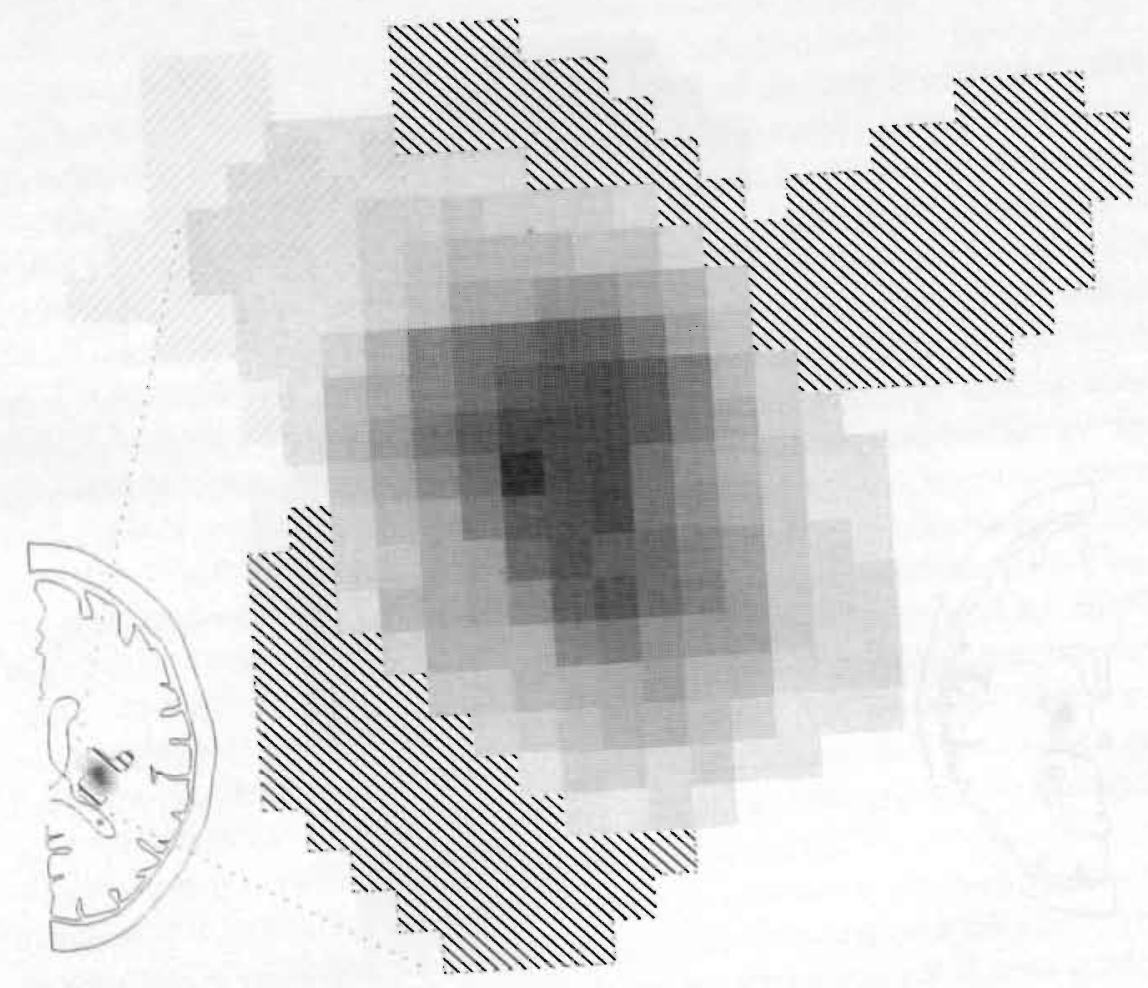

Fig. 6.3: Upper level internal capsule. 

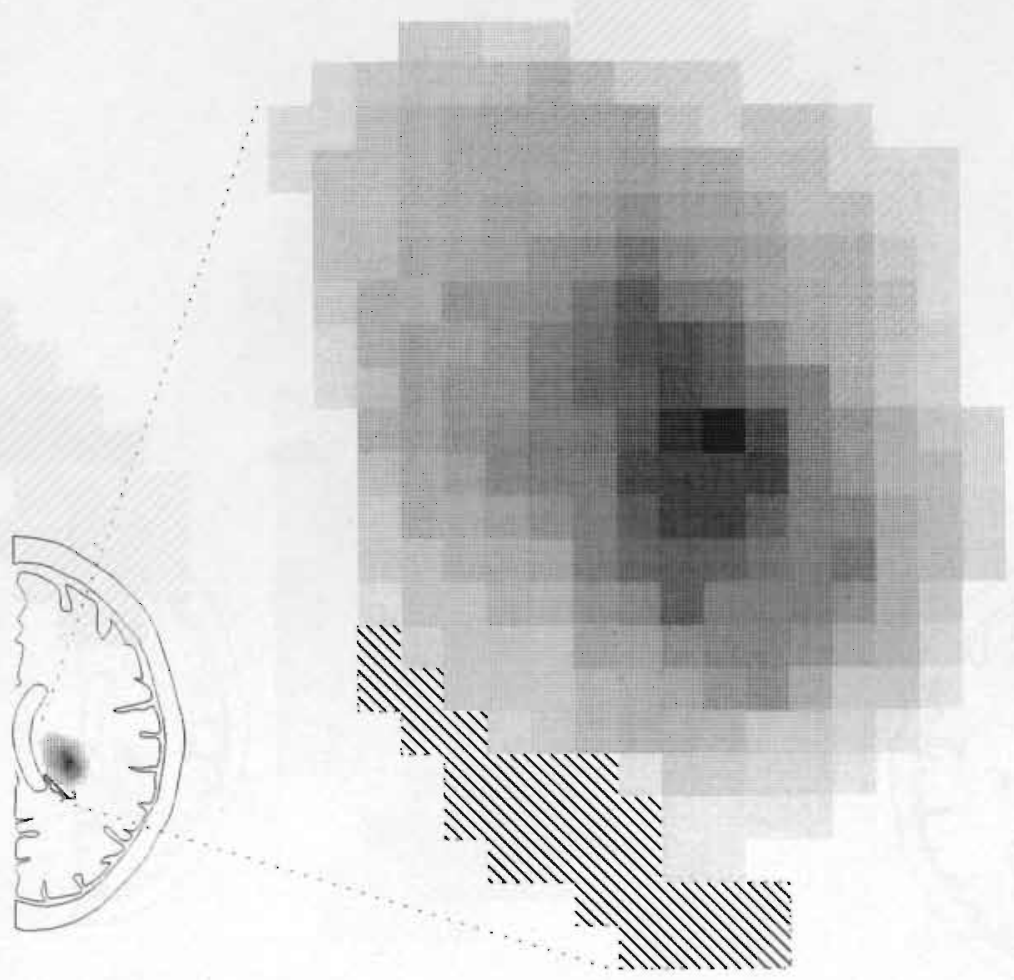

Fig. 6.4: Level of paraventricular region. 


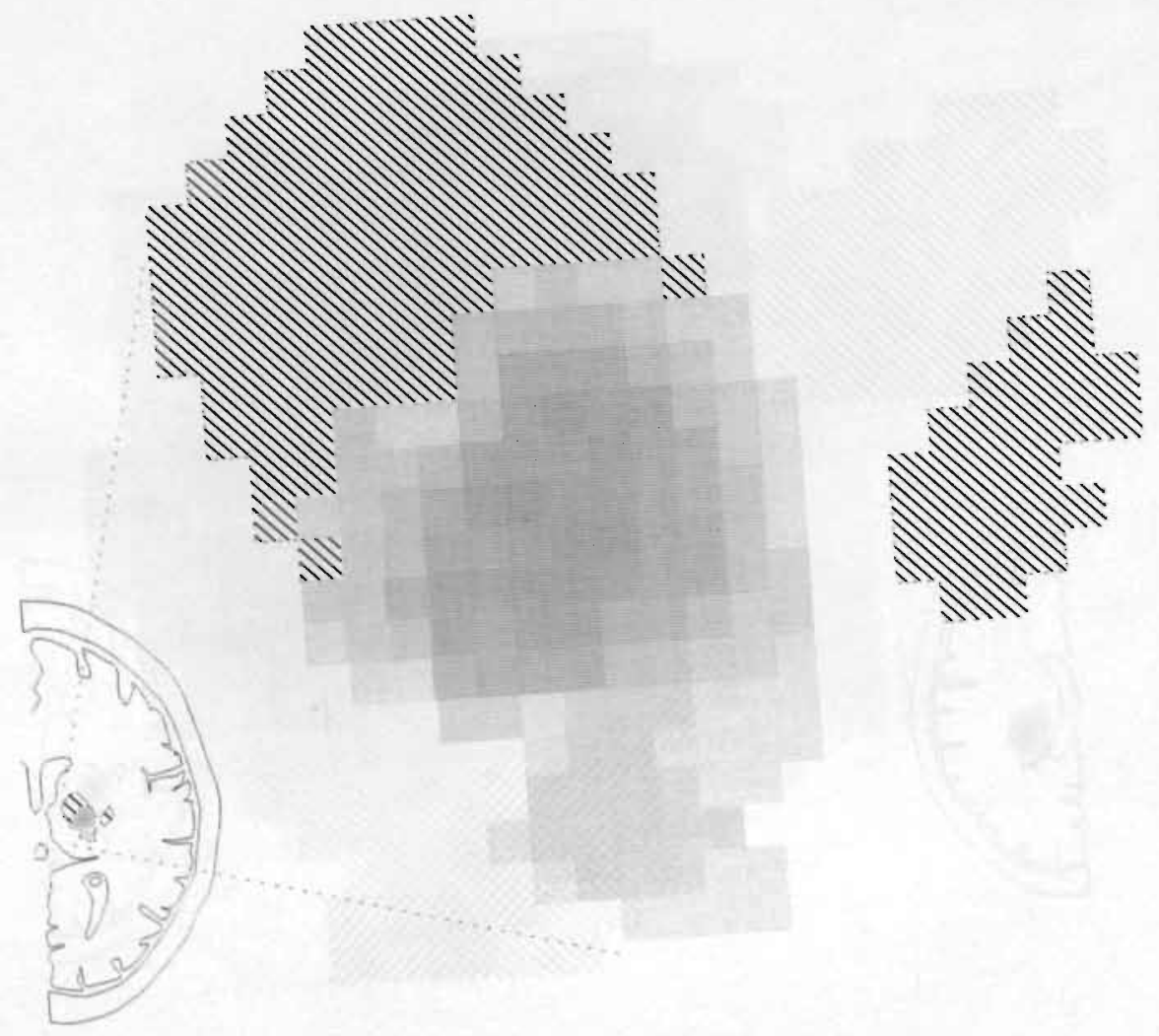

Fig. 6.5: Lower level internal capsule. 


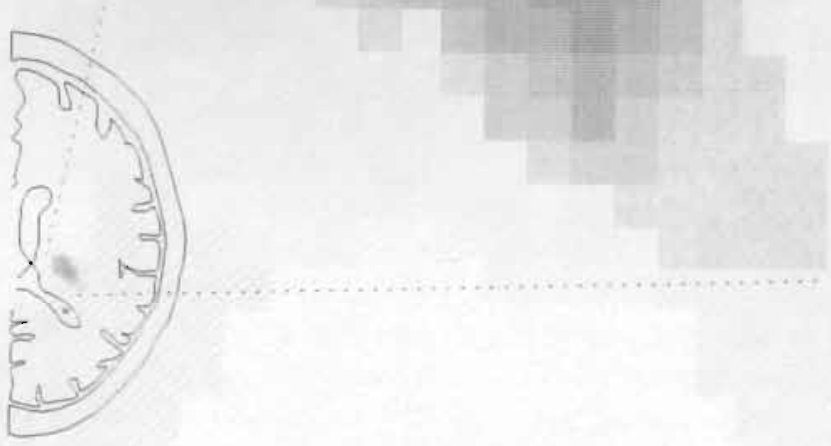

Fig. 6.6: Upper level internal capsule. 


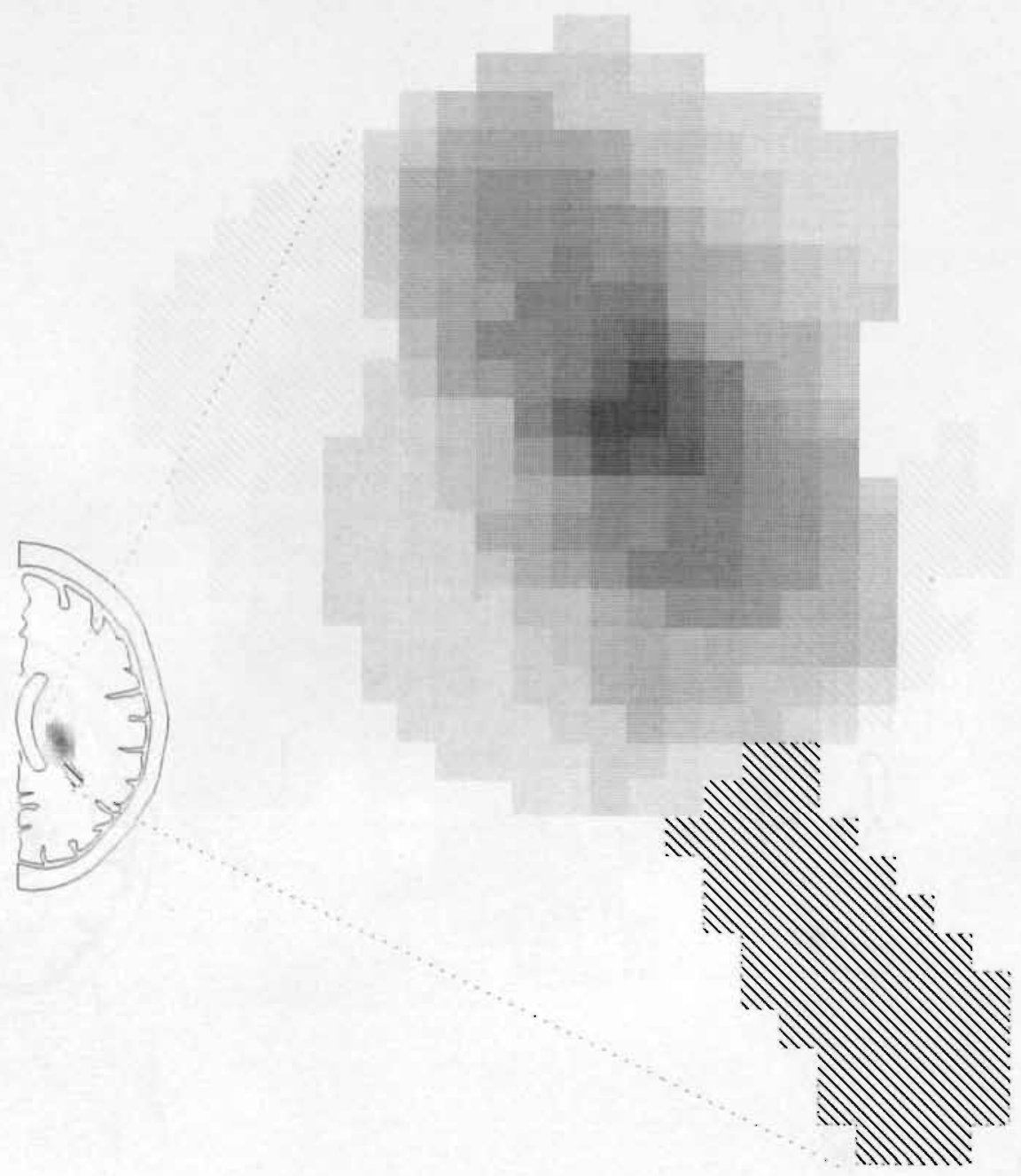

Figure 6.7: 26 AChA infarcts restricted to the posterior paraventricular region. Two infarcts were finally assigned to another vaseular territory (striated area). 

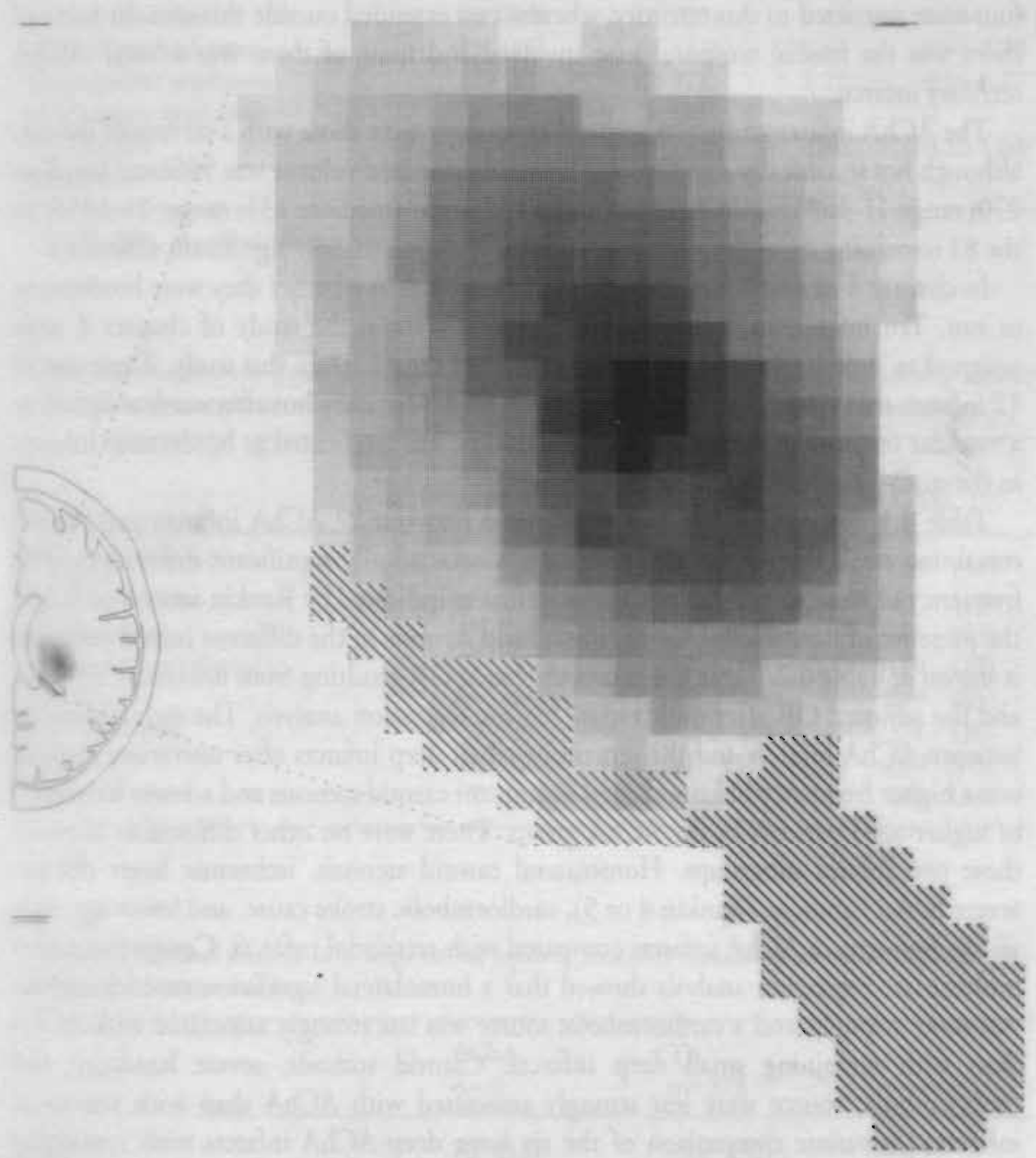

Figure 6.8: Projection diagrams of $26 \mathrm{AChA}$ infarcts restricted to the posterior paraventricular region superimposed (on translucent page, equal to figure 6.7) on diagrams of the posterior paraventricular part of 29 'definite' AChA infarcts with extension to the posterior paraventricular region (equal to figure 6.4). Projections are done to indicate the anatomical-topographical overlap of both infarct territories. 
Four of the $51 \mathrm{AChA}$ infarcts involving the posterior leg of the internal capsule extended into the lateral part of the thalamus, and 22 involved the medial part of the lentiform nucleus. Three of these 51 infarcts involved borh structures. When considering selectively the 29 AChA infarcts extending into the posterior part of the paraventricular corona radiata region, 13 of these involved the medial part of the lentiform nucleus, whereas none involved the lateral thalamus.

Our series contained 42 large deep infarcts. Six of these involved the AChA territory; four were restricted to this territory, whereas two extended outside this area. In none of them was the medial temporal lobe involved and none of them was a 'total' AChA territory infarct.

The AChA infarct group was somewhat younger than those with a territorial infarct, although not statistically significant. The mean estimated volume was $546 \mathrm{~mm}^{3}$ (median 270; range 11-3685) in AChA infarcts, and $376 \mathrm{~mm}^{3}$ (median: 135; range: 11-3456) in the 83 remaining small deep infarcts, which is not a statistically significant difference.

In chapter 4 all small deep infarcts were assessed as to whether they were borderzone or not. Ten infarcts indicared as borderzone infarcts in the study of chapter 4 were assigned as 'definite' belonging to the territory of the AChA in this study. Three out of 12 infarcts that were initially confined to the AChA territory but afterwards assigned to a vascular territory of different small penetrators, were indicated as borderzone infarcts in the study presented in chapter 4.

Table 6.1 compares the clinical syndromes between $77 \mathrm{AChA}$ infarcts and the 83 remaining small deep infarcts. There were no statistically significant differences. The frequency of vascular risk factors, major deficit as indicated by Rankin score 4 or 5 , and the presence of homolateral high grade carotid stenosis in the different infarct subtypes is shown in Table 6.2. Table 6.4 shows the crude OR resulting from univariate analysis, and the adjusted $\mathrm{OR}$ after multivariate logistic regression analysis. The only difference between AChA infarcts and the remaining small deep infarcts after univariate analysis was a higher frequency of homolateral significant carotid stenosis and a lower frequency of higher-aged patients in the AChA group. There were no other differences between these two infarct subgroups. Homolateral carotid stenosis, ischaemic heart disease, severe initial handicap (Rankin 4 or 5), cardioembolic stroke cause, and lower age were all less frequent in AChA infarcts compared with territorial infarcts. Comparison after multivariate regression analysis showed that a homolateral significant carotid stenosis was more strongly, and a cardioembolic source was less strongly associated with AChA than with remaining small deep infarcts. Carotid stenosis, severe handicap and cardioembolic source were less strongly associated with AChA than with territorial infarcts. Univariate comparison of the six large deep AChA infarcts with remaining territorial infarcts yielded no differences (see Table 6.3). Both 30-day case fatality and one-year morrality were lower in the small deep infarct group, 3/160 and 125/160 respectively, than in the territorial infarct group, 49/384 and 107/384 respectively; OR:0.13, 95\%CI: 0.05-0.38; $\mathrm{p}<0.0001$, and OR: 0.48; 95\%CI: 0.29-0.78; $<<0.003$, respectively. Table 6.5 shows the 30 -day case fatality and the one-year mortality in the three infarct subgroups. Although both small deep infarct subtypes had a more favourable outcome than $\mathrm{TI}$, one-year mortality in the AChA group was even lower than that in the remaining SDI. 
Table 6.1 Clinical syndromes in small anterior choroidal artery infarcts (AChA) compared with remaining small deep infarcts $(S D I) . O R=$ odds ratio. $C I=$ confidence interval. Percentages between brackets. $O R<1$ : less frequent in $A C h A$.

\begin{tabular}{lrllll}
\hline & AChA & $\begin{array}{l}\text { remaining } \\
\text { SDI } \\
\mathrm{n}=83\end{array}$ & $\begin{array}{l}\text { AChA } \\
\text { vs remaining } \\
\text { SDI } \\
\text { OR }\end{array}$ & $95 \% \mathrm{CI}$ \\
\hline cortical syndrome & $10(13)$ & $21(25)$ & 0.44 & $0.18-1.09$ \\
pure motor syndrome & $35(45)$ & $26(31)$ & 1.83 & $0.90-3.70$ \\
sensorimotor syndrome & $21(27)$ & $12(14)$ & 2.22 & $0.93-5.27$ \\
pure sensory syndrome & 0 & $(0)$ & $3(4)$ & & - \\
DCHS/AH & $11(14)$ & $18(22)$ & 0.60 & $0.22-1.61$ \\
unknown & 0 & $(0)$ & $3(4)$ & & - \\
\hline
\end{tabular}

$D C H S / A H=$ dysarthria clumsy hand syndromelataxic hemiparesis

Table 6.2 Frequency of different features in 77 AChA infarcts and 83 remaining small deep infarcts (SDI) in other vascular territories, and 384 territorial infarcts (TI). Percentages between brackets.

\begin{tabular}{|c|c|c|c|c|c|c|c|}
\hline \multirow[b]{2}{*}{ male } & \multicolumn{2}{|c|}{$\begin{array}{l}\text { AchA } \\
n=77\end{array}$} & \multicolumn{2}{|c|}{$\begin{array}{l}\text { SDI } \\
\mathrm{n}=83\end{array}$} & & \multicolumn{2}{|c|}{$\begin{array}{l}\text { TI } \\
\mathrm{n}=384\end{array}$} \\
\hline & & (60) & 46 & (55) & & 198 & (52) \\
\hline diabetes mellitus & & (17) & 13 & (16) & & 61 & (16) \\
\hline hypertension & 37 & (48) & 35 & (42) & 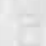 & 166 & (43) \\
\hline ischaemic heart disease & 13 & (17) & 12 & (14) & & 110 & (29) \\
\hline carotid test & 65 & (84) & 58 & (70) & & 249 & (65) \\
\hline carotid stenosis & 9 & (12) & 2 & (3) & & 74 & (30) \\
\hline Rankin 4/5 & 24 & (31) & 31 & (37) & & 240 & (63) \\
\hline cardioembolic & 7 & (9) & 16 & (19) & & 132 & (34) \\
\hline
\end{tabular}

Table 6.3 Clinical features in 6 Large AChA infarts and 378 remaining territorial infarcts (TT). Percentages between brackets.

\begin{tabular}{|c|c|c|c|}
\hline & $\begin{array}{l}\text { AChA } \\
n=6\end{array}$ & $\begin{array}{l}\text { TI } \\
\mathrm{n}=378\end{array}$ & p-value \\
\hline male & $2 \quad(33)$ & $196 \quad(52)$ & 0.43 \\
\hline diabetes mellitus & 1 (17) & $60 \quad(16)$ & 1.00 \\
\hline hypertension & $4 \quad(66)$ & 162 & 0.41 \\
\hline ischaemic heart disease & $1 \quad$ (17) & $109 \quad(29)$ & 0.68 \\
\hline carorid rest & $6(100)$ & $243(64)$ & 0.09 \\
\hline carotid stenosis & 1 (17) & $73 \quad(30)$ & 0.67 \\
\hline Rankin 4/5 & (66) & $236 \quad(62)$ & 1.00 \\
\hline cardiac embolism & (33) & $130(34)$ & 1.00 \\
\hline
\end{tabular}

${ }^{*}$ Fisher exact test 


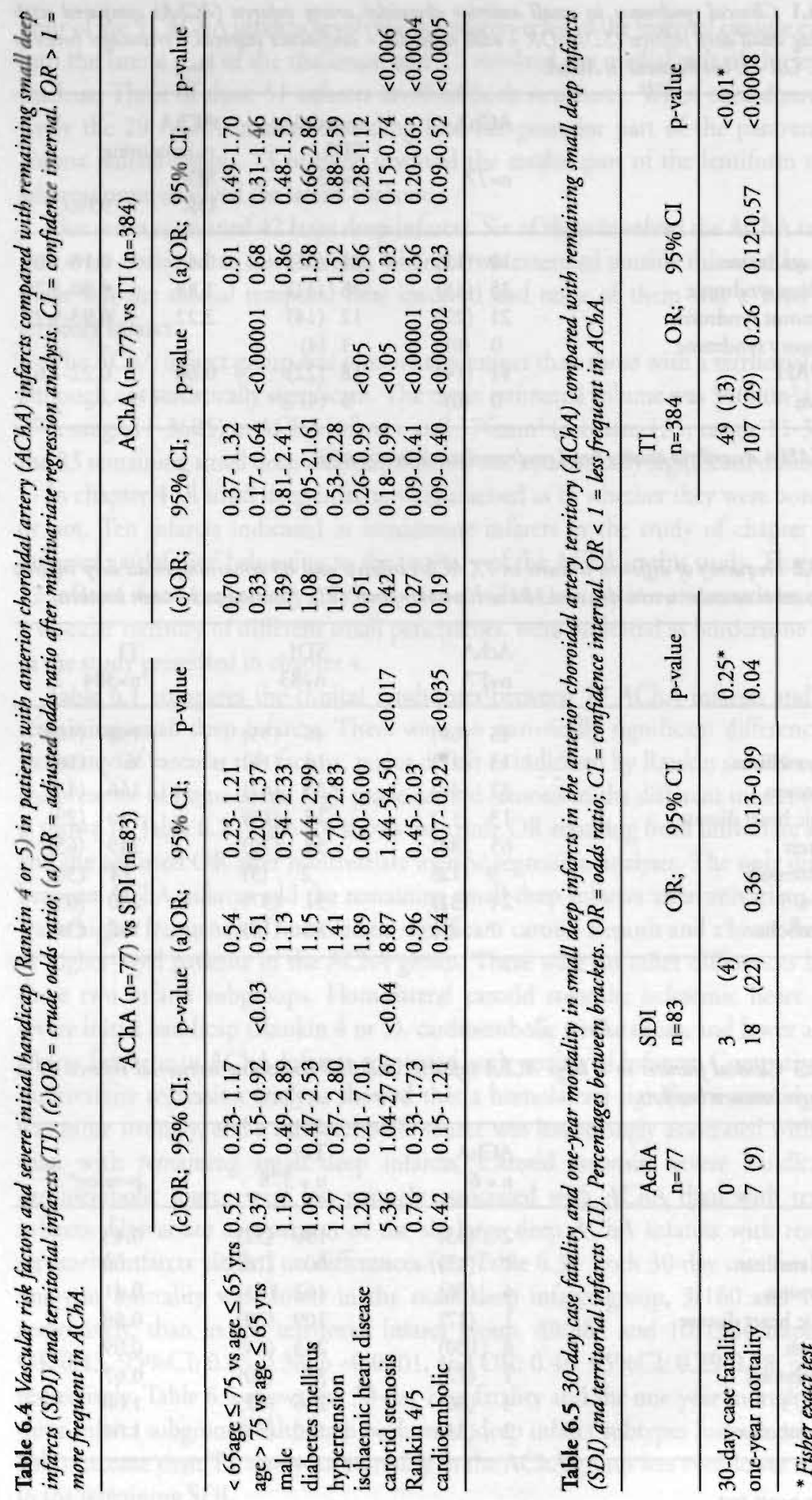




\section{DISCUSSION}

The most consistent supply area of the AChA contains the optic tract, posterior limb of the internal capsule, cerebral peduncle and choroid plexus, although the exact AChA territory may show large variations. $1,2,13,39,75,124,125$. In our 755 consecutive patients with a brain infarct due to atherosclerotic thromboembolism or cardiac embolism, $42 \mathrm{had} \mathrm{a}$ large deep ( $>20 \mathrm{~mm}$ diameter) infarct on CT. Only six of these involved, or were restricted to, the AChA territory, but none of them was a complete AChA territory infarct, whereas the medial temporal lobe was not involved in any of them. Although several anatomical studies described the medial part of the temporal lobe as AChA territory ${ }^{1,62,130}$, it is infrequently mentioned in clinical studies on brain infarcts. ${ }^{107}$ The frequent occurrence of anastomosis between the $\mathrm{AChA}$ and the posterior communicating, posterior cerebral, or posterior choroidal artery may explain this. $2,13,14,39,126$

There were 77 small deep AChA infarcts, which is 10 per cent of the 755 consecutive patients, and 48 per cent of all small deep infarcts verified by CT. Sterbini et al. found 28 patients with a CT confirmed infarct in the AChA territory, which was 2.9 per cent of all hospitalized infarct patients in the same period. ${ }^{145}$ In 100 consecutive patients with a deeply located infarct in the Lausanne stroke registry Ghika et al. found 23 infarcts in the AChA territory. ${ }^{65}$ Most AChA infarcts were small, whereas larger-sized or total AChA infarcts were rare. $42,65,74,75,107,145$ We aimed to analyse the most prevalent $\mathrm{AChA}$ infarct type which, obviously, is that of small size. Before characterizing such AChA infarcts, the territory supplied by the AChA should be defined. Most authors agree that the posterior two-thirds and the retrolenticular part of the posterior leg of the internal capsule is supplied by the AChA. 2,13,28,42,75,107,124,125,137,145 However, in clinical studies the lateral thalamus, the medial part of the lentiform nucleus, and especially the posterior paraventricular corona radiata region are in dispute. ${ }^{20,71,75,107,119,145}$ From autopsy cases, pathological injection studies and their own clinical series Mohr ${ }^{107}$ opposed the view of Helgason ${ }^{76}$ who, as others, found extension of AChA infarcts into the posterior corona radiata region. ${ }^{42,71,75,76}$ In several autopsy studies the posterior paraventricular region is considered as AChA territory. ${ }^{1,13,39}$ By merely using the currently often employed vascular templates of Damasio ${ }^{41}$, no conclusions can be drawn as to which vessel supplies this region, because the templates did not derive from actually studied series. ${ }^{41,107}$ Several factors may complicate an exact topographical description of the AChA territory, and that of the vascular supply of the paraventricular region in particular. Beevor and Abbie found in their autopsy studies a wide inter-individual variability in the supply area of the AChA. ${ }^{1,2,13,14}$.This variability may depend on differences in function of collateral circulation through anastomosal vessels. 2,13,39,126,152 In addition, the vascular supply area of the small penetrators may generally show large variation..$^{56-58}$ The same holds true with regard to the exact vascular supply of the periventricular white matter, which makes it hazardous to indicate the demarcation between these two different vascular supply areas in an individual case. ${ }^{15,18,45,101}$

We hypothesized that if 'definite' AChA infarcts, that are mainly located in the posterior leg of the internal capsule, extend upwards into the paraventricular corona radiata region, this region is likely being supplied by the AChA. Twenty-nine of our 51 'definite' AChA infarcts showed such an upward extension. It is unlikely that the lower 
part of these infarcts resulted from $\mathrm{AChA}$ obstruction, whereas the infarct in the upper part was simultaneously caused by obstruction of a separate vessel in another vascular territory. Nor only would a simultaneous obstruction in two separate vascular territories producing adjacent small infarcts be unlikely, but, moreover, the small size of our infarcts may suggest obstruction of a single, small perforating artery. ${ }^{10}$ The angle at which CT slices were made, unlikely produced a topographical artefact. Furthermore, our composite topographical projection figure of the upwardly extending AChA infarcts overlaps with that of infarcts located exclusively in the posterior paraventricular area (see Figure 6.8). This finding also argues in favour of the AChA as supplying vessel for this area. Because small deep infarcts frequently occur in the paraventricular corona radiata region, this region is in any case likely being supplied by small deep penetrators. ${ }^{15.26 .45 .62 .130}$ Thus, as an alternative for the AChA the lenticulostriate arteries would be the next most likely supplying vessels for this area. However, only one of the infarcts located in the lenticulostriate territory at the level of the internal capsule/basal ganglia in our series that extended upwards was continuous with the posterior part of this region, whereas seven extended into the anterior part. Therefore, one of our main conclusions is that small infarcts in the posterior paraventricular corona radiara region are most likely AChA territory infarcts. Some $(n=10)$ of the infarcts that were finally considered as AChA infarcts, and some $(n=3)$ of the infarcts initially confined to the AChA territory but after topographical analysis confined to another vascular territory, had been assigned as borderzone infarcts in chapter 4 . These infarcts may be similar to the 'lacunas' as described by De Reuck, located in a 'periventricular arterial borderzone' (see chapter 2) between vessels originating from the lenticulostriate or choroidal arteries and the medullary branches of the major cerebral arteries. ${ }^{45,46}$ No injection study of the originating arteries in the territories of the lacunas has been performed so far, so that the question as to whether those lacunas belong to one or more (borderzone) vascular territories remains unanswered. Moreover, in our topographical analysis of the AChA infarcts there were ten 'definite' AChA infarcts that in chapter 4 were considered to be located in the deep borderzone. Eight of these were located in the posterior paraventricular region which is 31 per cent of all infarcts in that region. The finding of a high percentage of borderzone infarcts in an infarct group which was topographically indicated as 'definite' AChA territory infarcts may indicate that infarcts regarded on CT to be 'borderzone' infarcts are in fact infarcts in a territory of one end-artery. Also the size of such infarcts is compatible with the notion that such infarcts can be considered to be caused by the occlusion of a single perforator.

A less controversial point is whether the lateral thalamic border and the medial part of the lentiform nucleus are supplied by the AChA. Our finding that four of the 51 'definite' AChA infarcts with the largest part of the infarct in the posterior leg of the internal capsule involved the lateral thalamic border concurs with Mohr et al. who concluded that superficial involvement of the lateral thalamus may occur. ${ }^{107}$ In a pathological analysis of the AChA in 50 hemispheres Fujii et al. described involvement of the thalamus in 10 per cent. ${ }^{62}$ Others showed similar findings. ${ }^{76,119,130}$ Such thalamic involvement might merely be due to surrounding oedema rather than ischaemic necrosis caused by obstruction of presumed AChA thalamic branches. Another region more consistently involved in AChA infarcts is the medial part of the lentiform nucleus: 
12 of the 16 cases in Mohr's series and 6 of 23 in the series of Helgason. ${ }^{76.107}$ Both these authors concluded from the available literature that the medial part of the lentiform nucleus is regularly supplied by the AChA. This concurs with our findings: $22(42 \%)$ of the 51 'definite' AChA infarcts involved the medial part of the lentiform nucleus.

Afrer we identified which infarcts should be considered as AChA territory infarcts, different clinical features were studied and compared with different subtypes of nonAChA infarcts to see whether AChA infarcts constitute a separate clinical entity. The clinical syndrome of AChA infarcts has frequently been described. ${ }^{18,24,35,36,42,73,75.83,399,107}$ Our patients were distinguished not only by a characteristic CT lesion but 87 per cent had one of the lacunar syndromes. We found no clear differences in clinical syndromes between the $77 \mathrm{AChA}$ infarcts and the 83 remaining small deep infarcts, nor berween the 51 'definite' and the remaining $26 \mathrm{AChA}$ infarcts. Only three of the $10 \mathrm{AChA}$ infarct patients with a corrical syndrome had hemianopia, a symptom frequently present in larger AChA infarcts. ${ }^{18,75,107}$ There could be two reasons for this low figure: firstly, most infarcts in our series were small and largely located in the posterior two-thirds of the posterior internal capsule thus sparing the optic radiation; secondly, the optic tract and lateral geniculate body may receive anastomoses from the posterior choroidal artery, the posterior communicating artery, and leptomeningeal arteries. ${ }^{13,126,152,166,167}$ This could also explain why in AChA infarcts visual field disturbances are often transient. In any case, the absence of hemianopia should not argue against AChA territory location of an infarct. Some authors consider the presence of ataxic symptoms not compatible with AChA territory lesions. Ataxic symptoms could be due to the incorrect inclusion of patients with corona radiata lesions, as was suggested by Mohr and described by others in case reports. ${ }^{73.83 .107}$ However, in most patients with ataxic symptoms in an earlier study the lesion was located in the posterior internal capsule. ${ }^{27}$ We found no differences in the frequency of ataxic symptoms between the AChA infarcts that were restricted to the posterior part of the internal capsule ('definite' $\mathrm{AChA}$ territory) and those restricted to the posterior corona radiata region. Fourteen per cent of our AChA infarcts had ataxic symptoms, either dysarthria clumsy hand syndrome or ataxic hemiparesis, a finding similar to 13 per cent of the series of Ghika ${ }^{65}$ Helgason described in a selected series, 23 patients with hypaesthesic ataxic hemiparesis of which 22 had a lacunar infarct in the contralateral internal capsule. Fifteen of these infarcts extended into the superior paraventricular region. ${ }^{76}$ In our series, none of the 29 infarcts that were located in the posterior internal capsule and extended upwards, had ataxic symptoms. This contradicts the view of Mohr that ataxic symptoms are found more frequently if corona radiata lesions are included. Only five of the 26 infarcts that were confined to the paraventricular region produced ataxic symptoms. Obviously, ataxic symptoms are just as common among small AChA infarcts as in small deep infarcts in general. All in all we found no characteristic clinical features which discriminate $A C h A$ infarcts from other small deep infarcts.

The underlying cause of small deep AChA infarcts is not fully clarified. Mohr suggested that including posterior corona radiata infarct cases would result in a 'disproportionate increase in the frequency of typical small vessel disease'. However, most symptomatic 
small deep infarcts are not located in this area whereas the size of an infarct does not necessarily imply a certain vascular pathology. Sterbini ${ }^{145}$ found 41 per cent with hypertension, 26 per cent with diabetes mellitus and 30 per cent with a possible cardiac or carotid embolic source in 28 AChA cases with varying infarct size. Six of 16 cases described by Decroix ${ }^{42}$ had either a cardiac or carotid embolic cause. Bruno ${ }^{34}$ found 65 per cent with hypertension, 33 per cent with diabetes mellitus, and only six per cent with a cardioembolic source in $31 \mathrm{AChA}$ infarcts. All cases had carotid studies of which 27 were normal. Out of 16 patients who had angiography, 15 showed a patent AChA. The authors concluded that 'small-vessel disease' was the most frequent underlying vasculopathy with hypertension as a single most important risk factor. A similar conclusion was drawn by Helgason who also included diabetes mellitus as an important risk factor. ${ }^{76}$ Ghika found small artery disease the most likely cause in 42 per cent of 32 AChA patients, whereas 27 per cent had possible embolism from a carotid source, and 17 per cent from a cardiac source. ${ }^{65}$ The heterogeneiry of the series studied so far make general conclusions regarding the cause of AChA infarcts difficult, whereas comparison of AChA patients with other infarct subtypes has not been performed. We found a high percentage with hypertension, but this did not differ from remaining small deep or territorial infarcts. Probably, hypertension can be regarded as a non-specific risk factor for this type of infarct as it is for small deep infarcts in general. 27.95.96 The selection of only CT positive cases, which was one of the inclusion criteria in the study, is unlikely to have created a bias in this respect. Comparison with the territorial infarct group suggests that cardiac and carotid embolism are unlikely causes of AChA infarcts. Therefore, the cause of small-size AChA infarction is most likely small vessel obstruction as it is in most small deep - often called 'lacunar' - infarcts in general. ${ }^{27,95}$ However, carotid embolism may be a more frequent stroke cause in AChA than in other small deep infarcts as our data suggest. We do not consider the higher frequency of carotid stenosis to indicate a lowflow state in the AChA, and in the medullary branches of the major cerebral arterial territories, thus provoking deep 'borderzone' infarction. Therefore, angiography and eventual carotid surgery should not a priori be denied in this infarct subgroup. The larger AChA infarcts resembled territorial infarcts regarding vascular risk factors and potential underlying stroke cause. This suggests that most of such infarcts are caused by large artery thromboembolism or cardiac embolism similar to large deep, or so-called striatocapsular infarcts, and similar to territorial infarcts as we and others have found. ${ }^{29,155,157}$

Our final study aim was to see whether stroke outcome in AChA infarcts in terms of 30day case fatality and one-year mortality would differ from that in other infarct subgroups. Our present data concur with our earlier finding ${ }^{30}$ : small deep infarcts had a lower 30-day case fatality and a lower one-year mortality than territorial infarcts. However, figures were even more favourable in the AChA infarcts than in the remaining small deep infarcts, a difference that probably relates to the younger age of the AChA patients. Because of low numbers multivariate analysis could not be pursued. Furthermore, random variation related to small numbers may also have played a role.

Therefore, our second main conclusion is that neither clinical symptoms, vascular risk factor profile, presumed underlying cause, nor stroke outcome in terms of 30-day 
case fatality and one-year mortality lend support to the idea that small deep infarcts in the AChA territory should be considered as a clinical entity separate from other small deep infarcts. Consequently, small deep AChA infarcts are nor different from small deep borderzone infarcts (see chapter 4 ). We reached similar conclusions with regard to large AChA infarcts, although the numbers in this group were small. Consequently, the small and larger infarcts in the territory of the AChA should be investigated and treated as similar infarct subtypes in general. 


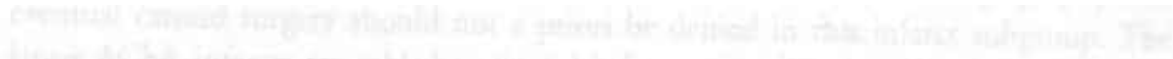

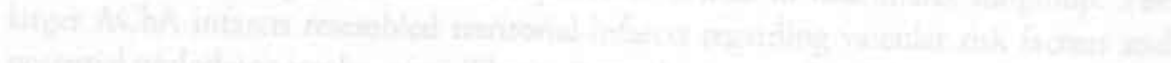

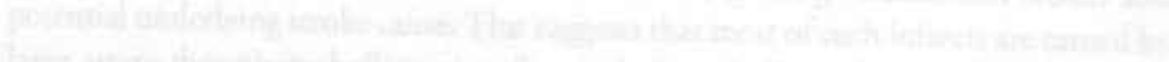

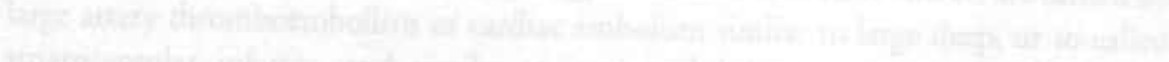

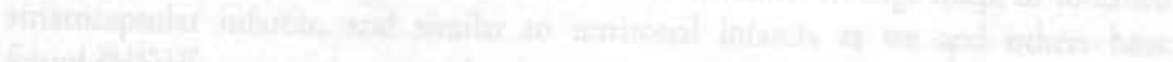
and

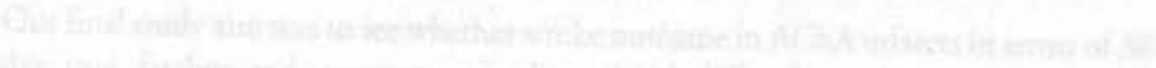

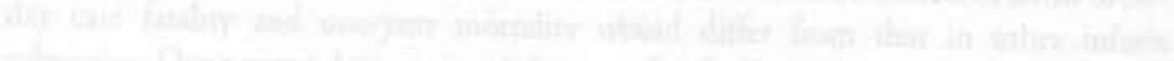

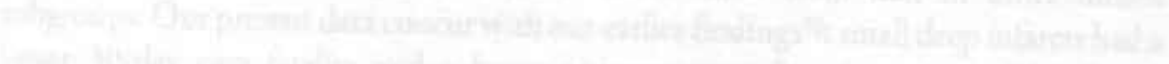
The -

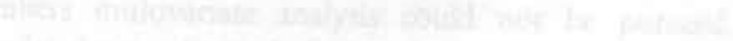
ㄴ.

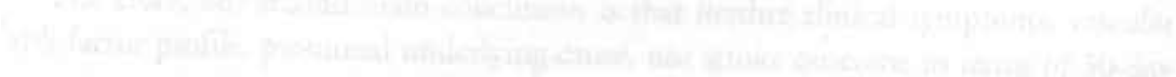




\section{CHAPTER 7}

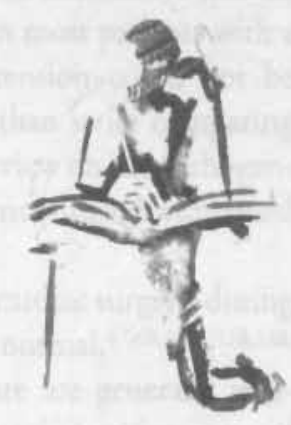

Borderzone brain infarcts following cardiac surgery and their relationship to cerebral haemodynamic compromise

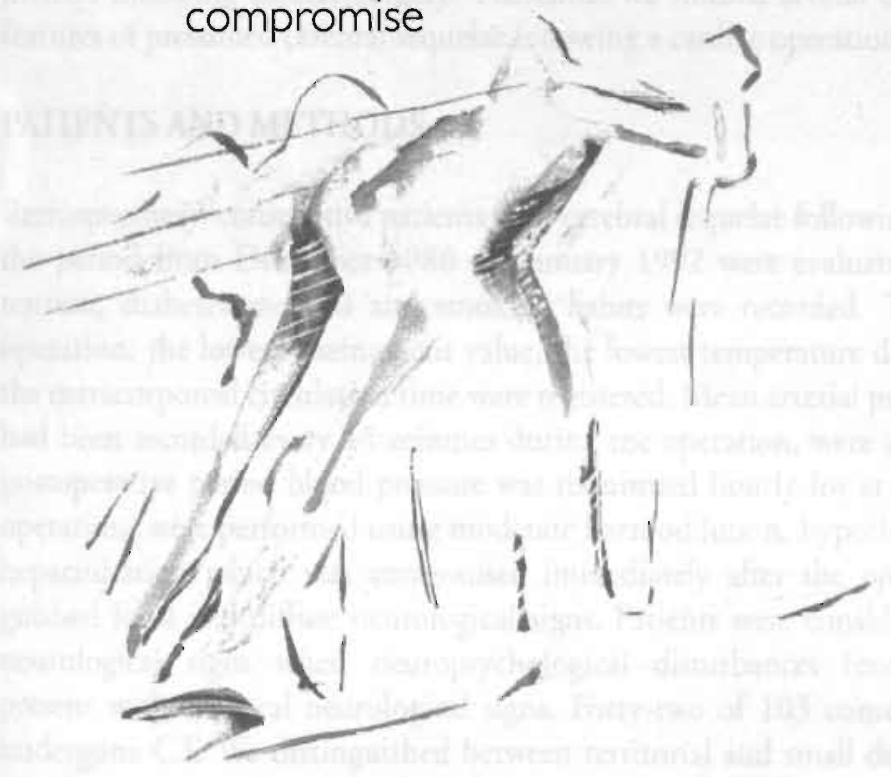




\section{T93T9AHJ}

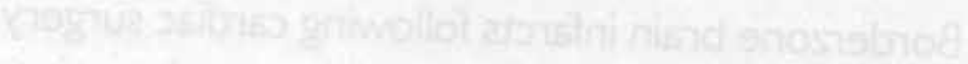

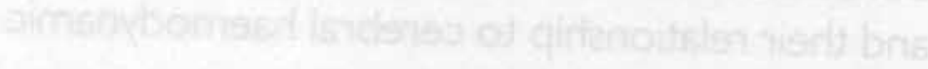

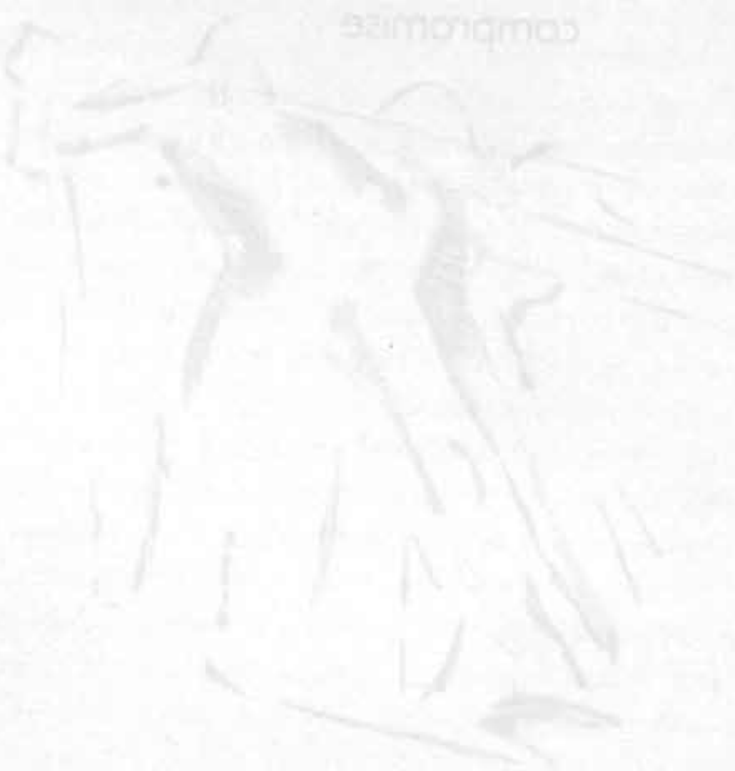




\section{INTRODUCTION}

The exact cause of brain infarcts located in vascular borderzones is largely unknown (see chapter 2). Hypoperfusion, preferentially in the presence of carotid obstructive lesions, is generally held to be a major cause. $3,22,44,84,133,150,162$ However, in most patients with a lesion in the vascular borderzone on $\mathrm{CT}$, a period of hypotension could not be documented (see chapter 4).22,26,82,142,154,156 Case studies rather than series comparing borderzone with non-borderzone infarct cases sustain the current view on the pathogenesis of this infarct subtype. ${ }^{82,135}$ In chapter 4 and 5 only one patient with a documented period of hypotension prior to the stroke was found.

Brain infarction may occur as a peri-operative complication of cardiac surgery, during

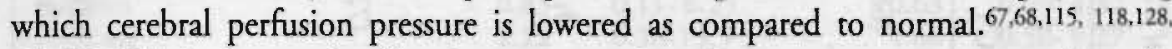
139,143,144,151 Peri-operative blood pressure and perfusion pressure are generally welldocumented. We hypothesized that if hypotension/hypoperfusion is a major cause of borderzone brain infarcts, infarcts following cardiac surgery would be most likely to be locared in the vascular borderzones, and furthermore, that blood pressure values and perfusion parameters among such cases would be lower than in those with territorial infarcts following cardiac surgery. Therefore, we studied several clinical and CT scan features of presumed cerebral sequelae following a cardiac operation.

\section{PATIENTS AND METHODS}

Retrospectively, consecutive patients with cerebral sequelae following cardiac surgery in the period from December 1986 till January 1992 were evaluated. Age, sex, hypertension, diabetes mellitus and smoking habits were recorded. The type of cardiac operation, the lowest haematocrit value, the lowest temperature during operation and the extracorporeal circulation time were registered. Mean arterial pressure values, which had been recorded every 15 minutes during the operation, were also analysed. In the postoperative period blood pressure was monitored hourly for at least three days. All operations were performed using moderate haemodilution, hypothermia, and systemic heparinisation which was antagonised immediately after the operation. We distinguished focal and diffuse neurological signs. Patients were considered to have diffuse neurological signs when neuropsychological disturbances (encephalopathy) were present without focal neurological signs. Forty-two of 103 consecutive patients had undergone CT. We distinguished between territorial and small deep borderzone, and non-borderzone infarcts. Borderzone infarcts were defined according to the criteria of chapter 4. Surgical data were incomplete in three patients, whereas in two CT was missing, leaving 37 patients in whom $\mathrm{CT}$ and clinical findings could be correlated. Differences were analysed using odds ratios (OR) with $95 \%$ confidence interval $(95 \%$ $\mathrm{CI})$ and Yates' corrected chi-square $\left(\chi^{2}\right) .{ }^{138}$

\section{RESULTS}

There were 23 males and 14 females, with a median age of 68 (range 32-83) years. The mean CT delay was 5 (range 1-44) days following cardiac surgery. Sixteen patients had 
I) Table 7.1 Different features in patients with a borderzone infarct (group I), a non-borderzone infarct (group II) and with normal CT (group III). Between brackets: median and range.

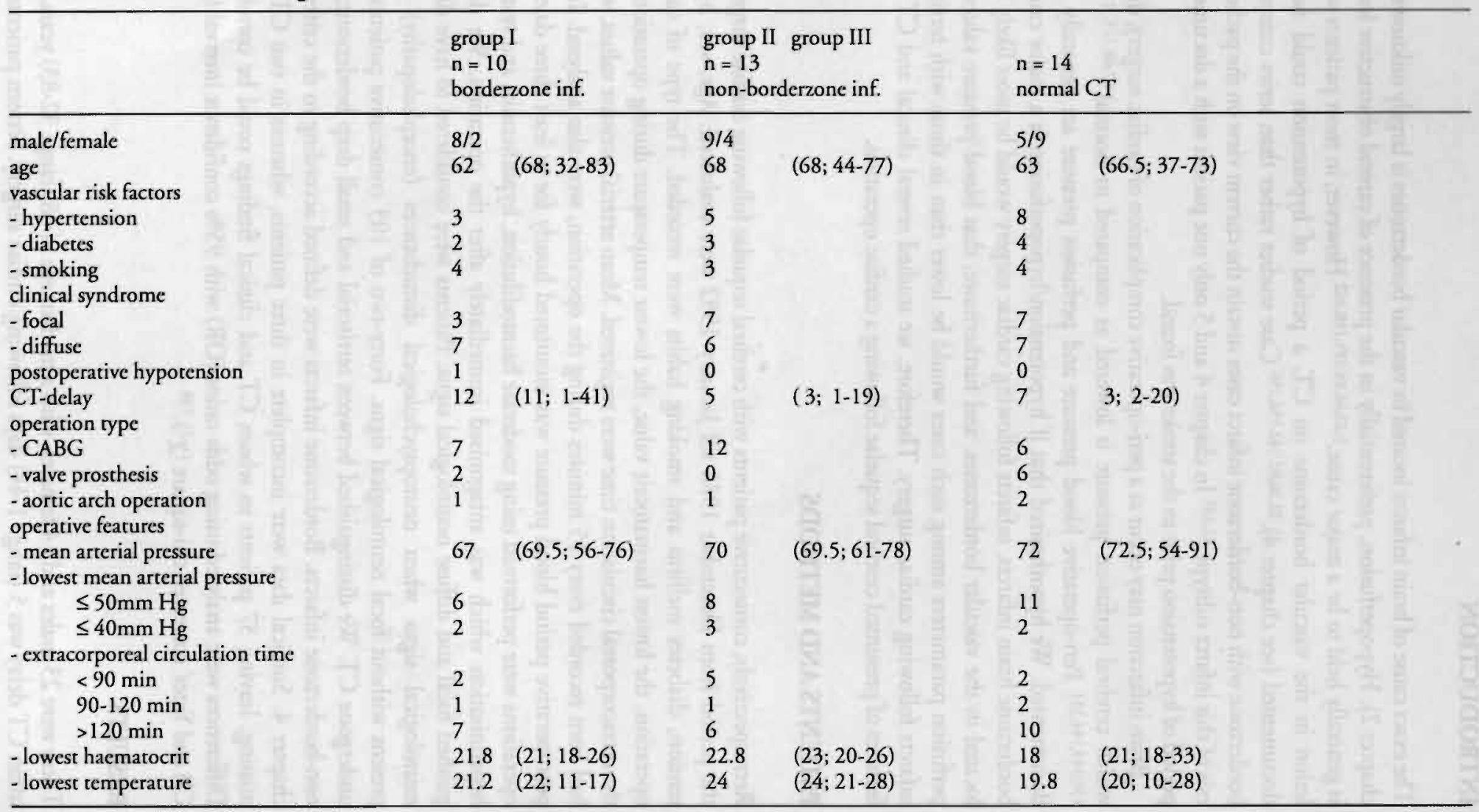


Table 7.2 Comparison of different features between borderzone infarcts, non-borderzone infarts, and cases with normal $C T$, by means of odds ratios with $95 \%$ confidence interval (CI).

borderzone infarcts

$\mathrm{n}=10$

compared with

\begin{tabular}{ll}
\hline non-borderzone infarcts & normal CI \\
$\mathrm{n}=13$ & $\mathrm{n}=14$ \\
OR;95\% CI & OR;95\% CI
\end{tabular}

vascular risk facrors

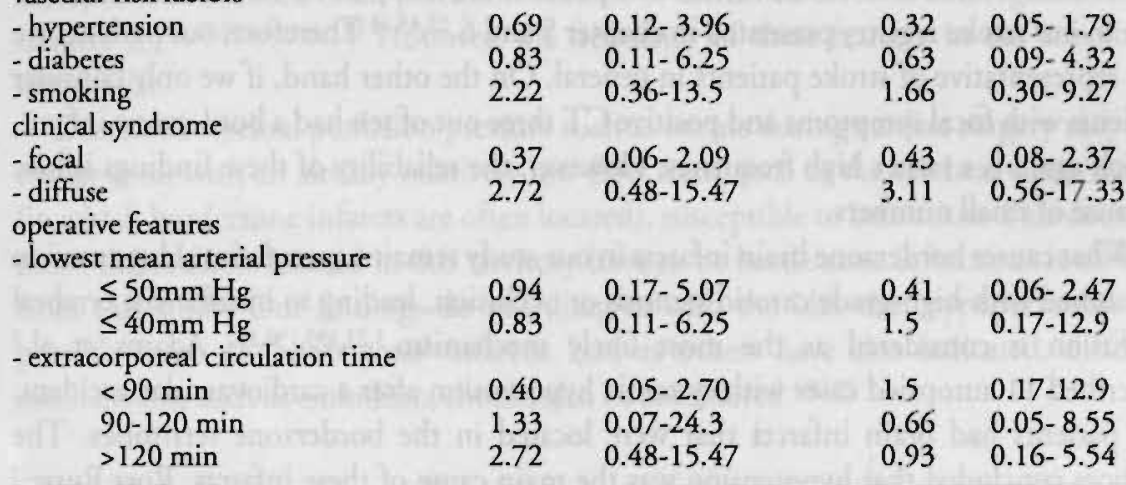

hypertension, and 9 diabetes mellitus. In 17 patients focal neurological signs were detected and 20 patients had signs pointing to diffuse cerebral dysfunction. CT was normal in 14 patients (38\%) and showed infarction in $23(62 \%)$. Ten of these (27\%) infarcts were located in one of the vascular borderzone areas: 6 territorial, 2 deep, and 2 both territorial and deep. Thirteen patients had a non-borderzone infarct, 10 of which were territorial and 3 were small deep infarcts. Table 7.1 shows the different features in patients with a borderzone infarct, those with a non-borderzone infarct, and those with normal CT. Because of the low numbers the territorial and deeply located borderzone infarcts were analysed as one group in comparison with the remaining infarcts with abnormal and those with normal CT respectively. Comparison between groups by means of odds ratios is shown in Table 7.2. Because no differences between the three groups were detected, we did not expect comparison between groups by multivariate analysis to reveal any significant differences.

\section{DISCUSSION}

Five of the 42 patients who underwent $\mathrm{CT}$, in our retrospective study could not be evaluated because of incomplete data. Because the reasons for this were not obviously related to the features under study (in three cases CABG was performed elsewhere for logistic reasons, whereas $\mathrm{CT}$ was missing in the remaining two), this omission is unlikely to have produced a significant bias. Our conclusions cannot be generalized to all patients with neurological sequelae following cardiac surgery, because the large majority of operated patients in our series did not undergo CT. Many patients could not undergo 
$\mathrm{CT}$ in the early postoperative phase because they were attached to a respirator and several types of monitoring, some of which were invasive. Some could not undergo CT because of a poor cardiovascular condition. This is probably the reason that others have also reported a relatively low number of patients with $\mathrm{CT}^{82,134,135}$

Among 37 parients we found ten with a borderzone infarct, which is $27 \%$. In stroke series approximately $10 \%$ of patients have an infarct located in one of the vascular borderzones (see chapter 4). ${ }^{26,84,150,162}$ Our findings may suggest that an infarct following cardiac surgery is more likely to be a borderzone infarct. However, our study also included patients with clinically findings indicating an ischaemic encephalopathy rather than a stroke. In stroke series such patients are likely to be excluded, as was the case in our stroke registry presented in chapter 5 and 6.22,43.48 Therefore, our patients are not representative of stroke patients in general. On the other hand, if we only consider patients with focal symptoms and positive CT three out of ten had a borderzone infarct, which again is a rather high frequency. However, the reliability of these findings is low, because of small numbers.

What causes borderzone brain infarcts in our study remains specularive. Hyporension combined with high-grade carotid stenosis or occlusion, leading to insufficient cerebral perfusion is considered as the most likely mechanism. 3.22,133,150,162 Adams et al. ${ }^{3}$ described 11 autopsied cases with systemic hypotension after a cardiovascular accident. Six patients had brain infarcts that were located in the borderzone territories. The authors concluded that hypotension was the main cause of these infarcts. Ross Russell and Bharucha ${ }^{135}$ described four patients with bilateral borderzone infarction following cardiovascular surgery. As judged from their CT images, some of the infarcts may well fit the criteria for territorial borderzone infarcts. They suggested generalized cerebral hypotension combined with suspected carotid obstructive lesions as likely causes, but carotid lesions were not substantiated. They also mentioned hypocapnia-induced vasoconstriction, or lowered perfusion pressure from raised intracranial pressure by venous obstruction during operation as contributing factors, whereas embolism was considered unlikely. Malone et al. ${ }^{77}$ reported nine selected cases who had died following cardiac surgery and who had infarcts in the vascular borderzone area. The authors presumed that cerebral hypoperfusion was the most likely infarct cause. Howard et al. ${ }^{82}$ described four patients with borderzone infarcts on CT after cardiac surgery, three of which were bilateral. Also in this study, the CT morphology of some of the infarcts seemed to resemble non-borderzone territorial infarcts. All patients had sustained a period of documented hypotension, and were probably selected for that reason. These studies on selected cases with borderzone infarcts suggest that lowered cerebral perfusion pressure can cause cerebral ischaemia in the vascular borderzone areas. This does not necessarily imply that hypotension is a major cause of such infarcts, because hypotension was not documented in most borderzone infarct cases in other studies (see chapter 4). ${ }^{22,48}$ Furthermore, not all brain infarcts following cardiac surgery are located in one of the borderzone areas, as our results illustrate. Others also described territorial infarcts following cardiac surgery, and other mechanisms, such as embolism, have been suggested. ${ }^{68,109}$ Although our data suggest that the frequency of borderzone infarcts may be higher following cardiac surgery than in stroke series, we found no indication to suggest that the cerebral perfusion had been less optimal in these patients than in those 
who had a territorial infarct, or no infarct on CT. Registered periods of hypotension, the (lowest) mean arterial pressure, lowest haematocrit, and extracorporeal circulation time were similar in all the subgroups. Therefore, peri-operative haemodynamic compromise alone does not explain the occurrence of borderzone infarction. The groups might have differed with regard to the presence of carotid lesions, but, unfortunately these were not documented. However, in neurological asymptomatic patients undergoing cardiac surgery a carotid stenosis does not increase the risk of brain infarction and is therefore unlikely to be associated with a certain brain infarct subtype in these patients. ${ }^{63,64.72}$ Patients with diabetes mellitus, COPD, or those with hypertension may be more susceptible to reduced brain perfusion because of disturbed cerebral autoregulation (see chapter 2). ${ }^{22,47,87,117,146,159}$ However, the frequency of these features in our subgroups was similar.

Decreased cerebral perfusion pressure such as occurs during cardiac surgery may just render areas with an already relatively low-flow state, such as the cerebral white matter (in which borderzone infarcts are often located), susceptible to infarction. This does not mean that infarcts located in this territory have to be borderzone infarcts, as is obvious from this study. Our findings do not disagree with the idea that hypoperfusion is a possible cause of 'borderzone' infarcts; but, as others have also indicated, different mechanisms, such as embolism, should also be considered. ${ }^{68,109}$ 


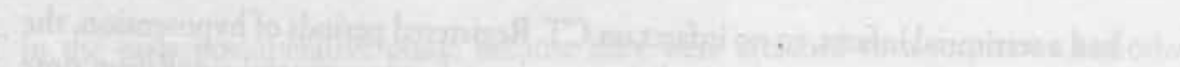

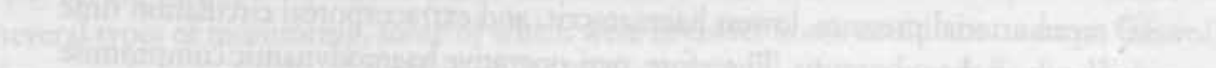
The

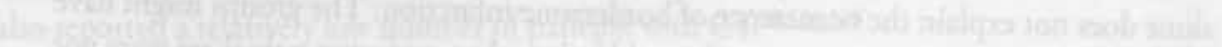

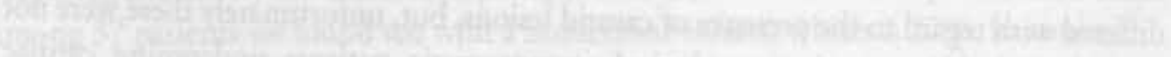

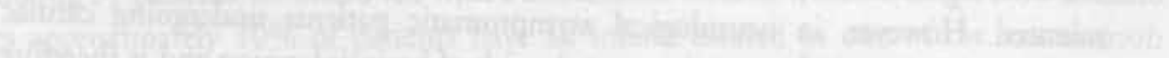

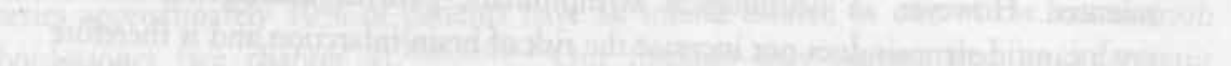

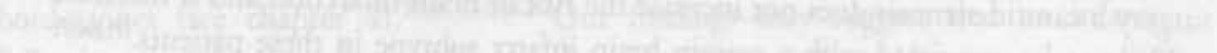

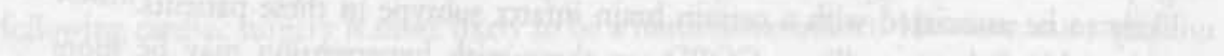

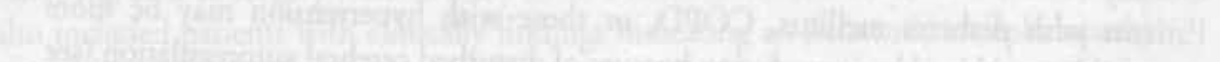

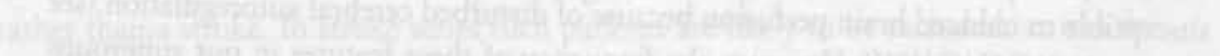

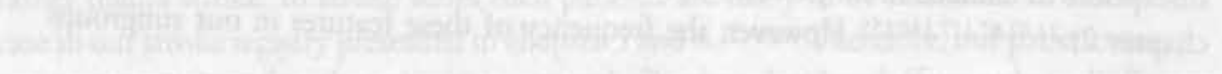

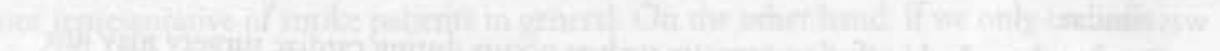

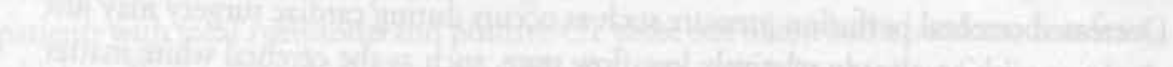

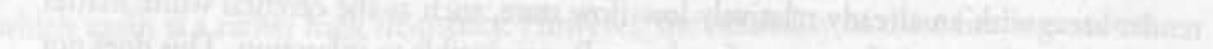

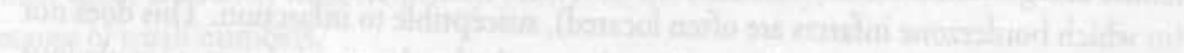

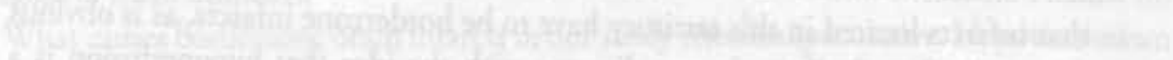

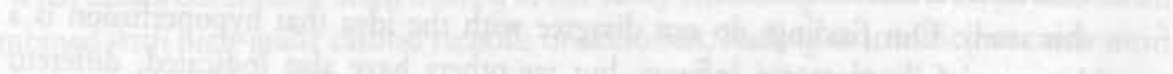

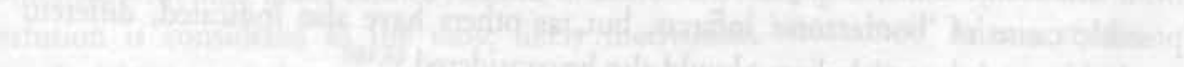
4.

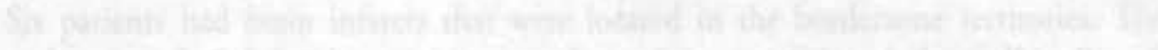

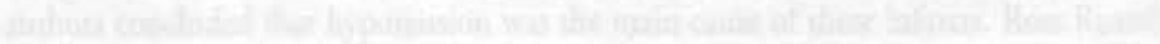

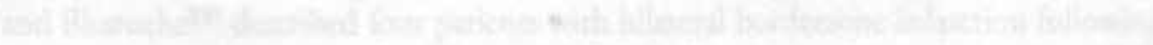

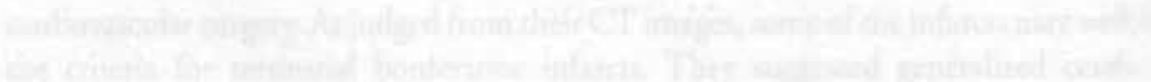

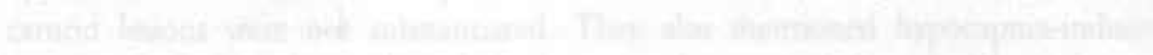


CHAPTER 8

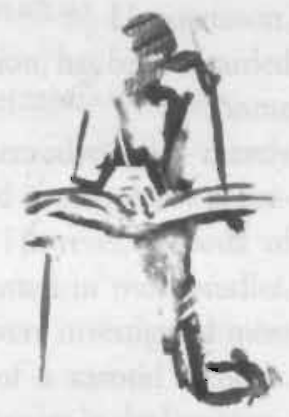

General Discussion

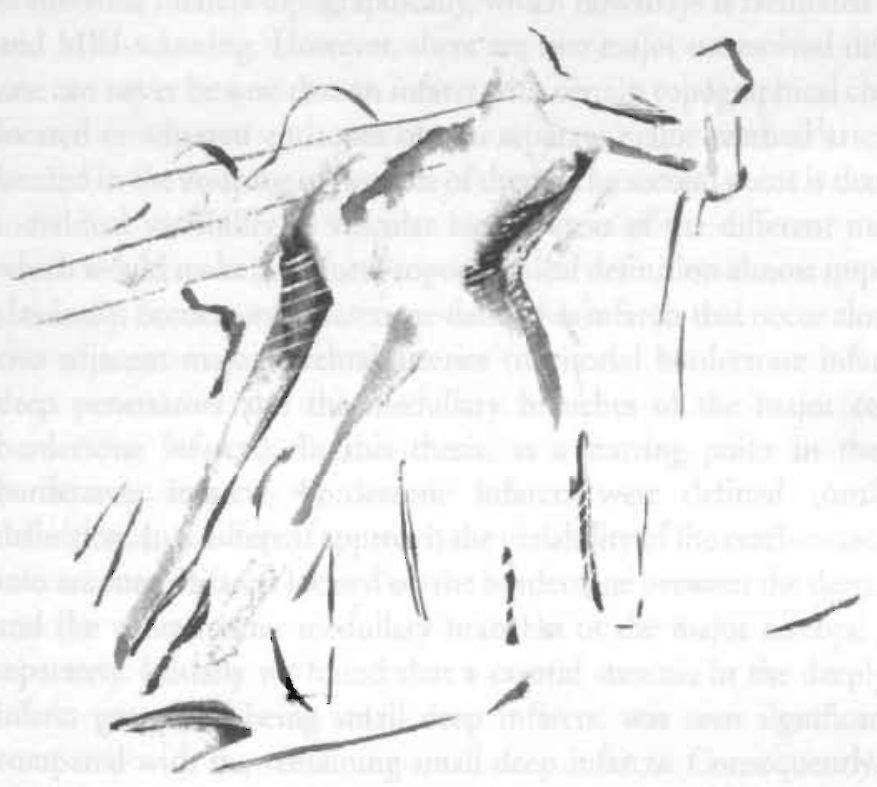




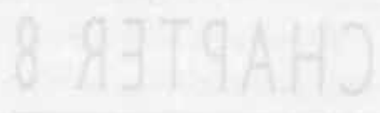

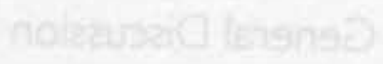

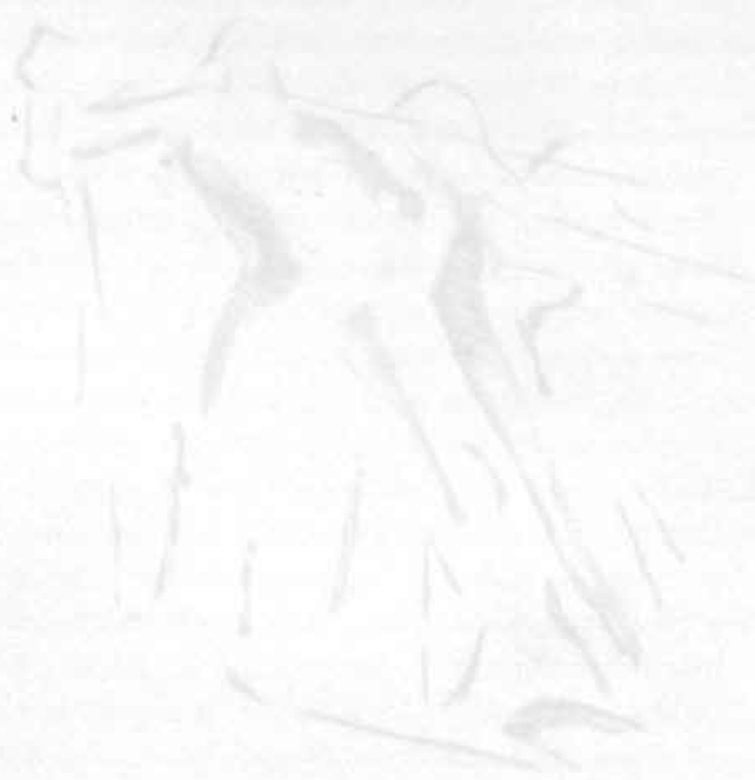


Borderzone infarcts are topographically defined as located in the territory of two adjacent major cerebral arteries, or between the deep penetrators and medullary branches of the major cerebral arteries. ${ }^{17,21,22,31,43,70,131,156,158,164}$ In most studies borderzone infarcts are related to specific pathophysiological mechanisms of which a haemodynamic stroke cause is the most important one. ${ }^{131,150,162,163}$ Hypotension, especially in the presence of severe internal carotid artery obstruction, has been regarded as the most frequent feature that induces borderzone infarction..$^{21,22,131,158,160,161}$ Some authors go as far as considering a stroke mechanism to be 'haemodynamic', merely because the patient has significant carotid obstructive disease, and consequently appreciate a brain infarct to be 'borderzone' or 'watershed'. 21,158 However, periods of hypotension prior to a brain infarct have hardly been documented in most studies, whereas features that indicate a possible sustained hypotension were investigated most of the time in patients who were selected on the presence of a carotid stenosis. Obviously, the definition of borderzone infarction is somewhat obscure in the literature. This is mainly due to the inclusion of the presumed cause or even possible indirect signs of such a cause into the definition. Because the term 'borderzone' originally referred to anatomical areas in pathological studies, it would seem most appropriate to define borderzone infarcts topographically, which nowadays is facilitated by the advent of CTand MRI-scanning. However, there are two major unresolved difficulties. One is that one can never be sure that an infarct with certain topographical characteristics is indeed located in adjacent endzones of two separate major cerebral arteries, instead of being located in the endzone of just one of them. The second point is that there is a large interindividual variability in vascular supply areas of the different major cerebral arteries, which would make a uniform topographical definition almost impossible. Nevertheless, classically, borderzone infarcts are defined as infarcts that occur along the borderzones of two adjacent major cerebral arteries (territorial borderzone infarcts), or between the deep penetrators and the medullary branches of the major cerebral arteries (deep borderzone infarcts). In this thesis, as a starting point in the study of territorial borderzone infarcts, borderzone infarcts were defined considering the classical definition. In a different approach the variability of the cerebrovascular supply was taken into account. Infarcts located on the borderzone between the deep penetrating branches and the white matter medullary branches of the major cerebral arteries were studied separately. Initially we found that a carotid stenosis in the deeply located borderzone infarct group, all being small deep infarcts, was seen significantly more frequently compared with the remaining small deep infarcts. Consequently, we suggested that a small deep infarct in combination with the presence of an ipsilateral carotid stenosis may indicate a haemodynamic stroke mechanism, as has been suggested by others. ${ }^{17,113,154,156}$ However, after studying small deep infarcts, after the total number of infarct patients in our brain infarct registry had significantly increased, no additional small deep borderzone infarcts with a significant carorid stenosis were found. Consequently, the difference was no longer statistically significant, so that the initial finding was most probably caused by random variation due to small numbers. Therefore, an association between carotid stenosis and the fact that some small deep infarcts are located in what has classically been considered as the deep borderzone area, could not be confirmed. Consequently, such infarcts are nor likely to be caused by a haemodynamic stroke 
mechanism, even more so because in none of the infarcts prior hyporension had been registered, nor were there any indirect clinical signs of periods of hypotension prior to the stroke onset. Also in the territorial infarct group, a carotid stenosis could not be related to the borderzone location of infarction. Only one parient in the territorial infarct group sustained pre-stroke hypotension. It is therefore highly unlikely that borderzone infarcts as defined in the present study, are caused by hypotension in the presence of carotid obstructive disease. However, hypotension cannot be excluded as a cause of such or any type of cerebral infarction. But then the question is whether it is a common mechanism, and whether such infarcts are (mainly) located in a borderzone area. Patients whose records about degree and duration of hypotension are well-kept are those who undergo a cardiosurgical operation. All of these patients that were studied in chapter 7 of this thesis had documented periods of hypotension. However, these were not more pronounced in the group with a borderzone infarct than in the other patients. The number of patients with a borderzone infarct in that study however, was higher than in the series from the brain infarct registry. Furthermore, peri-operative haemodynamic parameters were not more unfavourable in patients with a borderzone infarct than in those with a non-borderzone infarct. All in all this means that hypotension may cause infarcts located in what traditionally has been called borderzone areas, but not exclusively in that region. However, only one parient with hyporension was found in our prospectively registered series of 752 patients with a first-ever supratentorial brain infarct, which indicates that this mechanism is far from common, and therefore other mechanisms in cardio-surgical patients have to be considered.

What other pathophysiological mechanism may cause borderzone infarcts? Diabetes mellitus and COPD, especially when simultaneously present, were strongly associated with territorial borderzone infarcts. Both diabetes mellitus and chronic hypercapnia in COPD patients may cause autoregulatory disturbances. ${ }^{7117,146,159}$ Besides, most territorial borderzone infarcts are largely located in the cerebral white matter, an area where the cerebral blood flow is relatively low. ${ }^{169}$ Therefore, the combination of COPD and DM may render the so-called borderzone territories susceptible to infarction in states of low-flow such as thromboembolism. However, no specific factors creating such a lowHow state could be found in the study. Even when 'typical' borderzone infarcts, such as those with a slitlike or rectangular shape while extending over several CT slices, were considered separately, no association with prior stroke hypotension or severe carotid obstructive disease was found. Nevertheless, patients with DM or COPD, but especially those with a combination of these two features may be at higher risk of what we called borderzone infarct, because of deteriorated cerebral autoregulation.

None of the other risk factors or clinical features that were studied was significantly associated with borderzone infarcts in this study. Also the 30-day case fatality and the one-year mortality did not differ between the different groups. Moreover, when the variability of the cerebrovascular supply was taken into account, borderzone infarct characteristics did not differ from those in 'definite non-borderzone infarcts', which were infarcts definitely only located in a territory of one end-artery. From these data we conclude that clinically diagnosed borderzone infarcts do not constitute a separate clinical entity. Also, the question remains unanswered so far as to whether borderzone infarcts are really located in adjacent endzones of at least two different major cerebral arteries. 
An important finding was the high frequency of asymptomatic - mostly borderzone - infarcts in patients with symptomatic borderzone infarcts. This may indicate that borderzones are clinically 'silent' regions. We hypothesized that in states of marginal cerebral perfusion, such as in patients with autoregulatory dysfunction due to COPD and/or DM, during a cerebrovascular event such as thromboembolism, areas that are funcrionally less important receive less blood in favour of more important areas such as the cerebral cortex. These more important cortical regions may benefit from a possible state of 'luxury perfusion' due to a white matter infarct, by way of a vascular steal phenomenon. However, if this was a common phenomenon, asymptomatic infarcts in borderzone regions would likely be more frequent among all types of cerebral infarction than has been found up till now.

The relatively high frequency of asymptomatic infarcts, most of which were of the borderzone type and belonging to the symptomatic borderzone infarct group, may indicate a certain consistency in stroke mechanism. This was especially the case in small deep infarcts that are most likely due to local cerebral small-vessel disease. Because almost all small deep borderzone infarcts fit the definition of small deep infarcts in general, they were also likely to be caused by such small-vessel disease, which brings us to the suggestion that it is not likely that borderzone small deep infarcts are located within two separate vascular territories. Their size (smaller than two centimetres in diameter) fits the assumption that they are caused by the occlusion of a single perforator, and therefore they are more likely to be arterial endzone infarcts. Additional evidence came from the topographical study on anterior choroidal artery territory infarcts in chapter 6, which showed that infarcts assumed to be small deep borderzone infarcts in prior chapters, were, when topographically studied in more detail, almost all confined to the area occupied by small deep penetrators. This offers further evidence that such infarcts, although judged to be located in the vascular borderzone between the deep penetrators and the medullary branches of the major cerebral arteries, are in fact caused by the obstruction of a single penetrator, rather than being considered to be situated partially in a penetrator territory, and partially in a medullary arterial branch territory. Furthermore, the demarcation between these two areas may vary berween individuals. However, such variability in vascular supply areas has not been studied as was done with regard to the cortical supply areas of the three major cerebral arteries, ${ }^{168}$ although, also the vascular supply area of the different penetrators has been known to vary considerably. ${ }^{18}$ There is no evidence to suggest that what have classically been considered as territorial borderzone infarcts are indeed located in two different vascular supply areas. This can only be studied by comparing post-mortem vascular perfusion studies of patients who had a borderzone infarct on CT during life. But even then, post-mortem findings do not necessarily reflect ante-mortem states, because during life cerebral vascular supply areas may vary within one person depending on factors such as local metabolic and oxygen demand. 


\section{From the present study the following is concluded:}

- Although low-flow states can cause infarcts that are classically considered to be borderzone infarcts, no evidence was found that hypotension was a major contributing factor to these infarcts in a prospective series of 752 brain infarct patients, nor was there any relationship with carotid artery obstructive disease.

- Diabetes mellitus and COPD may render the brain more susceptible to white matter (classically considered as borderzone) infarcts, due to failure of autoregulation in case of a cerebrovascular compromising event, such as thromboembolism.

- Ir has never been proven that borderzone infarcts are indeed located in the adjacent endzones of two or more separate major cerebral arteries. The present study makes a (small) deep borderzone infarct subtype in the vascular territory on the junction of the deep penetrating branches and the perforating medullary branches of the major cerebral arteries highly unlikely. Also, territorial borderzone infarcts may in fact merely be located in the vascular endzones of only one artery.

- The vascular risk factor profile was similar in borderzone and non-borderzone infarcts, as was the stroke outcome, which leads to the conclusion that borderzone infarcts do not constitute a homogeneous clinical entity.

- The clinical concept of borderzone infarction rests on very little evidence, therefore remains fiction rather than fact, and might just as well be abandoned. 


\section{CHAPTER ?}

Summary

Samenvatting

Journalistieke weergave
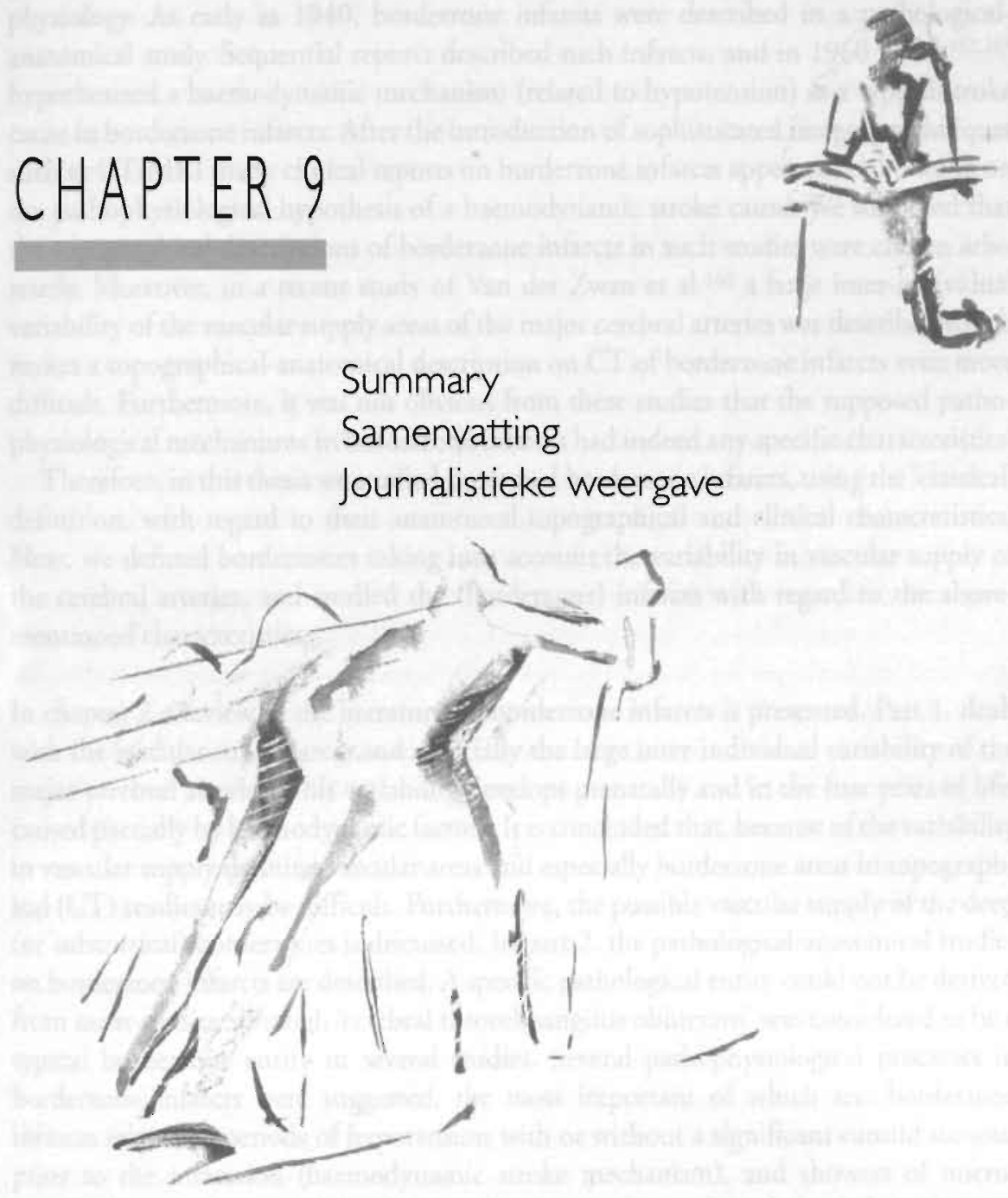


\section{SUMMARY}

Infarcts on the border of two different vascular systems - borderzone infarcts - are generally considered to be a specific infarct entity with regard to localisation and pathophysiology. As early as 1940 , borderzone infarcts were described in a pathologicalanatomical study. Sequential reports described such infarcts, and in $1960 \mathrm{Zülch}^{162.163}$ hypothesized a haemodynamic mechanism (related to hypotension) as a typical stroke cause in borderzone infarcts. After the introduction of sophisticated imaging techniques such as CT/MRI many clinical reports on borderzone infarcts appeared, elaborating on the pathophysiological hypothesis of a haemodynamic stroke cause. We supposed that the topographical descriptions of borderzone infarcts in such studies were chosen arbitrarily. Moreover, in a recent study of Van der Zwan et al. ${ }^{168}$ a large inter-individual variability of the vascular supply areas of the major cerebral arteries was described which makes a topographical-anatomical description on $\mathrm{CT}$ of borderzone infarcts even more difficult. Furthermore, it was not obvious from these studies that the supposed pathophysiological mechanisms in borderzone infarcts had indeed any specific characteristics.

Therefore, in this thesis we studied presumed borderzone infarcts, using the 'classical' definition, with regard to their anatomical-topographical and clinical characteristics. Next, we defined borderzones taking into account the variability in vascular supply of the cerebral arteries, and studied the (borderzone) infarcts with regard to the abovementioned characteristics.

In chapter 2 a review of the literature on borderzone infarcts is presented. Part 1. deals with the vascular supply areas and especially the large inter-individual variability of the major cerebral arteries. This variability develops prenatally and in the first years of life, caused partially by haemodynamic factors. It is concluded that, because of the variability in vascular supply defining vascular areas and especially borderzone areas in topographical (CT) studies may be difficult. Furthermore, the possible vascular supply of the deep (or subcortical) borderzones is discussed. In part 2. the pathological-anatomical studies on borderzone infarcts are described. A specific pathological entity could not be derived from most studies although 'cerebral thromboangiitis obliterans' was considered to be a typical borderzone entity in several studies. Several pathophysiological processes in borderzone infarcts were suggested, the most important of which are: borderzone infarcts related to periods of hypotension with or without a significant carotid stenosis prior to the infarction (haemodynamic stroke mechanism), and showers of microemboli from different origins lodging in the small arteries of the infarcted areas. Although the pathological processes were mostly described in detail, the studies lacked sufficient clinical data to have any clinical significance. Part 3. deals with CT scan characteristics of borderzone infarcts. The definitions of borderzone infarcts are derived from descriptions in current topographical-anatomical CT atlases, and in several studies borderzone infarcts were ill-defined. Haemodynamic compromise of the borderzone territories, mostly related to a carotid stenosis, with or without accompanying periods of hypotension is suggested by many as a specific cause of borderzone infarcts. In part 4 . it is underlined that the pathophysiology of borderzone infarcts is not clear, and that CT scan studies lack large prospective series, including comparison of borderzone infarcts with other infarct types. 
In chapter 3 we described 143 consecutive prospectively registered parients with a firstever supratentorial stroke due to a small deep infarct. Ninety-one patients had an abnormal CT, 74 of whom had non-invasive carotid studies. Twelve of these patients had a sympromatic small deep infarct in the borderzone between the areas supplied by the deep penetrators and the medullary branches of the major cerebral arteries. Four of these 12 had ipsilateral carotid stenosis of more than 50 per cent (one with total occlusion), as opposed to three of 62 remaining patients with CT confirmed small deep non-borderzone infarcts (OR:9.83; 95\%CI:1.70-57.04; $\mathrm{p}<0.01$ ). The number of patients with a porential cardioembolic cause did not differ between borderzone and the remaining small deep infarcts, which makes cardiac embolism a less likely cause of borderzone small deep infarcts. Although the numbers in this initial series were small, these data could be taken to suggest that borderzone location of small deep infarcts rogether with the presence of an ipsilateral carotid stenosis may indicate a haemodynamic stroke mechanism.

In chapter 4 borderzone infarcts according to the generally accepted definitions are described in 539 consecurive patients with a first-ever supratentorial brain infarct who had an abnormal CT scan. Clinical and CT scan features were analysed and compared with those in remaining infarcts. We found 69 (13\%) borderzone infarcts of which 28 were territorial and 41 deep borderzone infarcts. Chronic obstructive pulmonary disease, diabetes mellitus and asymptomatic infarcts were significantly more frequent in territorial borderzone infarcts in comparison with remaining territorial infarcts. A significant carotid stenosis ( $>50 \%$ ) was not seen more frequently in borderzone infarcts than in the remaining infarcts, not even in a selected group of six (very 'typical') borderzone infarcts. Comparison of small deep borderzone infarcts with the remaining small deep infarcts revealed no statistically significant differences except the significantly higher frequency of asymptomatic (mainly borderzone) infarcts in the small deep borderzone group ((a)OR:3.33; 95\%Cl:1.50-7.41; $\mathrm{p}<0.003)$. We concluded that in patients with COPD and/or DM cerebral areas of relatively low perfusion, such as the 'low' perfused borderzone (merely white matter) areas may be rendered susceptible to infarction in states of low-flow such as thromboembolism. We did not find any other specific risk factor related to borderzone infarcts, and hyporension prior to the infarcts could not be registered in our stroke registry. Therefore, no evidence for the generally accepted concept of a haemodynamic stroke cause in borderzone infarcts was found. The high frequency of asymptomatic infarcts in the borderzone group indicates that borderzones are clinically 'silent' regions; moreover, the stroke mechanism in these regions may be a consistent one. The stroke outcome did not differ between borderzone and nonborderzone infarcts. We concluded that there is no evidence for a specific clinical entity of borderzone infarcts, whereas the pathophysiology of borderzone infarcts may not be different from that in other small deep or territorial infarcts, which is obstruction of one (end-)artery, mainly by thromboembolism.

In chapter 5 we defined borderzone areas taking into account the territories of variable vascular supply of adjacent major cerebral arteries. Those territories were reconstructed from the findings of Van der Zwan et al. ${ }^{168}$ who described the inter-individual varia- 
bility of the major cerebral arteries. Three hundred and thirty-three patients with a territorial infarct on $\mathrm{CT}$ entered the study, 42 of whom had a borderzone infarct, 216 were non-borderzone infarcts and 75 were 'mixed' infarcts. The findings of clinical and CT features were similar to those described in territorial infarct subgroups in chapter 4 . The borderzone infarcts did not differ from 'definite' non-borderzone infarcts. Therefore, there is also in this study no evidence in favour of the hyporhesis that borderzone infarcts are located in two adjacent arterial supply areas, rather than in the endzone of one end-artery. Moreover, this study also lends no support to the idea of the existence of a separate brain infarct entity that could be assigned as 'borderzone' infarct.

Chapter 6 describes a study of patients with a compatible CT lesion of a supratentorial ischaemic infarct. The topographical relationship and clinical features in cases with a small deep infarct in the anterior choroidal artery territory (AChA) were compared with these features in other small deep infarcts, and in territorial infarcts. Firstly, we identified the area supplied by the AChA. This was done by studying composite diagrams of supposed AChA infarcts. Infarcts largely located outside the generally included AChA territory were presumed to belong to a different vascular territory. Because infarcts that were restricted to the posterior part of the paraventricular corona radiata region showed almost complete overlap with the paraventricular area occupied by AChA infarcts that extended upwards, we concluded that infarcts in the posterior paraventricular region were most likely AChA infarcts. Comparison of vascular risk factors between small deep AChA infarcts and remaining small deep infarcts by way of multivariate regression analysis only showed a significant carotid stenosis to be more frequent in the AChA group ((a)OR:8.87; 95\% CI:1.44-54.50), and a cardioembolic source to be less frequent (a) OR:0.24; 95\%CI:0.07-0.92). Compared with territorial infarcts a carotid stenosis and cardiac embolism were less frequent in small deep AChA infarcts: (a)OR 0.33, 0.23 respectively; $95 \% \mathrm{Cl}: 0.15-0.74,0.09-0.52$ respectively. We concluded that, pathophysiologically, small infarcts in the AChA territory do not constitute an infarct subtype different from small deep infarcts in general, although carotid embolism may be a more frequent infarct cause. When the CT nominated AChA infarcts were compared with CT findings of the small deep infarcts as described in chapter 4, it appeared that 10 of the 77 AChA infarcts were indicated as borderzone infarct in chapter 4. We concluded from these findings that infarcts that are considered as borderzone infarcts are more likely to be infarcts in a territory of one (end-)artery; also the size of such infarcts argues in favour of single artery infarction.

In chapter 7 we evaluated the hypothesis that if hypotension or hypoperfusion are major causes of borderzone infarction (as defined in chapter 4), infarcts following cardiac surgery would most likely be located in the vascular borderzone areas, whereas cerebral perfusion would be lower among such infarcts compared with territorial infarcts. Ten (27\%) of 37 retrospectively registered patients with brain infarction following cardiac surgery had an infarct in one of the vascular borderzones on CT, $13(35 \%)$ had a territorial infarct, whereas CT was normal in 14 (38\%). Sex, age, vascular risk factors, perioperative blood pressure values and perfusion parameters did not differ among these three subgroups. We concluded that brain infarcts following cardiac surgery are more 
often located in white matter areas that are considered to be borderzones. However, when these infarcts are compared with the figures from stroke series, peri-operative haemodynamic compromise alone does not sufficiently explain the infarct mechanism. Other mechanisms such as embolism should also be considered.

\section{Conclusions:}

1. Although low-flow states can cause infarcts that are classically considered to be borderzone infarcts, no evidence was found that hypotension was a major contributing factor to these infarcts in a prospective series of 752 brain infarct patients, nor was there any relationship with carotid artery obstructive disease.

2. Diabetes mellitus and COPD may render the brain more susceptible to white matter (classically considered as borderzone) infarcts, due to failure of autoregulation in cases of a cerebrovascular compromising event, such as thromboembolism.

3. It has never been proven that borderzone infarcts are indeed located in the adjacent endzones of two or more separate major cerebral arteries. The present study makes a (small) deep borderzone infarct subtype in the vascular territory on the junction of the deep penetrating branches and the perforating medullary branches of the major cerebral arteries highly unlikely. Also, territorial borderzone infarcts may in fact merely be located in the vascular endzones of only one artery.

4. The vascular risk factor profile was similar in borderzone and non-borderzone infarcts, as was the stroke outcome, which leads to the conclusion that borderzone infarcts do not constitute a homogeneous clinical entiry.

5. The clinical concept of borderzone infarction rests on very little evidence, therefore remains fiction rather than fact, and might just as well be abandoned. 


\section{SAMENVATTING}

Herseninfarcten op de grens van twee verschillende vaatgebieden - borderzone infarcten - worden in het algemeen met betrekking tot lokalisatie en pathofysiologie beschouwd als een specifieke entiteit. Reeds in 1940 werden borderzone infarcten in een pathologisch-anatomische studie beschreven. Meerdere studies volgden, en in 1960 postuleerde Zülch ${ }^{162.163}$ de hypothese dat een haemodynamisch mechanisme (in relatie tor hypotensie) gezien zou moeten worden als de kenmerkende oorzaak van borderzone infarcten. Na de introductie van verfijnde beeldvormende technieken zoals CT en MRI verschenen vele klinische studies over borderzone infarcten, waarin verder werd ingegaan op de pathofysiologisch geaarde hypothese van Zülch betreffende de haemodynamische oorzaak van borderzone infarcten. Wij veronderstelden dat de topografie van borderzone infarcten in dergelijke studies willekeurig werd vastgesteld. Bovendien beschreef Van der Zwan e.a. ${ }^{168}$ in een recente studie een grote mate van inter-individuele variabiliteit in de vasculaire bevloeiïngsgebieden van de grote hersenarteriën. Dit maakt een topografisch-anatomische beschrijving van borderzone infarcten op CT zelfs nog moeilijker, zo niet onmogelijk. Vervolgens bleek het allesbehalve duidelijk uit de klinische studies af te leiden of de veronderstelde pathofysiologische mechanismen van borderzone infarcten daadwerkelijk enige specifieke kenmerken hadden.

Gezien de onzekerheden en onduidelijkheden werden in deze studie de anatomischtopografische en klinische kenmerken bestudeerd van als borderzone infarct geduide infarcten, uitgaande van de 'klassiek' gebruikte definitie. Vervolgens bestudeerden we borderzone infarcten rekening houdende met de variabiliteit van de bevloeiïngsgebieden van de cerebrale arteriën.

In hoofdstuk 2 wordt een overzicht gegeven van de literatuur over borderzone infarcten. In deel 1 . worden de vasculaire bevloeiïngsgebieden en meer specifiek de grote mate van inter-individuele variabiliteit van de grote cerebrale arteriën beschreven. Deze variabiliteit ontstaat reeds in utero en tijdens de eerste levensjaren, gedeeltelijk ten gevolge van haemodynamische factoren. Geconcludeerd wordt dat het exact definiëren van vasculaire territoria en met name de borderzone territoria, in topografische (CT) studies beperkt wordt door de variabiliteit van arteriële bevloeingsgebieden. Vervolgens wordt in dit deel de arteriële vascularisatie van de diepe (subcorticale) borderzones besproken. In deel 2. worden de pathologisch-anatomische studies over borderzone infarcten beschreven. In de meeste studies werd geen specifieke pathologische entiteit gevonden, hoewel in sommige studies 'cerebrale thromboangiitis obliterans' als typisch voor borderzone infarcten werd beschouwd. Verscheidene pathofysiologische processen als oorzaak van borderzone infarcten werden geopperd, waarvan de twee belangrijkste zijn: borderzone infarcten in relatie tot perioden van hypotensie voorafgaand aan het infarct, al dan niet in combinatie met een significante carotisstenose (haemodynamisch infarct mechanisme); en 'regens' van microembolieën van verschillende vasculaire oorsprong, resulterend in multiple obstructies van de kleine arteriën in het geïnfarceerde gebied. Alhoewel pathologische processen meestal gedetailleerd beschreven werden, is de klinische relevantie van deze studies zeer beperkt tengevolge van het gebrek aan voldoende klinische gegevens. In deel 3. worden studies beschreven van borderzone 
infarcten, die gediagnostiseerd zijn met behulp van CT-scan kenmerken. De definities van borderzone infarcten zijn in deze studies meestal afgeleid van beschrijvingen in de meest actuele anatomisch-topografische CT-scan atlassen. Desalniettemin zijn in sommige studies de definities van borderzone infarcten wel zeer beperkt gebleven. Veel auteurs beschouwen de haemodynamische compromittering van de borderzone territoria, meestal gerelateerd aan een carotisstenose, en al dan niet gepaard met perioden van hypotensie, als de specifieke oorzaak van borderzone infarcten. In deel 4 . wordt nog eens onderstreept dat de pathofysiologie van borderzone infarcten op z'n minst onduidelijk is, en dat prospectieve patiëntenseries en vergelijkingen van borderzone infarcten met andere infarcten in de beschreven CT-scan studies ontbreken.

In hoofdstuk 3 worden 143 achtereenvolgende prospectief geregistreerde patiënten beschreven met een eerste supratentorieel gelegen klein diep - small deep - herseninfarct, waarvan er 91 een afwijkende CT-scan hadden. Van hen ondergingen 74 patiënten een non-invasief onderzoek van de carotiden. Twaalf van deze patiënten hadden een symptomatisch small deep infarct dat gelegen was in de borderzone tussen de bevloeiïngsgebieden van de diepe penetratoren en de medullaire takken van de grote hersenarteriën. Vier van hen hadden een ipsilaterale carotisstenose van meer dan 50\% (één had een totale occlusie); dit ten opzichte van drie van de resterende 62 patiënten met een non-borderzone small deep infarct (OR: 9.83; 95\%CI: 1.70-57.04; $\mathrm{p}<0.01$ ). Het aantal patiënten met een potentiële cardiale emboliebron verschilde niet tussen deze groepen, hetgeen betekent dat een cardiale emboliebron een minder waarschijnlijke oorzaak is van een small deep borderzone infarct. De gegevens van deze studie suggereren dat kleine diepe infarcten gelegen in de borderzone in combinatie met de aanwezigheid van een ipsilaterale carotisstenose ontstaan op haemodynamische basis; de patiënten aantallen zijn echter klein.

In hoofdstuk 4 worden, aan de hand van de algemeen geldende definities, borderzone infarcten beschreven in 539 achtereenvolgende patiënten met een eerste supratentorieel gelegen herseninfarct en een afwijkende CT-scan. Klinische en CT-scan bevindingen werden geanalyseerd en vergeleken tussen borderzone infarcten en resterende infarcten. We vonden 69 (13\%) borderzone infarcten waarvan 28 territoriaal en 41 diepgelegen waren. Chronisch obstructief pulmonaal lijden (COPD), diabetes mellitus (DM) en asymptomatische infarcten kwamen significant vaker voor in territoriale borderzone infarcten in vergelijking met de resterende territoriale infarcten. Een significante carotisstenose ( $>50 \%$ ) was niet frequenter in borderzone infarcten dan in resterende infarcten, zelfs niet in een geselecteerde groep van 6 (zeer 'typical') borderzone infarcten. Vergelijking van de small deep borderzone infarcten met resterende small deep infarcten leverde geen statistisch significante verschillen op, met uitzondering van de significant hogere frequentie van asymptomatische (voornamelijk borderzone) infarcten in de small deep borderzone groep ((a)OR:3.33; 95\%Cl:1.50-7.41; p<0.003). We concludeerden dat in patiënten met COPD en/of DM cerebrale territoria met een relatief lage perfusie, zoals de 'low' perfusie borderzone (vnl. witte stof) territoria, erg gevoelig zijn voor infarcering wanneer ze in een low-flow staat geraken zoals dit het geval is tijdens thromboembolisatie. We vonden geen andere specifieke risicofactoren in relatie tor borderzone 
infarcten, ook hypotensie voorafgaand aan een infarct werd in deze patiëntengroep niet vastgesteld. Concluderend geeft deze studie geen aanwijzingen voor het tot nog toe geldende concept van een haemodynamische oorzaak van een borderzone infarct. De hoge frequentie van asymptomarische infarcten in de borderzone groep geeft aan dat borderzones klinisch 'stille' gebieden zijn, bovendien wijst dit op een consistentie van het infarct mechanisme. Het klinisch beloop tussen borderzone en non-borderzone infarcten was niet verschillend. Wij concluderen dat borderzone infarcten geen specifieke klinische entiteit vormen, terwijl de pathofysiologie van borderzone infarcten niet anders is dan die van andere small deep en territoriale infarcten, hetgeen neer komt op obstructie van een (eind-)arterie, voornamelijk ten gevolge van thromboembolisatie.

In hoofdstuk 5 werden borderzone territoria gedefinieerd rekening houdende met de variabiliteit van de vasculaire bevloeiïngsgebieden van de grote hersenarteriën. De grenzen van de verschillende territoria werden afgeleid van de studie van Van der Zwan e.a. ${ }^{168}$ die de inter-individuele variabiliteit van de grote hersenarteriën vastlegden. Drie honderd drie-en-dertig patiënten met een territoriaal infarct op CT werden in deze studie opgenomen, waarvan er 42 een borderzone infarct, 216 een non-borderzone infarct, en 75 een 'mixed' infarct hadden. De resultaten van de klinische en CT kenmerken tussen borderzone en overige infarcten waren gelijk aan die van hoofdstuk 4. Borderzone infarcten verschilden niet van 'definite' non-borderzone infarcten. Derhalve zijn er ook in deze studie geen aanwijzingen gevonden die de hypothese dat een borderzone infarct een infarct is dat gelokaliseerd is in een gebied van twee aaneensluitende arteriën, meer aannemelijk maakt dan de hypothese dat het een infarct is gelokaliseerd in een gebied van één eind-arterie. Ook geeft deze studie geen ondersteuning aan het bestaan van een aparte herseninfarct entiteit, genaamd 'borderzone infarct'.

In hoofdstuk 6 worden van de patiënten met een eerste supratentorieel gelegen herseninfarct de patiënten met een compatibele laesie op de CT-scan geselecteerd. Topografische relaties en klinische kenmerken van patiënten met een small deep infarct in het gebied van de arteria choroidea anterior (AChA) werden vergeleken enerzijds met andere small deep infarcten, anderzijds met territoriale infarcten. Ten eerste werd het vascularisatiegebied van de $A C h A$ vastgesteld. Dit werd gedaan na bestudering van de topografische compositiediagrammen van alle veronderstelde $A C h A$ infarcten. Infarcten die grotendeels buiten het algemeen geldende AChA-gebied gelegen waren, werden geacht tot een ander vaatgebied te behoren. Omdat de infarcten die uitsluitend in het posterieure deel van de paraventriculaire corona radiata gelegen waren, samenvielen met het naar paraventriculair uitbreidend deel van de dieper gelegen infarcten, concludeerden we dat de infarcten in het posterieure paraventriculaire gebied het meest waarschijnlijk ook AChA infarcten zijn. Vergelijking van vasculaire risicofactoren d.m.v. multivariate logistische regressie toonde alleen dat een significante carotisstenose frequenter voorkomt in de small deep AChA groep in vergelijking met de resterende small deep infarcten ((a)OR:8.87; 95\%Cl:1.44-54.40) en een cardiale emboliebron minder frequent in de small deep AChA groep t.o.v. de overige small deep infarcten: (a)OR:0.24; $95 \% \mathrm{CI}: 0.07-0.92)$. In vergelijking met de territoriale infarcten waren een carotisstenose en een cardiale emboliebron minder frequent in AChA infarcten: (a)OR 
$0.33,0.23$ respectievelijk; $95 \% \mathrm{CI}: 0.15-0.74,0.09-0.52$ respectievelijk. We concluderen dat pathofysiologisch gezien kleine infarcten in het AChA gebied geen deel uitmaken van een specifiek infarct type dat zich onderscheidt van small deep infarcten in het algemeen, alhoewel carotis embolieën waarschijnlijk wel een meer frequente oorzaak zijn van AChA infarcten. De op CT-scan als AChA infarct geduide laesies werden vervolgens geanalyseerd zoals de small deep infarcten volgens de borderzone criteria van hoofdstuk 4. Het bleek dat 10 van de 77 AChA infarcten op die manier als borderzone infarct te duiden waren. Op grond van deze bevindingen concluderen we dat infarcten die als borderzone infarct beschouwd worden eerder eind-arterie infarcten zijn, bovendien pleit de grootte van zo'n small deep infarct daar ook voor.

In hoofdstuk 7 wordt de hypothese getoetst dat indien hypotensie of hypoperfusie belangrijke oorzaken van borderzone infarcten zijn (volgens de definitie in hoofdstuk 4), infarcten in patiënten na een cardiochirurgische ingreep waarschijnlijk gelokaliseerd zijn in de vasculaire borderzone gebieden, terwijl de cerebrale perfusie in dergelijke patiënten lager zal zijn dan in patiënten met territoriale infarcten. Tien (27\%) van de 37 retrospectief geregistreerde patiënten met een herseninfarct na cardiochirurgie hadden op de CT een infarct gelokaliseerd in een van de vasculaire borderzones, $13(35 \%)$ hadden een territoriaal infarct, terwijl bij 14 (38\%) de CT niet afwijkend was. Geslacht, leeftijd, vasculaire risicofactoren, peri-operatieve bloeddrukregistraties, en perfusie parameters waren alle niet verschillend in deze 3 subgroepen. We concluderen dat herseninfarcten na cardiochirurgie nogal eens in dié delen van de witte stof gelokaliseerd zijn die beschouwd worden als borderzone gebieden. Indien we echter deze infarcten vergelijken met elders gelokaliseerde infarcten of met data van andere stroke registraties blijkt dat de peri-operatief gecompromitteerde haemodynamiek niet voldoende het infarct mechanisme in borderzone infarcten verklaart; andere mechanismen zoals thromboembolieën dienen ook overwogen te worden.

\section{Conclusies:}

1. Alhoewel een toestand van 'low-flow' infarcten kan veroorzaken die traditioneel als borderzone infarcten worden geduid, werden in deze prospectieve studie van 752 patiënten met herseninfarcten geen aanwijzingen gevonden dat hypotensie een belangrijke oorzakelijke factor is van dergelijke infarcten.

2. Diabetes mellitus en chronisch obstructief pulmonaal lijden kunnen, tengevolge van stoornissen in de autoregulatie bij compromittering van de cerebrale vascularisatie de hersenen kwetsbaarder maken voor infarcten in de witte stof (die klassiek als borderzone wordt beschouwd).

3. Tot nu toe is er geen bewijs geleverd voor de opvatting dat borderzone infarcten daadwerkelijk gelokaliseerd zijn in aangrenzende eindzones van twee of drie verschillende grote cerebrale arteriën. In deze studie wordt het onwaarschijnlijk gemaakt dat 'small deep' borderzone infarcten inderdaad gelegen zijn in zowel het gebied van de diep penetrerende takken alsook in het gebied van de perforerende medullaire takken van een van de grote hersenarteriën. Bovendien zijn territoriale borderzone infarcten waarschijnlijk ook gelokaliseerd in de eindzone van slechts één grote hersenarterie. 
4. Het vasculaire risicofactorenprofiel in borderzone en in non-borderzone infarcten is gelijk; dit geldt ook voor het klinisch beloop; derhalve concluderen we dat borderzone infarcten geen specifieke klinische entiteit vormen.

5. Het traditionele concept van borderzone infarcten is niet op klinische evidentie gebaseerd. Daarom zou men dit concept dan ook beter kunnen verlaten. 


\section{JOURNALISTIEKE WEERGAVE}

Een herseninfarct is het versterf van een stukje hersenweefsel. Zo'n herseninfarct kan ontstaan t.g.v. meerdere oorzaken, zoals een bloedstolsel vanuit een slagader in de hals, of vanuit het hart, of t.g.v. een meer algemene vernauwing van bloedvaten in de hersenen (atherosclerose); maar soms ook door oorzaken zoals (te) lage bloeddruk of een slechte regulatie van de doorbloeding lokaal in de hersenen.

Het is mogelijk dat een bepaalde lokalisatie van een herseninfarct samenhangt met een specifieke oorzak. 'Borderzone' (grenszone) infarcten zijn infarcten met zo'n typische lokalisatie. Dit is bijzonder omdat men veronderstelt dat deze infarcten gelegen zijn in het doorbloedingsgebied van twee aaneensluitende grote hersenslagaders, dit in tegenstelling tot andere herseninfarcten die steeds gelegen zijn in het doorbloedingsgebied van één grote hersenslagader. Herseninfarcten zijn meestal goed waar te nemen op een CT-scan (gecomputeriseerde röntgenfoto) van de hersenen.

Aan de hand van de bestudering van de huidige wetenschappelijke stand van zaken dienen zich twee problemen aan. Ten eerste worden op grond van CT-scan lokalisaties borderzone infarcten vastgesteld; hierbij veronderstelt men, zoals gezegd, dat het aangeduide infarct gelegen is in het doorbloedingsgebied van twee verschillende aaneensluirende slagaders. Ten tweede wordt een specifieke oorzaak, namelijk (lokale) lage bloeddruk, eventueel in combinatie met een vernauwing van een halsslagader, aan deze infarcten toebedacht. Voor beide veronderstellingen die in de huidige literatuur veelal gebruikt worden, lijkt onvoldoende bewijs.

We hebben in deze studie deze veronderstellingen onderzocht in 752 patiënten aan de hand van hun CT-scans en hun risicofactoren op het krijgen van een herseninfarct. Hierbij werden de borderzone infarcten met andere typen van herseninfarcten vergeleken. De studie werd verricht aan de hand van de in de literatuur geldende definities van borderzone infarcten. Nadien werd deze nog een keer herhaald waarbij de definitie werd aangepast rekening houdende met een bepaalde mate van variatie in de hersendoorbloeding van de verschillende grote hersenslagaders tussen verschillende individuen.

In beide studies bleek het risicofactorenprofiel van borderzone infarcten geen anleiding te geven deze infarcten inderdaad te onderscheiden van herseninfarcten met andere lokalisaties. Bovendien bleek niets er op te wijzen dat deze borderzone infarcten inderdaad gelegen zijn in het gebied van twee verschillende aaneensluitende slagaders, hetgeen juist zo typisch voor deze infarcten geacht werd.

Naar aanleiding van onze studie lijkt het dan ook weinig zinvol om het begrip 'borderzone' infarct voor klinische doeleinden (d.w.z. met betrekking tot diagnostiek en behandeling) te handhaven. 


\section{REFERENCES}

1. Abbie AA. The clinical significance of the anterior choroidal artery. Brain 1933;56:233-246.

2. Abbie AA. The blood supply of the lateral geniculate body, with a note of the morphology of the choroidal arteries. J Anat 1933;67:491-527.

3. Adams JH, Brierley JB, Connor RCJ, Treip CS. The effects of systemic hypotension upon the human brain. Clinical and neuropathological observations in 11 cases. Brain 1966;89:235-267.

4. Akelairis AJ. Symmetrical bilateral granular atrophy of the cerebral cortex of vascular origin. A clinico-pathologic study. Am J Psychiat 1942;99:447-453.

5. Allen CMC. Clinical diagnosis of the acute stroke syndrome. Q J Med 1983;208:515-523.

6. Angeloni U, Bozzao L, Fantozzi L, Bastianello S, Kushner M, Fieschi C. Internal borderzone infarction following acute middle cerebral artery occlusion. Neurology 1990;40:1196-1198.

7. Appenzeller $O$. The autonomic nervous system. Fourth revised and enlarged edition; 1990. Elsevier, Amsterdam, New York, Oxford. pp 560-561, 573-574.

8. Archie JP, Feldtman RW. Critical stenosis of the internal carotid artery. Surgery 1981;89(1):67-72.

9. Bamford J, Sandercock P, Jones L, Warlow Ch. The natural history of lacunar infarction: The Oxfordshire Community Stroke Project. Stroke 1987;18:545-551.

10. Bamford JM, Warlow CP. Evolution and testing of the lacunar hyporhesis. Stroke 1988;19:1074-1082.

11. Bamford JM, Sandercock PAG, Warlow CP, Slattery J. Interobserver agreement for the assessment of handicap in stroke patients. Stroke 1989;20:828.

12. Bamford J, Sandercock P, Dennis M, Burn J, Warlow C. Classification and natural history of clinically identifiable subtypes of cerebral infarction. The Lancet 1991;337:1521-1526.

13. Beevor CE. The cerebral arterial supply. Brain 1907;30:403-425.

14. Beevor CE. On the distribution of the different arteries supplying the human brain. Philos Trans R Soc London (Biol), 1909;200:1-55.

15. Bergh van den R. Centrifugal elements in the vascular pattern of the deep intracerebral blood supply. Angiology 1969;20:88-94.

16. Bladin CF, Chambers BR, Donnan GA. Confusing stroke terminology: Watershed or borderzone infarction? Letrers to the editor. Stroke 1993;24:477-478.

17. Bladin CF, Chambers BR. Clinical features, pathogenesis, and computed tomographic characteristics of internal warershed infarction. Stroke 1993;24:1925-1932.

18. Bleecker De J, De Reuck J, Vingergoets G, Thiery E, Ceusters W. Het arteria choroidea anterior syndroom. Tijdschr v Geneeskunde 1988;44(4):259-262.

19. Bogousslavsky J, Regli F. Cerebral infarction with transient signs (CITS): do TIA's correspond to small deep infarcts in internal carotid artery occlusion? Stroke 1984;15:536-539.

20. Bogousslavsky J, Regli F, Delaloye B, Delaloye-Bisschoff A, Uske A, Despland PA. 
Hémiataxie et déficit sensitif ipsilateral. Infarctus du territoire de l'artère choroïdienne antérieure. Diaschisis cérébelleux croisé. Rev Neurol 1986;142:671-676.

21. Bogousslavsky J, Regli F. Borderzone infarctions distal to internal carotid artery occlusion: prognostic implications. Ann Neurol 1986;20:346-350.

22. Bogousslavsky J, Regli F. Unilateral watershed cerebral infarcts. Neurology 986;36:373-377.

23. Bogousslavsky J, Van Melle G, Regli F. The Lausanne Stroke Registry: analysis of 1,000 consecutive patients with first stroke. Stroke 1988;19:1083-1092.

24. Bogousslavsky J, Miklossy J, Regli F. Deruez J-P. Assal G, Delaloye B. Subcortical neglect: neuropsychological, SPECT and neuropathological correlations with anterior choroidal artery territory infarction. Ann Neurol 1988;23:448-452.

25. Bogousslavsky J. The plurality of subcortical infarction. Stroke 1992;23:629-631.

26. Bogousslavsky J, Regli F. Centrum ovale infarcts: subcortical infarction in the superficial territory of the middle cerebral artery. Neurology 1992;42:1992-1998.

27. Boiten J, Lodder J. Lacunar infarcts. Pathogenesis and validity of the clinical syndromes. Stroke 1991;22:1374-1378.

28. Boiten J, Lodder J. Discrete lesions in the sensorimotor control system. A clinicaltopographical study of lacunar infarcts. Journal of the Neurological Sciences 1991;105:150-154.

29. Boiten J, Lodder J. Large striatocapsular infarcts; clinical presentation and pathogenesis in comparison with lacunar and cortical infarcts. Acta Neurol Scand 1992;86:298-303.

30. Boiren J, Lodder J. Prognosis for survival, handicap and recurrence of stroke in lacunar and superficial infarction. Cerebrovasc Dis 1993;3:221-226.

31. Bories J, Derhey S, Chiras J. CT in hemispheric ischaemic attacks. Roles of scanning: CT, PET and MRI. Second part. Neuroradiology 1985;27:468-483.

32. Brierley JB, Prior PF, Calverley J, Jackson SJ, Brown AW. The pathogenesis of ischaemic neuronal damage along the cerebral arterial boundary zones in papio anubis. Brain 1980;103:929-965.

33. Bruno A, Graff-Radford NR, Biller J, Adams HP. Absence of carotid artery disease in patients with anterior choroidal artery territory infarction. (abstract) Ann Neurol 1987;22(1):160.

34. Bruno A, Graff-Radford NR, Biller J, Adams HP. Anterior choroidal artery territory infarction: A small vessel disease. Stroke 1989;20:616-619.

35. Buge A, Escourolle R, Hauw J, Rancurel G, Gray F, Tempier P. Syndrome pseudobulbaire aigu par infarctus bilateral limité du territoire des artères choroidiennes antérieures. Rev Neurol (Paris) 1979;135(4):313-318.

36. Cambier J, Graveleau Ph, Decroix JP. Elghozi D, Massoz M. Le syndrome de l'artère choroidienne antérieure étude neuropsychologique de 4 cas. Rev Neurol (Paris) 1983;131:553-559.

37. Caplan RR. Carotid artery disease. N Engl J Med 1986;315:886-888.

38. Carpenter DA, Grubb RL, Powers W. Borderzone hemodynamics in cerebrovascular disease. Neurology 1990;40:1587-1592.

39. Carpenter MB, Noback CR, Moss ML. The anterior choroidal artery. Its origins, course, distribution, and variations. Arch Neurol Psychiat, Chicago, 1954;71;714722. 
40. Cillessen JPM, Kappelle LJ, Van Swieten JC, Algra A, Van Gijn J. Does cerebral infarction after a previous warning occur in the same vascular territory? Stroke 1993;24:352-354.

41. Damasio H. A computed tomographic guide to the identification of cerebral vascular territories. Arch Neurol 1983;40:138-142.

42. Decroix JP, Graveleau Ph, Masson M, Cambier J. Infarction in the territory of the anterior choroidal artery. A clinical and computerized tomographic study of 16 cases. Brain 1986;109:1071-1085.

43. Del Sette M, Streifler JY, Hachinski VC, Eliasziw M, Fox AJ, Barnetr HJM. Small borderzone infarct is a marker for high grade carorid stenosis. Proceedings of the 2nd European Stroke Conference. Cerebrovasc Dis 1992;2:198.

44. De Reuck J. The human periventricular arterial blood supply and the anatomy of cerebral infarctions. Eur Neurol 1971;5:321-334.

45. De Reuck J, Van der Eecken $H$. The topography of infarcts in the lacunar state. Cerebral vascular disease. Proceedings of the 7th International Conference Salzburg. 1974. Edited by J.S. Meyer, H. Lechner and M. Reivich.

46. De Reuck J, Van der Eecken HM. The arterial angioarchitecture in lacunar state. Acta Neurol Belg 1976;76:142-149.

47. Dobkin BH. Orthostatic hypotension as a risk factor for symptomatic occlusive cerebrovascular disease. Neurology 1989;39:30-34.

48. The Dutch TIA Trial Study Group. Predictors of major vascular events in patients with a transient ischaemic attack or nondisabling stroke. Stroke 1993;24:527531.

49. Donnan GA, Norrving B, Bamford JM, Bogousslavsky J. Subcortical infarction: classification and terminology, Cerebrovasc Dis 1993;3:248-251.

50. Eecken van der HM, Adams $\mathrm{R}$. The anatomy and functional significance of the meningeal arterial anastomoses of the human brain. J Neuropath Exp Neurol 1953;12:132-157.

51. Eecken van der HM. The anastomoses between the leptomeningeal arteries of the brain. Springfield, Il., Charles C Thomas, 1959.

52. Fisher CM. Occlusion of the carorid arreries. Further experiences. Arch Neurol Psychiat 1954:72:187-204.

53. Fisher CM. Cerebral thromboangiitis obliterans. Medicine (Baltimore) 1957:169209.

54. Fisher CM. Lacunes: small, deep cerebral infarcts. Neurology 1965;15:774-784.

55. Fisher CM. The arterial lesions underlying lacunes. Acta Neuropathol (Berlin) 1969;12:1-15.

56. Fisher CM. Capsular infarcts. The underlying vascular lesions. Arch Neurol 1979;36:65-73.

57. Fisher CM. Lacunar strokes and infarcts: A review. Neurology 1982;32:871-876.

58. Fisher CM. Lacunar infarcts. A review. Cerebrovasc Dis 1991;1:31 1-320.

59. Fisher M. McQuillen JB. Bilateral cortical border-zone infarction. A pseudo brainstem stroke. Arch Neurol 1981;38:62-63.

60. Fisher M, Lingley JF, Blumenfeld A, Felice K. Anterior choroidal artery territory infarction and small-vessel disease. (Letter). Stroke 1989;20:1591-1592. 
61. Foix Ch, Chavany JA. Hillemand P, Schiff Wertheimer S. Oblitération de l'artère choroidienne antérieure. Ramollissement de son territoire cérébral, hemiplégie, hémianesthésie, hemianopsie. Bulletin de la Societé d’Ophthalmologie (Paris) 1925;27:221-223.

62. Fujii K, Lenkey C, Rhoton AL. Microsurgical anatomy of the choroidal arteries: lateral and third ventricles. Journal of Neurosurgery 1980;52:165-188.

63. Furlan AJ, Craciun AR. Risk of stroke during coronary artery bypass graft surgery in patients with internal carotid artery disease documented by angiography. Stroke 1985;16:797-799.

64. Gerraty RP, Gates PC, Doyle JC. Carotid stenosis and perioperative stroke risk in symptomatic and asymptomatic patients undergoing vascular and coronary surgery. Stroke 1993;24:1115-1118.

65. Ghika J, Bogousslavsky J, Regli F. Infarcts in the territory of the deep perforators from the carotid system. Neurology 1989;39:507-512.

66. Ghika JA, Bogousslavsky J, Regli F. Deep perforators from the carotid system. Template of the vascular territories. Arch Neurol 1990;47:1097-1100.

67. Gilman S. Cerebral disorders after open-heart operations. N Engl J Med 1965;272:489-498.

68. Gilman S. Neurological complications of open heart surgery. Editorial. Ann Neurol 1990;28:475-476.

69. Götze W, Krücke W. Über Paramyloidose mit besonderer Beteiligung der peripheren Nerven und granulärer Atrophie des Gehirns. Arch Psychiat Nervenkr 1942;114:182-213.

70. Graeber M, Jordan E, Mishra SK, Nadeau SE. Watershed infarction on computed tomographic scan. Arch Neurol 1992;49:311-313.

71. Graff-Radford N, Damasio H, Yamada T, Eslinger PJ, Damasio AR. Nonhemorrhagic thalamic infarcrion. Brain 1985;108:485-516.

72. Graor RA. Management of coexistent carotid artery and coronary artery disease. Stroke 1988;19:1441-1444.

73. Gutmann DH, Scherer S. Magnetic resonance imaging of ataxic hemiparesis localized in the corona radiata. Stroke 1989;20:1571-1573.

74. Helgason C, Caplan LR, Goodwin J, Hedges T. Anterior choroidal artery-territory infarction. Report of cases and review. Arch Neurol 1986;43:681-686.

75. Helgason CM. A new view of anterior choroidal artery territory infarction. J Neurol 1988:235:387-391.

76. Helgason CM, Wilbur AC. Capsular hypesthetic ataxic hemiparesis, Stroke 1990;21:24-33.

77. Herholz K, Heindel W, Rackl A, Neubauer I, Steinbrich W, Pietrzyk U, ErasmiKörber H, Heiss W. Regional cerebral blood flow in parients with leuko-araiosis and atherosclerotic carotid artery disease. Arch Neurol 1990;47:392-396.

78. Hillen B. The variability of the Circle of Willis: univariate and bivariate analysis. Acra Morphol Neerl Scand 1986;24:87-101.

79. Hillen B. The variability of the circulus arteriosus (Willisii): order or anarchy? Acta Anat 1987;129:74-80.

80. Hommel M, Besson G, Le Bas JF, Gaia JM, Pollak P, Borgel F, Perret J. Prospective 
study of lacunar infarction using magnetic resonance imaging. Stroke 1990;21:546-554.

81. Hornby AG, Gatenby EV, Wakefield $\mathrm{H}$. The advanced Learner's dictionary of current English, 1971 second edition. London, Oxford University Press.

82. Howard R, Trend P, Ross Russell RW. Clinical features of ischemia in cerebral arterial border-zones after periods of reduced cerebral blood flow. Arch Neurol 1987;44:934-940.

83. Huang CY, Lui FS. Ataxic hemiparesis, localization and clinical features. Stroke 1984;15(2):363-366.

84. Jörgensen L, Torvik A. Ischaemic cerebrovascular diseases in an autopsy series, part 2. Prevalence, location, pathogenesis, and clinical course of cerebral infarcts. J Neurol Sci 1969;9:285-320.

85. Kappelle LJ, Koudstaal PJ, van Gijn J, Ramos LMI, Keunen JEE. Carotid angiography in patients with lacunar infarction. A prospective study. Stroke 1988;19:1093-1096.

86. Kobayashi S, Okada K, Yamashita K. Incidence of silent lacunar lesion in normal adults and its relation to cerebral blood flow and risk factors. Stroke 1991;22:13791383.

87. Kontos HA. Cerebral microcirculation in stroke. In: Barnetr HD, Mohr JP, Stein BW, Yatsu FM (eds) Stroke, vol 1, Pathophysiology, diagnosis and management. Churchill Livingstone, 1986. Chapter 7, pp 91-95.

88. Kretschmann HJ, Weinrich W. Neuroanatomy and cranial computed tomography. Georg Thieme Verlag, Stuttgart, New York, 1986, 30-74.

89. Landau WM. Au clair de lacune. Holy, wholly, holey logic. Neurology 1989;39:725-730.

90. Latum van AC, Koudstaal PJ, van Gijn J, for the European Atrial Fibrillation Trial Study Groups. A comparison of CT-scan findings in TIA and minor stroke patients with or without nonvalvular atrial fibrillation. Proceedings of the Second European Stroke Conference. Cerebrovasc Dis 1992;2:195.

91. Le Blanc R, Yamamoto Y, Tyler JL, Diksic M, Hakim A. Borderzone ischemia. Ann Neurol 1987;22:707-713.

92. Lechner H, Schmidt R, Bertha G, Justich E, Offenbacher H, Schneider G. Nuclear magnetic resonance image white matter lesions and risk factors for stroke in normal individuals. Stroke 1988;19:263-263.

93. Levine RL, Lagraye HL, Dobkin JA, et al. Cerebral vasocapacitance and TLA's. Neurology 1989;39:25-29.

94. Lindenberg G, Spatz H. Uber die Tromboendarteriitis obliterans der Hirngefässe. (Cerebrale Form der Von Winiwarter-Buergerschen Krankheit). Virch Arch 1940;305:531-557.

95. Lodder J, Bamford JM, Sandercock PAG, Jones LN, Warlow CP. Are hypertension or cardiac embolism likely causes of lacunar infarction? Stroke 1990;21:375-381.

96. Lodder J, Boiten J. Incidence, natural history, and risk factors in lacunar infarction. In: Advances in Neurology, vol. 62. Cerebral small artery discase. Eds: P.M. Pullicino, L.R. Caplan and M. Hommel. Raven Press, New York, 1993. pp. 213227. 
97. Malone M, Prior P, Scholtz CL. Brain damage after cardiopulmonary by-pass: correlations between neurophysiological and neuropathological findings. J Neurol Neurosurg Psychiat 1981;44:924-931.

98. Marinkovic SV, Milisavljevic MM, Kovacevic MS. Anastomoses among the thalamoperforating branches of the posterior cerebral artery. Arch Neurol 1986;43:811-814.

99. Masson M, Decroix JP, Henin D, Dainou R, Gravelau Ph, Cambier J. Syndrome de l'artère choroidienne antérieure. Etude clinique et tomodensitométrique de 4 cas. Revue Neurol (Paris) 1983;139:547-552.

100. Matsui, Hirano A. An atlas of the human brain for computerised tomography. Tokyo: Tgaku-Shoin, 1978.

101. Mayer PL, Leon Kier E. The controversy of the periventricular white matter circulation: A review of the anatomic literature. Am J Neuroradiol 1991;12:223228.

102. Mayer JM, Lanoë Y, Pedetti L, Fabry B. Anterior choroidal artery territory infarction and carotid occlusion. Cerebrovasc Dis 1992;2:315-316.

103. Meyer JE. Über die Lokalisation Frühkindlicher Hirnschäden in arteriellen Grenzgebieten. Arch Psychiatr Z Neurol (Frankfurt) 1953;190:328-341.

104. Millikan C, Futrell W. The fallacy of the lacune hypothesis. Stroke 1990;21:12511257.

105. Mohr JP. Lacunes. Stroke 1982;13:3-11.

106. Mohr JP. Lacunes. Neurol Clin N Am 1983;1:201-221.

107. Mohr JP, Steinke W, Timsit SG. The anterior choroidal artery does not supply the corona radiata and lateral ventricular wall. Stroke 1991;22:1502-1507.

108. Moody DM, Bell MA, Challa VR. Features of the cerebral vascular pattern that predict vulnerability to perfusion or oxygenation deficiency: an anatomic study. Am J Neurorad 1990;11:431-439.

109. Moody DM, Bell MA, Challa VR, Johnston WE, Prough DS. Brain microemboli during cardiac surgery or aortography. Ann Neurol 1990;28:477-486.

110. Mounier-Véhier F, Leys D, Godefroy O, Rondepierre Ph, Marchau M jr, Pruvo JP. Borderzone infarct subtypes: preliminary study of the presumed mechanism. Eur Neurol 1994;34:11-15.

111. Nelson MD jr, Gonzalez-Gomez I, Gilles FH. The search for human telencephalic ventriculofugal arteries. AJNR 1991;12:215-222.

112. Norris JW, Zhu CZ. Stroke risk and critical carorid stenosis. J Neurol Neurosurg Psychiat 1990;53:235-237.

113. Norris JW, Zhu CZ. Silent stroke and carotid stenosis. Stroke 1992;23:483-485.

114. Norrving $B$, Cronqvist $S$. Clinical and radiologic features of lacunar versus nonlacunar minor stroke. Stroke 1989;20:59-64.

115. O'Sullivan K, Cunningham AJ. Intraoperative cerebral ischaemia. Brit J Hosp Med 1989;42:286-296.

116. Overbeeke JJ van. The development of the variations of the basal cerebral arteries. An ontogenetic study. Thesis. University of Utrecht, 1991.

117. Paulson OB, Strandgaard S, Edvinsson L. Cerebral autoregulation. Cerebrovasc Brain Met Rev 1990;2:161-192. 
118. Pedley TA. Emerson RG. Neurological complications of cardiac surgery. In: Recent advances in clinical neurology. Churchill Livingstone, 1984:159-178.

119. Percheron G. Les artères du thalamus humain. Les artères choroidiennes. Rev Neurol 1977;133:547-558.

120. Pollanen MS, Deck JHN. Directed embolization is an alternate cause of cerebral watershed infarction. Arch Pathol Lab Med 1989;113:1139-1141.

121. Pollanen MS, Deck JHN. The mechanism of embolic watershed infarction: Experimental studies. Can J Neurol Sci 1990;17:395-398.

122. Powers WJ, Press GA, Grubb RL jr, Gado M, Raichle ME. The effect of hemodynamically significant carotid artery disease on the hemodynamic status of the cerebral circulation. Ann Intern Med 1987;106:27-35.

123. Powers WJ. Cerebral hemodynamics in ischemic cerebrovascular disease. Ann Neurol 1991;29:231-240.

124. Pullicino PM. The course and territories of cerebral small arteries. In: Advances in Neurology. Edited by Pullicino PM, Caplan LR, Hommel M. New York: Raven Press, 1993:11-41.

125. Pullicino PM. Diagnosis of perforating artery territories in axial, coronal and sagittal planes. In: Advances in Neurology. Edited by Pullicino PM, Caplan LR, Hommel M. New York: Raven Press, 1993:41-72.

126. Rand RW, Brown WJ, Stern WE. Surgical occlusion of anterior choroidal arteries in parkinsonism. Neurol (Minneapolis) 1956;6:390-401.

127. Raynaud C, Rancurel G, Tzourio N, et al. SPECT analysis of recent cerebral infarction. Stroke 1989;20:192-204.

128. Reed GL, Singer DE, Picard EH, De Sancris RW. Stroke following coronary-artery bypass surgery. N Engl J Med 1988;10:1246-1250.

129. Révèsz T, Hawkins CP, Du Boulay EPGH, Barnard RO, McDonald WI. Pathological findings correlated with magnetic resonance imaging in subcortical arteriosclerotic encephalopathy (Binswanger's disease). J Neurol Neurosurg Psychiat 1989;52:1337-1344.

130. Rhoton AL jr, Fujii K, Fradd B. Microsurgical anatomy of the anterior choroidal artery. Surg Neurol 1979;12:171-187.

131. Ringelstein B, Zeumer H, Angelou D. The pathogenesis of strokes from internal carotid artery occlusion. Diagnostic and therapeutical implications. Stroke 1983;14:867-875.

132. Ringelstein EB, Berg-Dammer E, Zeumer H. The so-called atheromatous pseudoocclusion of the internal carotid artery. A diagnostic and therapeutical challenge. Neuroradiol 1983;25:147-155.

133. Romanul FCA, Abramowicz A. Changes in brain and pial vessels in arterial borderzones. Arch Neurol 1964;11:657-667.

134. Rorick MB, Furlan AJ. Risk of cardiac surgery in patients with prior stroke. Neurology 1990;40:835-837.

135. Ross Russell RW, Bharachu N. The recognition and prevention of border zone cerebral ischaemia during cardiac surgery. Quarterly J Med, New Series XLVII 1978;187:303-323.

136. Sacco SE, Wishnant JP, Broderick JP, Phillips SJ, O'Fallon WM. Epidemiologic 
characteristics of lacunar infarcts in a population. Stroke 1991;22:1236-1241.

137. Saeki N, Rhoton AL jr. Microsurgical anatomy of the upper basilar artery and the posterior circle of Willis. J Neurosurg 1977;46:563-578.

138. Sandercock P. The odds ratio: a useful tool in neurosciences. J Neurol Neurosurg Psychiat 1989;52:817-820.

139. Shaw PJ, Bates D, Cartlidge NEF, Heaviside D, Julian DG, Shaw DA. Early neurological complications of coronary artery bypass surgery. Brit Med J 1985;291:1384-1387.

140. Shaw PJ, Bates D, Cartlidge NEF, French JM, Heaviside D, Julian DG, Shaco DA. Neurologic and neuropsychological morbidity following major surgery: comparison of coronary artery bypass and peripheral vascular disease. Stroke 1987;18:700-707.

141. Shellshear JL. A contribution to our knowledge of the arterial supply of the cerebral cortex in man. Brain 1927;50:236-253.

142. Sloan MA, Clarke Haley E. The syndrome of bilateral hemispheric borderzone ischemia. Stroke 1990;21:1668-1673.

143. Smith PLC, Treasure T, Newman SP, Joseph P, Ell P, Scheidau A, Harrison MJG. Cerebral consequences of cardiopulmonary bypass. Lancet 1986;12:823-828.

144. Sotaniemi KA. Cerebral outcome after extracorporeal circulation. Arch Neurol 1983;40:75-77.

145. Sterbini GLP, Agatiello LM, Stocchi A, Solivetti FM. CT of ischemic infarctions in the territory of the anterior choroidal artery: a review of 28 cases. Am J Neuradiol $1987 ; 8: 229-232$.

146. Strandgaard S, Olesen J, Skinhoj E, Lassen NA. Autoregulation of brain circulation in severe arterial hypertension. Br Med J 1973;1:507-510.

147. Sullivan T, Villanueva-Meyer J, Ching-Kuan L, Giombetti RE, Mena I. Watershed infarcts, Tc ${ }^{99 m}$ HMPAO SPECT and CT correlation. Clin Nuclear Med 1991;3:170-173.

148. Tegeler $\mathrm{CH}$, Shi F, Morgan T. Carotid stenosis in lacunar stroke. Stroke 1991;22:1124-1128.

149. Torvik A, Skullerud K. Watershed infarcts in the brain caused by microemboli. Clin Neuropathol 1982;3:99-105.

150. Torvik A. The pathogenesis of watershed infarcts in the brain. Stroke 1984;15:221-223.

151. Tufo HM, Ostfeld AM, Shekell R. Central nervous system dysfunction following open-heart surgery. JAMA 1970;212:1333-1340.

152. Ueda M, Morinaga K, Matsumoto $Y$, Omiya N, Mikami J, Sato $H$, Enoue $Y$, Okawara S. Infarction in the territory of the anterior choroidal artery due to embolic occlusion of the internal carotid artery. Report of two cases. No To Shinkei 1990;42:655-660.

153. Valk J. Computed tomography and cerebral infarction. Raven Press, New York, 1980.

154. Waterston JA, Brown MM, Butler P, Swash M. Small deep cerebral infarcts associated with occlusive internal carotid artery disease. A hemodynamic phenomenon? Arch Neurol 1990;47:953-957. 
155. Weiller C, Ringelstein B, Reiche W, Thron A, Buell U. The large striatocapsular infarct. A clinical and pathophysiological entiry. Arch neurol 1990;47:1085-1091.

156. Weiller C, Ringelstein B, Reiche W, Buell U. Clinical and hemodynamic aspects of low-flow infarcts. Stroke 1991;22:1117-1123.

157. Weiller C, Willmes K, Reiche W, Thron A, Isence C, Buell K, Ringelstein B. The case of aphasia or neglect after striatocapsular infarction. Brain 1993;116:15091525.

158. Wodarz R. Watershed infarctions and computed tomography. A topographical study in cases with stenosis or occlusion of the carotid artery. Neuroradiology $1980 ; 19: 245-248$.

159. Wood JH. Cerebral blood flow. Physiologic and clinical aspects. McGraw-Hill New York. 1987:413-416.

160. Yamauchi H, Fukuyama H, Kimura J, Konishi J, Kameyama M. Hemodynamics in internal carotid artery occlusion examined by positron emission tomography. Stroke 1990;21:1400-1406.

161. Yanagihara T, Sundt, Jr TM, Piepgras DG. Weakness of the lower extremity in carotid occlusive disease. Arch Neurol 1988;45:297-301.

162. Zülch KJ. Über die Entstehung und Lokalisation der Hirninfarkte. Zbl Neurochir 1961;21:158-178.

163. Zülch KJ. Die Pathogenese von Massenblutung und Erweichung unter besonderer Berücksichtigung Klinischer Gesichtspunkte. Acta Neurochir (Wien) 1961:51117.

164.Zülch KJ. The cerebral infarct. Pathology, pathogenesis, and computed tomography. 1985. Springer-Verlag, Berlin, Heidelberg, New York, Tokyo.

165. Zwan A van der, Hillen B. Araldite $F$ as injection material for quantitative morphology of cerebral vascularisation. Anat Rec 1990;228:230-236.

166. Zwan van der A. The variability of the major vascular territories of the human brain. Thesis, October 1991.

167. Zwan van der A, Hillen B. Review of the variability of the territories of the major cerebral arteries. Stroke 1991;22:1078-1084.

168. Zwan van der A, Hillen B, Tulleken CAF, Dujovny M, Dragovic L. Variability of the territories of the major cerebral arteries. J Neurosurg 1992;77:927-940.

169. Zwan van der A, Hillen B, Tulleken CAF, Dujovny M. A quantitative investigation of the variability of the major cerebral arterial territories. Stroke 1993;24:19511959. 


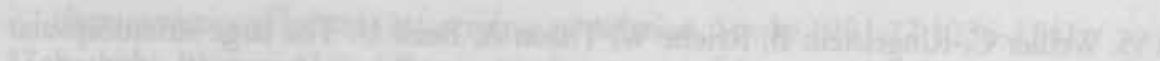

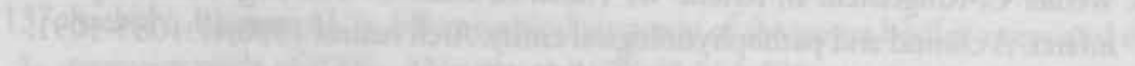

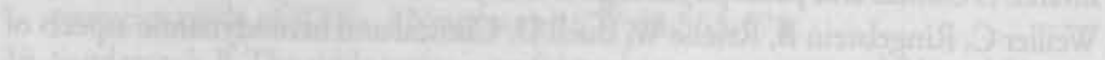

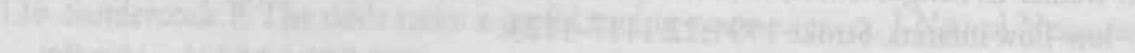

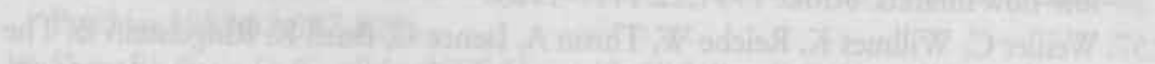

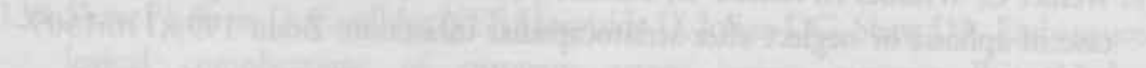

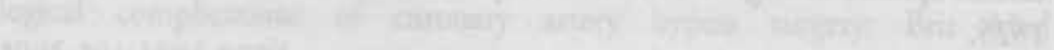

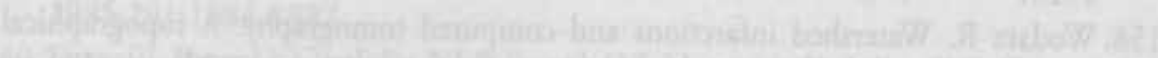

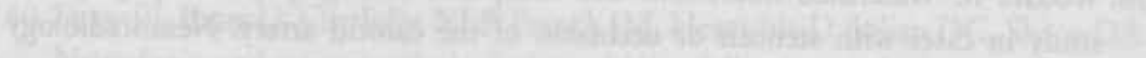

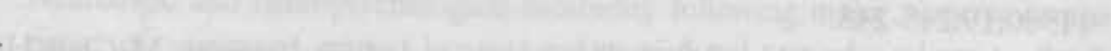

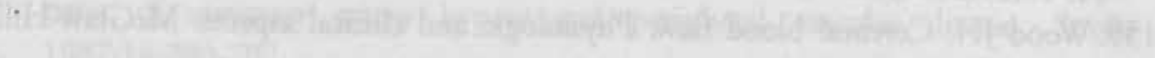

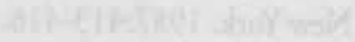

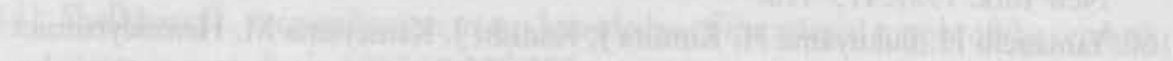

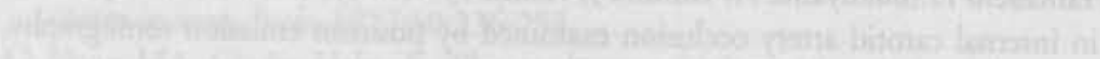

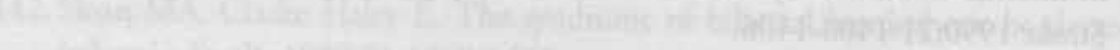

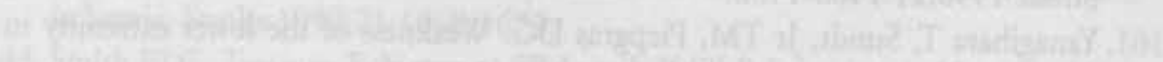

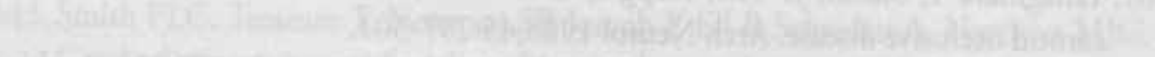

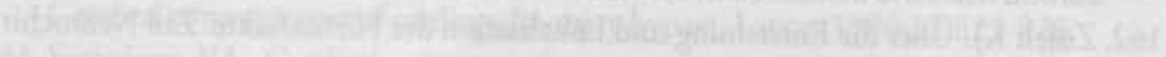

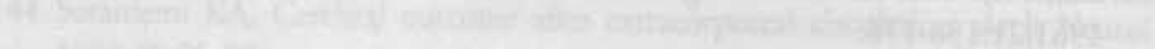

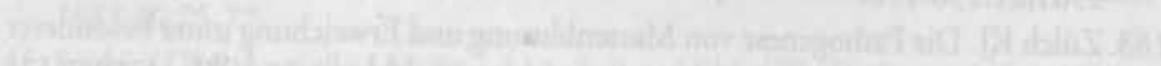

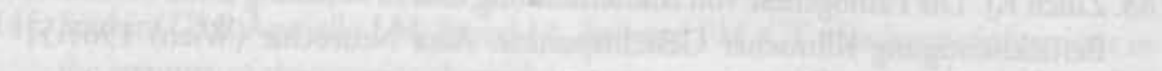

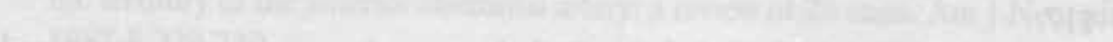

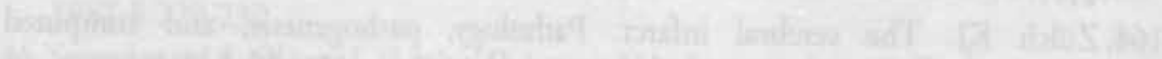

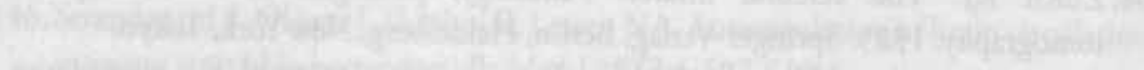

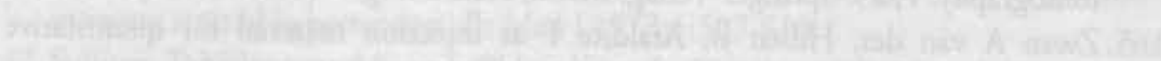

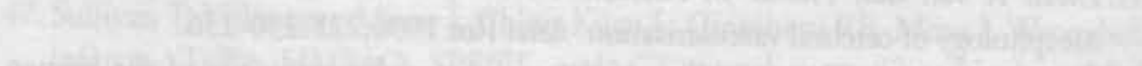

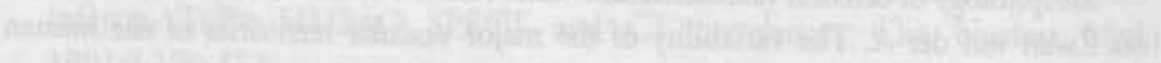

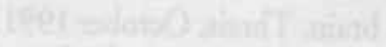

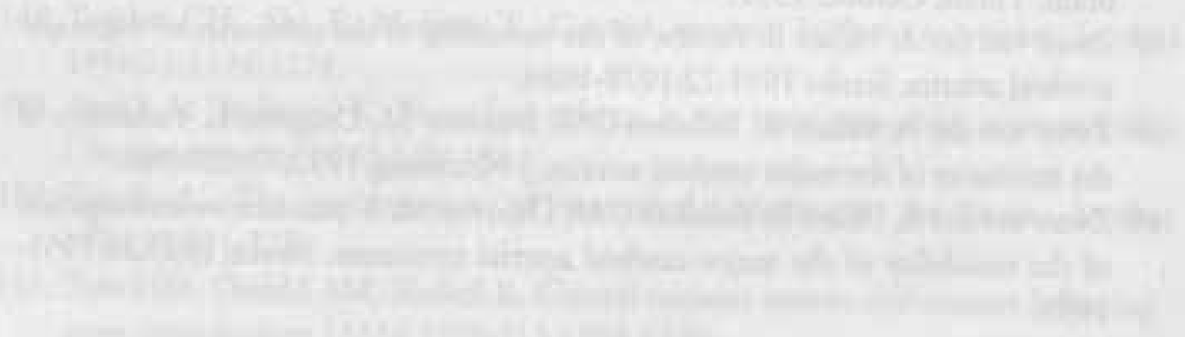


Het schrijven van een proefschrift is als het lopen van een marathon: af en toe een kleine inzinking en de moeilijkste stukjes aan het eind.

De voldoening ligt bij (achter?) de finish.

Raymond Hupperts, juni 1994 


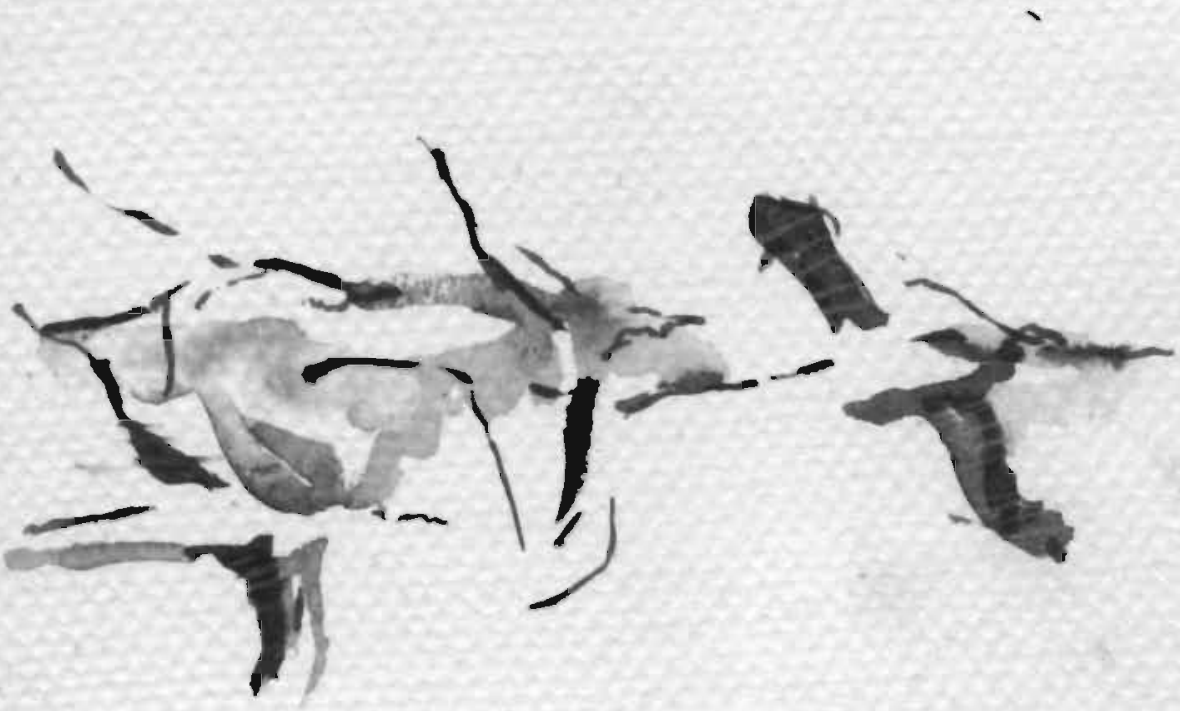

